\title{
DUNCAN WINDER: ARCHITECTURAL PHOTOGRAPHER
}

\author{
BY \\ SEBASTIAN CLARKE
}

\begin{abstract}
A thesis
submitted to the Victoria University of Wellington

in fulfilment of the requirements for the degree of

Master of Architecture
\end{abstract}

Victoria University of Wellington 


\section{ABSTRACT}

In 1960s New Zealand, Duncan Winder (1919-1970) transitioned from architect to architectural photographer. With his architectural eye, Winder produced distinctive and seminal images of New Zealand post-war architecture and these images have an enduring relevance today. Despite this significant contribution to local architectural culture, contemporary knowledge of Winder's legacy and output has remained limited.

This research sought to raise awareness of his life and work. To contextualise Winder's work, a framework for image analysis was developed which drew on the visual languages of two architectural movements which were prominent during Winder's period of practice, Townscape and New Brutalism. In addition, a visual survey of New Zealand architectural photography from 1930 to 1970 was undertaken. This enabled contextualisation of Winder's photography with the work of other local photographers operating at the time. From the analysis, it is clear that Winder's photography shows aspects of both Townscape and New Brutalism, in terms of its compositional approach. This is not only interesting for the fact that these movements have historically been seen as oppositional, but because it exposes some of the ways in which their visual languages were related. The analysis also highlighted the 1960 s as a particularly healthy decade for the production of New Zealand architectural photography. This was demonstrated through the progressive improvement in the quality of published architectural photography and the increase in number of architectural photographers practicing locally.

It is positive that in recent years Winder's archive of photographs has been digitised and made publicly accessible, and that digitisation has enabled this research to provide original and thorough commentary on Winder's photography. The research has identified distinctive and memorable qualities of Winder's style, including his compositional use of thirds, his off-centre perspectives, and his attentiveness to tone and materiality. In this way, the research has provided appropriate ways to understand and value Winder's photography, and appreciate his significant contribution to New Zealand's architectural culture and history. 


\section{CONTENTS PAGE}

Abstract 2

List of Figures $\quad 4$

$\begin{array}{ll}\text { Chapter One: Introduction } & 8\end{array}$

$\begin{array}{ll}\text { Chapter Two: Literature Review } & 14\end{array}$

On the history of architectural photography 14

On the visual languages of New Brutalism and Townscape $\quad 27$

On the development of architectural photography in New Zealand, $1930-1970$

Chapter Three: Image Analysis $\quad 65$

Chapter Four: Discussion $\quad 113$

$\begin{array}{ll}\text { Chapter Five: Conclusion } & 119\end{array}$

$\begin{array}{ll}\text { Reference List } & 123\end{array}$

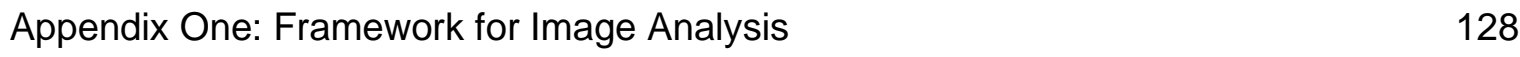




\section{LIST OF FIGURES}

Figure Page

$1 \quad$ An image produced as part of Missions Héliographiques. Gustave Le Gray, Central Portal of the Church of Saint-Jacques, Aubeterre, 1851

2 (no photographer credited). Steinway Hall, Daily Graphic 1873.

3 Charles Nègre, The Vampire, 1853.

$4 \quad$ Frederick H. Evans, Wells Cathedral, 1903.

$5 \quad$ László Moholy-Nagy, From the Radio Tower, Berlin, 1928.

$6 \quad$ Julius Shulman, Bass House (Case Study \# 20), Buff, Straub \& 23

$7 \quad$ Berenice Abbott, Seventh Avenue looking south from 35th Street, 24 Manhattan, 1935.

$8 \quad$ Helmut Gernsheim, Queen's Lane, Oxford, 1940.

9 (no photographer credited). Cover page for the article Townscape by 30 Hubert de Cronin Hastings (written under the name Ivan de Wolfe), 1949.

10 (no photographer credited). Excerpt from Gordon Cullen's Concise 32 Townscape, 1961.

11 Nigel Henderson, Photograph showing Hunstanton Secondary Modern 34 School, Norfolk, during construction, c.1949-c.1956.

12 Nigel Henderson, Photograph of installation view of Parallel of Life and Art exhibition, 1953.

13 (no photographer credited). Cover image for Reyner Banham's essay The New Brutalism, 1955.

14 Eric De Maré, General view showing steps leading up to the castle in Newcastle-upon-Tyne, 1945.

15 (no photographer credited). Flats, Wellesley Street, Auckland, S. S. Alleman, A.N.Z.I.A., Architect, 1931.

16 Frank Hofmann, Takapuna House, 1939.

17 Gerald Edgar Jones, New Dominican Convent, 1940.

18 Paul Pascoe, Looking through the terrace, over the harbour, 1941. 
19 Sparrow Industrial Pictures Ltd, Symonds Street flats. Home and Building, 1948.

20 John Holmwood, Our photographer at work, 1951.

21 (no photographer credited). Worth looking at, 1950.

22 Sparrow Industrial Pictures Ltd, A house for the sub-tropics, 1957.

23 Sparrow Industrial Pictures Ltd, The theme house, 1957.

24 Sparrow Industrial Pictures Ltd, Terrace at Mr. and Mrs. C M Ponder's 54 home, 1955.

25 Mannering and Donaldson, Seaside house with a "hypoid" roof, 1958.

$26 \quad$ Mannering and Donaldson, Christchurch Dental Nurses' Training 56 School, 1959.

27 Barry McKay Industrial Photography Ltd, Dadly Foundation for crippled 58 children, 1962.

28 Barry McKay Industrial Photography Ltd. Bank of New South Wales, Queen St., Auckland,1967.

29 Martin Barriball Ltd, Streetscape view, 1961.

30 Studio 57, Auckland Transport Office, 1960.

31 G. G. Thornton, Beacon on the mole, Lyttelton, 1963.

32 Mannering and Donaldson, Harwood Memorial Garden Crematorium, 62 1962.

33 Duncan Winder, View up Dixon Street, 1967.

34 Duncan Winder, McKay house in Silverstream, Upper Hutt, 1966.

35 Duncan Winder, Hall interior, McKay house, Silverstream, Upper Hutt, 68 1966.

36 Duncan Winder, Lounge interior, McKay house, Silverstream, Upper 69 Hutt, 1966.

37 Duncan Winder, Underside of Wellington motorway, 1969.

38 Duncan Winder, Underside of Wellington motorway, 1969.

39 Duncan Winder, Victoria University of Wellington, site works, 1969.

40 Duncan Winder, Art gallery [Dowse Art Museum?] under construction, $\quad 75$ Lower Hutt, 1970.

$41 \quad$ Duncan Winder, Tasman Hotel under construction, New Plymouth, $\quad 75$ 1964. 
42 Duncan Winder, Architectural concept model of the proposed stage two build of the Forest Research Institute, Rotorua, 1965.

43 Duncan Winder, Architect's concept model, Reserve Bank Building, The

Terrace, Wellington, 1966.

44 Duncan Winder, Balsa model of Aniwaniwa Visitor Centre, designed by John Scott, 1970.

45 Duncan Winder, Houses designed by architect Miles Warren, 1965.

46 Duncan Winder, University of Canterbury student accommodation exterior, Christchurch, 1965.

47 Duncan Winder, University of Canterbury entrance, Christchurch, 1965.

48 Duncan Winder, Platform, railway station, Christchurch, 1965.

49 Duncan Winder, View of railway station from the tracks, Christchurch, 82 1965.

50 Duncan Winder, Christchurch Railway Station, 1965.

51 Duncan Winder, Exterior of Lincoln College, Canterbury, 1965.

52 Duncan Winder, Exterior of School of Engineering at the University of Canterbury, 1965.

53 Duncan Winder, Exterior of School of Engineering at the University of Canterbury, 1965.

54 Duncan Winder, Victoria University library building, Wellington, c19621965.

55 Duncan Winder, Lecture theatre, Victoria University of Wellington, Kelburn, Wellington, 1968.

56 Duncan Winder, Houses, Te Aro, Wellington, 1968.

57 Duncan Winder, Flats, Nairn Street, Wellington, 1969.

58 Duncan Winder, Nairn Street flats, Brooklyn, Wellington, 1969.

59 Duncan Winder, Clifton Towers, a block of flats in Wellington, 1966.

60 Duncan Winder, Brandon Street, Wellington, c1962-1970. 95

61 Duncan Winder, Dixon Street, with Victoria University of Wellington in 96 the distance, Wellington, 1967.

62 Duncan Winder, Bowen Street, Wellington, 1962-1965. 97

63 Duncan Winder, Imperial Chemical Industries (ICI), ICl House, 98 Wellington, 1962-1965.

64 Duncan Winder, Imperial Chemical Industries (ICI), ICl House, Wellington, artists design, 1962-1965. 
65 Duncan Winder, Looking down stairs to entrance of H H York Ltd, 101 Petone, Lower Hutt, 1968.

66 Duncan Winder, Staircase, Roman Catholic mission house, Napier, 102 1968.

67 Duncan Winder, Anglican cathedral, interior, with lectern, Nelson, 1967.102

68 Duncan Winder, Mural inside overseas terminal, Clyde Quay, 103 Wellington harbour, c1962-1965.

69 Duncan Winder, Natusch house, by night, c1962-1970. 103

70 Duncan Winder, House interior, study, c1962-1970. 104

71 Duncan Winder, Drott travelift loader demonstration with container, 108 Wellington Harbour Board, c1962-1970.

72 Duncan Winder, Very large brick wall, unidentified location, 1970.

73 Duncan Winder, Ellerslie Racecourse, Auckland, 1969. 


\section{CHAPTER ONE: INTRODUCTION}

\section{Thesis introduction}

This thesis emerged from the realisation that many significant examples of modern architecture in New Zealand were photographed by someone who seemed to have been overlooked in historical consideration of New Zealand architectural culture. Important works of New Zealand twentieth century architecture were photographed by British-born architect Norman Henry Duncan Winder (known as Duncan Winder) with memorable precision and stylish, yet subtle, composition. Who was Duncan Winder and what influenced his nuanced architectural photography? These initial questions spurred this more formal thesis-based inquiry into Winder's contribution to New Zealand's post-war architectural culture.

In order to understand Winder's own role within our history, it is necessary to contextualise his photography. Appropriate means for contextualisation exist for Winder. First, he was trained in architecture in the mid-twentieth century, and second, he was British. For these reasons, this research considers how Winder's photography aligned with the dominant post-war architectural British movements of New Brutalism and Townscape.

\section{Research aims}

This research aims to advance understanding of Duncan Winder and his contribution, through photography, to New Zealand architectural culture.

Specifically, this research has three principal objectives. Firstly, to position Winder within the broader context of modern architectural photographers, both in New Zealand and internationally. Secondly, to explore how Winder's approach to architectural photography reflected influences of the post-war British architectural movements of New Brutalism and Townscape. Finally, to provide a biographical narrative of Winder's professional life.

\section{Thesis outline}

The thesis comprises five chapters. Chapter One is the introduction which outlines the research aims, outline and method. It also presents a biography of Winder. A literature review is presented as Chapter Two and includes three sections: the first is an international overview of the historical development of architectural photography until 1970; next is a discussion of the approaches to imagery, and specifically photographic imagery, within the architectural movements of New Brutalism and Townscape; and finally is a visual survey of the development of architectural photography in New Zealand from 1930 to 1970. Chapter Three presents an 
image-based analysis of Winder's photography. This is followed by a discussion of Winder's approach to photography within the contexts of New Brutalism and Townscape in Chapter Four. Finally, Chapter Five asserts conclusions against the research aims.

\section{Research method}

Contextual understanding of Winder's biography and his position within New Zealand and international architectural photography is established through a survey of literature and architectural photographs. The literature review focuses on theories of architectural photographic representation contemporaneous with Winder's career. The visual survey of New Zealand architectural photographs is be sourced from local architectural journals published between 1930 to 1970 . This period charts the beginning of regular publishing of architectural photographs in New Zealand architectural journals to the end of Winder's own contribution to the field. Architectural journals and other academic publications are be the primary source of material in the literature review and visual survey.

To enable the image analysis, categorisation of Winder's digitised photographs (from the Alexander Turnbull Library) is complied and case studies identified and assessed. Case studies allow themes, commonalities, and influences in his work to be identified.

An image analysis is be carried out against case studies of Winder's photographs, based on a framework informed by the literature review and visual survey. 


\section{Biography}

\section{Introduction}

This section of the introduction draws on a range of primary and secondary sources which provide insight into Winder's life.

It is important to note that developing a historical narrative of Winder has proved more difficult that was initially anticipated. What has become clear through this research is that Winder lived a solitary life, and this has meant that the availability of both reference material and individuals who could elucidate on aspects of his life are very limited.

\section{Early life and architectural education}

Norman Henry Duncan Winder (known as Duncan Winder) was born in 1919, in the town of Prescot, near Liverpool. His parents Leonard Norman Winder and Marion Rowed, married one year prior to his birth, and had one other child, Christena Winder (later Christena Shaw). ${ }^{1}$ Architectural colleagues of Winder's in Wellington recall him showing them images of his childhood Georgian-style family home. ${ }^{2}$

From the obituary of Winder published in the NZIA Journal, we know that Winder did his schooling and study of architecture in Liverpool. The Liverpool School of Architecture is an important centre of British architectural research and education, and was the first university school to design and offer degrees accredited by the Royal Institute of British Architects (RIBA). ${ }^{3}$ In the first quarter of the twentieth century, the school was known for its 'Liverpool Manner". A term coined by architectural critic Randall Phillips which acknowledged a preference for architectural design that was "consciously derived from the Ecole de Beaux Arts, ...large in scale and restrained in detail". ${ }^{4}$

His hobbies were recorded as sailing, photography and climbing. ${ }^{5}$

\footnotetext{
${ }^{1}$ National Archives United Kingdom, "Marriage license for Leonard Norman Winder and Marion Rowed."

2 Daryl Cockburn, email message to author, June 5, 2018.

${ }^{3}$ Richmond and Dunne, The World in One School, 12.

${ }^{4}$ Crouch, Design Culture in Liverpool, 1880-1914: The Origins of the Liverpool School of Architecture, 144.

5 Hill, "Obituary", 324.
} 


\section{Military service}

Winder served in World War II, as conscription requirements under the United Kingdom National Service (Armed Forces) Act 1939 would have required him to register to serve given his age. ${ }^{6}$

During his time in service, Winder was stationed in the Mountain Warfare Training Centre, located near the Lebanese town of Bsharri. This was a Special Forces School which taught soldiers skiing and mountaineering skills, and how to deal with winter conditions. Instructors were selected for their expertise in these areas. Winder served as a rock instructor, teaching mountaineering ${ }^{7}$.

Between the winter of $1941 / 1942$ and the summer of 1944 , more than 20,000 soldiers spent time at the Mountain Warfare Training Centre. ${ }^{8}$ This included many New Zealand and Australian soldiers, some of whom also worked at the centre as instructors. ${ }^{9}$ This may have been the first time that Winder came into close contact with New Zealanders.

Migration to, and life in, New Zealand

It is not known why Winder chose to migrate to New Zealand, however, New Zealand's assisted immigration scheme (active from 1947 to 1975) may have influenced Winder's decision. ${ }^{10}$

Winder left London on the RMS Rangitoto, and arrived in Auckland on 17 June 1955, aged 35 years. His occupation on the passenger list was recorded as architect. ${ }^{11}$

Winder settled in Wellington, working the architectural firm Gray Young Morton and Calder. His colleagues included Michael Fowler and Daryl Cockburn.

During his time at Gray Young Morton and Calder, he worked on the design of the Easterfield building at Victoria University of Wellington.

In 1962, Winder left Gray Young Morton and Calder. Martin Hill notes the reason for Winder's career change was to search for "something that could combine more of his talents", noting Winder's abilities as a craftsman and his love for the natural environment. ${ }^{12}$

6 UK Parliament, "Conscription: the second World War".

${ }^{7}$ Cox, The Lebanon: Some Memories of Mountain Warfare Training during World War II, 196.

${ }^{8}$ Mountain Warfare Training Centre, "The Training Centre".

${ }^{9}$ Mountain Warfare Training Centre, "Staff".

10 New Zealand History, "Assisted immigration to New Zealand 1947-1975".

${ }_{11}$ Archives New Zealand, "Passenger Lists, 1839-1973 database: Auckland (inwards), SS-1-230, Apr.Jun. 1955".

12 Hill, 324. 
Before committing full-time to photography, Winder spent time farming and furniture making. In addition to these interests, Winder also spent much of his spare time building and sailing his own yachts. ${ }^{13}$ Unsurprisingly, Winder's archive of photographs includes several images of sailing boats, and pastoral and natural landscapes of New Zealand.

Winder operated his photography studio from his home on Fernhill Terrace, Wadestown, Wellington. His architectural photography business was successful for many years, with his photographs published in the New Zealand Institute of Architects (NZIA) Journal and Home and Building. Winder is not recorded as being a member of either the NZIA Wellington branch or the Architectural Centre.

Winder died in 1970, aged 51 years. He was buried at Makara Cemetery, Wellington.

Winder's will and the legacy of his archive

Winder's will indicates support for religious organisations. He left his home and much of its contents to the Moral Re-Armament (MRA). The MRA was an international moral and spiritual movement that arose in Britain in the 1930s. ${ }^{14}$ Following World War II, the MRA launched international programmes to foster change in private and public life based on a change in morals, spirituality and personal character. ${ }^{15} \mathrm{He}$ also left his car to the Catholic Sisters of Mercy Wellington. ${ }^{16}$

Of key relevance to Winder's legacy as an architectural photographer is how Winder's will addresses his photographic archive. The will provided direction for its executor to provide Winder's photographic prints and negatives to the NZIA. ${ }^{17}$

The NZIA national office does not have any records of receiving Winder's archives, so it remains unknown who took responsibility for the archive. What we do know is that Winder's archive was separated into two distinct components that were deposited in different institutions. His collection of negatives was deposited with the Alexander Turnbull Library in Wellington, while his collection of photographs was deposited with the Architecture and Planning Library at the University of Auckland. Neither of these repositories have records which note how these collections came to them.

\footnotetext{
13 lbid., 324.

${ }^{14}$ Lineham, "Interdenominational Christianity".

15 Initiatives of Change New Zealand, "History".

16 Winder, Will, 1.

17 Ibid., 1.
} 
The significant component of Winder's archive is his collection of negatives, now with the Alexander Turnbull Library. Notably, this collection has now been digitised which has expanded the awareness of and access to Winder's photography. The digitisation of Winder's output is important within the context of post-war New Zealand architectural photography, as few of his contemporaries' archives have been made available online. This is due to the much larger scale of their archives, for example the Bill Sparrow archive includes over 200,000 images - making its digitisation much more-resource intensive and difficult to prioritise. In this way, Winder's archive, while relatively modest in scale, arguably represents the most significant accessible collection of post-war New Zealand architectural photography. It is for this reason, that Winder's images continue to be included in important architectural publications and exhibitions to this day. 


\section{CHAPTER TWO: LITERATURE REVIEW}

\section{On the history of architectural photography}

\section{Introduction}

Eric de Maré once declared that every effective photograph has an architectural quality. ${ }^{18}$ With their analogous concerns for texture, contrast, rhythm and spatial composition, it is true that photography and modern architecture share an innate empathy. More than simply facilitating people's interest in documenting their physical surrounds, photography has fundamentally repositioned how architecture is created and consumed. ${ }^{19}$ However, as the technology that enables photographic documentation has evolved, architectural theorists have increasingly scrutinised the interpretation and validity of the architectural image. This component of the literature review presents a concise overview of the development of architectural photography as a legitimate category of the photographic medium. It considers the changes in style of architectural photography, beginning with the introduction of photographic technology in the 1830 s and progressing to the period of the modern movement, in which photography performed a pivotal role in communicating a new international architectural paradigm.

\section{9 to 1880 s}

It is not difficult to understand the conditions that facilitated architecture's role as a pioneering photographic subject matter. The long exposures required for the production of early photography, coupled with the stationary monumentality of the built environment can explain the presence of architecture in many of the world's earliest recorded photographs, dating from the 1830 s and 1840s. ${ }^{20}$ The initial preoccupation of architectural photographers with head-on, factual documentation of significant historic structures reflected an extended commitment to the veduta language of representation and, as some historians argue, an uncomplicated faith in the ability of the photograph to truthfully portray its subject. ${ }^{21,22}$ While other historians have eschewed the notion that nineteenth-century architectural photography can be read as simply objective, Ackerman acknowledges the difficulty of defining early photography as pertaining to either a documentary or interpretative style, given the low level of recognition afforded to the

\footnotetext{
18 de Maré, Photography and Architecture, 13.

$19 \mathrm{lbid} ., 14$.

20 Herschman, "Part 1: 1839 to 1880", 2.

${ }^{21}$ A veduta is a highly detailed, usually large-scale painting or, more often, print of a cityscape or some other vista.

22 Pare, Photography and Architecture: 1839-1939, 17.
} 
vision of the individual photographer, relative to the belief that photographs 'made themselves'. ${ }^{23}$

By the 1850s, the urban streetscape (as opposed to single architectural landmarks) had emerged as an appealing and worthy photographic subject matter. As nineteenth century urban expansion and renewal projects endangered historic precincts within European cities such as Berlin, Paris and Vienna, photographers were employed to record the physical qualities of these disappearing urban streetscapes. ${ }^{24}$ Streetscapes, with their satisfying irregularities and scales of complexity, provided photographers with rich opportunities to explore the possibilities of conveying sympathy and subjectivity towards architecture, through experiments with light and perspective. In urban areas as well as rural ones, the ongoing loss of bygone architecture catalysed the formation of both official and amateur associations mandated with preserving the built environment through architectural photography. ${ }^{25}$ These documentary missions (such as the French Missions Héliographiques, which was established to photograph historic sites in order to promote their restoration) evidenced an awareness of the important role that photography continues to have in recording built environments across time (Figure 1). ${ }^{26}$

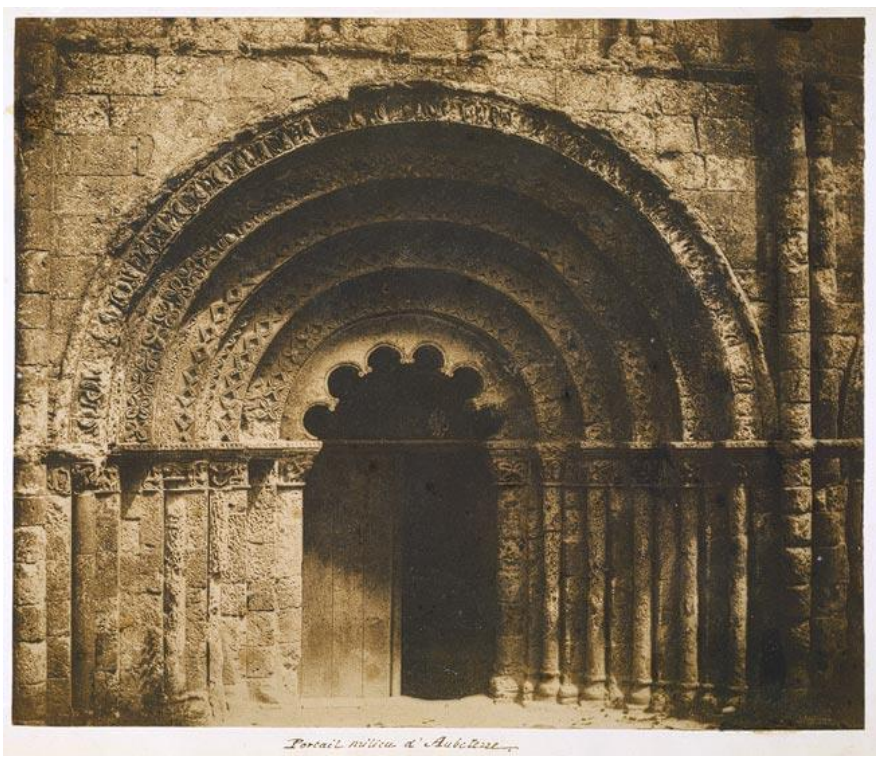

Figure 1: An image produced as part of Missions Héliographiques. Gustave Le Gray, Central Portal of the Church of Saint-Jacques, Aubeterre, 1851. File:GustaveLeGray.jpg, by The Metropolitan Museum, 2010. Wikimedia Commons (https:// https://commons.wikimedia.org/wiki/File:GustaveLeGray.jpg). In the public domain.

\footnotetext{
${ }^{23}$ Ackerman, "On the origins of architectural photography", 28.

24 Hershman, 26.

${ }^{25}$ Ackerman, 28.

${ }^{26}$ Nilsen, Architecture in Nineteenth Century Photographs: Essays on Reading a Collection, 49.
} 
Early photography afforded an expanded audience for architecture, therefore, it is unsurprising that reproduction and easy dissemination of the architectural image became pressing interests for photographers in the later part of the nineteenth century. In 1873, the method of printing images through the use of dots at different sizes and frequencies, known as the halftone process, was first successfully employed in a newspaper - for an architectural image of Steinway Hall in Manhattan (see Figure 2). ${ }^{27}$ By the end of the 1910s, the halftone process would become the most popular method of illustrating architectural magazines. ${ }^{28}$ Other improvements in the photographic equipment of the late nineteenth century, such as the introduction of the silver gelatin process, saw a marked increase in the number of photographers operating in a commercial environment. ${ }^{29}$ These advancements made it increasingly possible for architects to access and derive benefits from the architectural image.

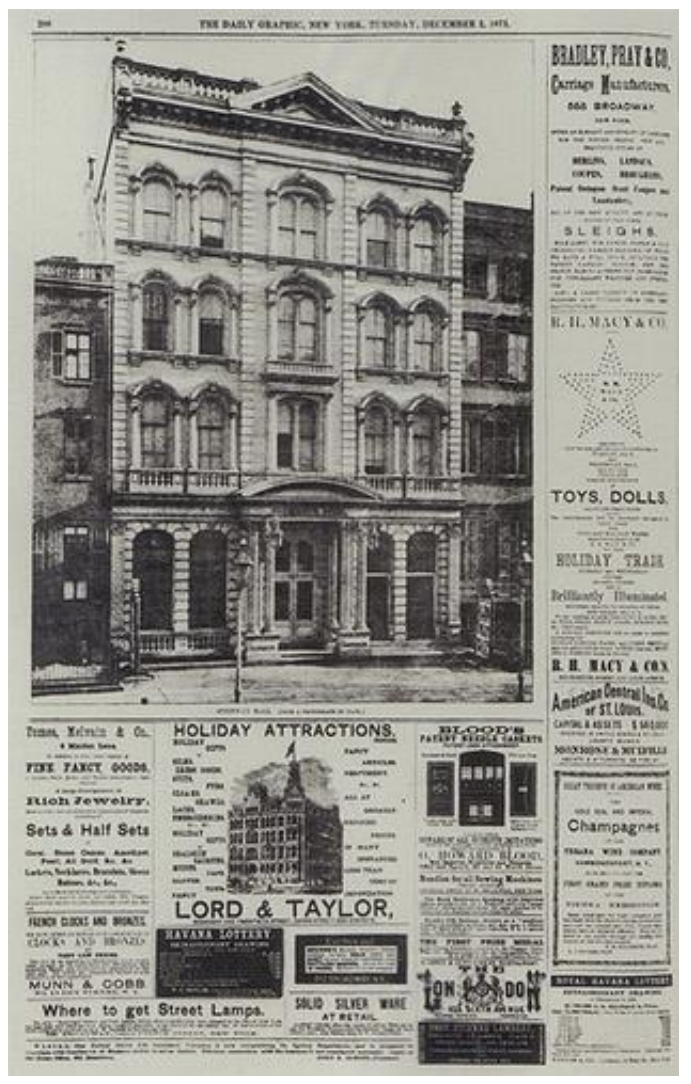

Figure 2: (no photographer credited). Steinway Hall, Daily Graphic 1873. From File:Steinway hall 1873.jpg, by The Daily Graphic, New York, 2008. Wikimedia Commons (https://commons.wikimedia.org/wiki/File:Steinway_hall_1873.jpg). In the public domain.

27 Design Facts, "No. 66 - First printed halftone photo".

${ }^{28}$ Elwall, Building with light: the international history of architectural photography, 89.

29 Pare, 15. 
1880s to 1930 s

Herschman suggested that by the 1880s, as the culture of architectural photography had matured over its first half century, the specialised photographic genre had established lasting conventions. ${ }^{30}$ These conventions were said to be grounded in existing forms of architectural representation, namely drawing. What is interesting is the way in which some photographers communicated their differing approaches to architectural photography. For example, French photographer Charles Nègre provided a telling account of the contrasting sorts of photographs he would take of the same architectural site for different artisan audiences: for sculptors, close up views of the most interesting details, for painters a picturesque view capturing the "poetic charm of the monument" (as seen in Figure Three, over page) and for the architect a factual view "with the aspect and precision of a geometric elevation". ${ }^{31}$ However, the potential of architectural photography was not confined to that of an earlier form of representation or that architects were not becoming interested in more experimental approaches to photography. This was the era in which photography was accepted as the dominant visual means of conveying architecture and this enabled broadened possibilities for photographic representation.

30 Hershman, 54.

${ }^{31}$ Ackerman, 30. 


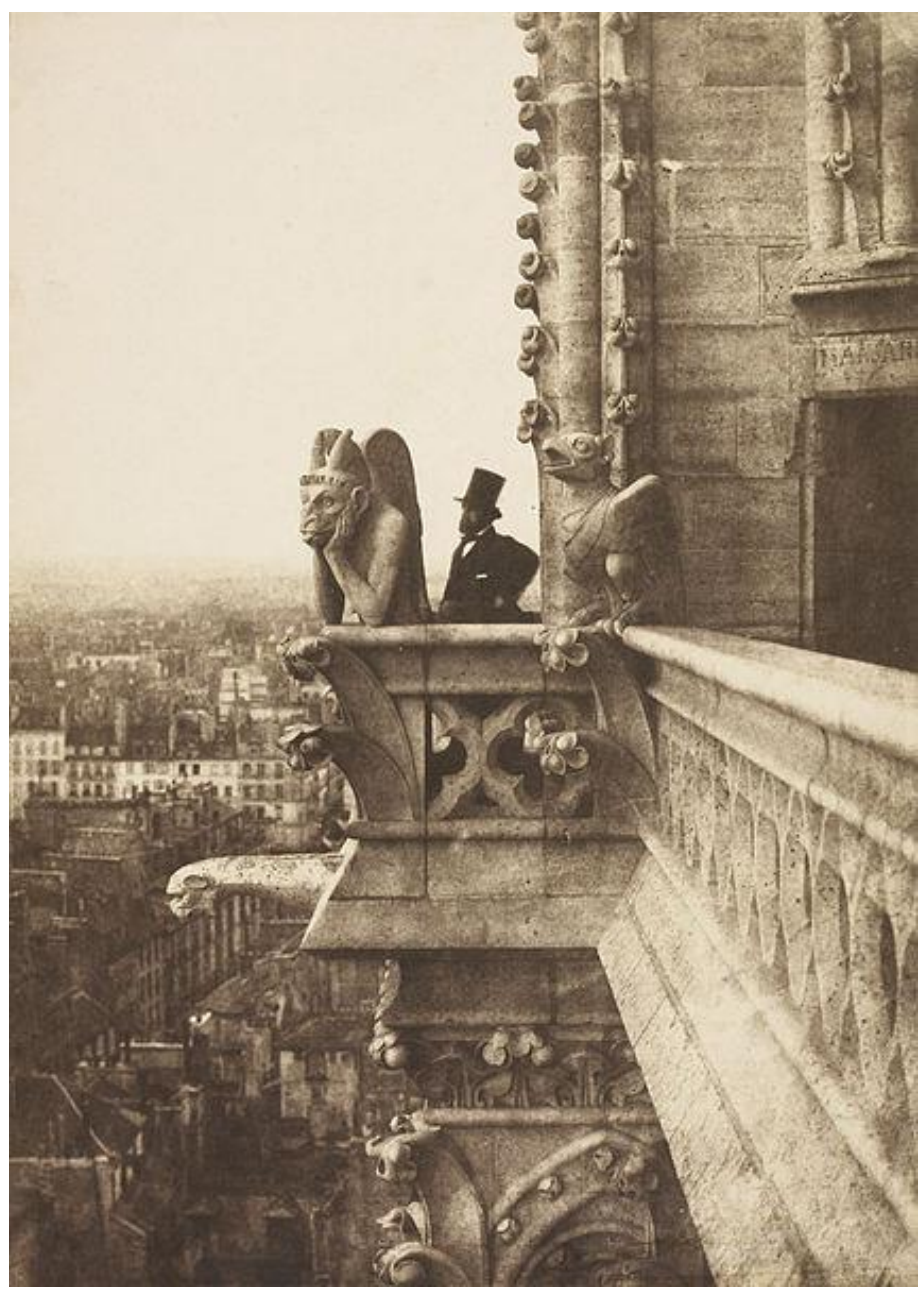

Figure Three: Charles Nègre, The Vampire, 1853. From File:Charles Nègre - The Vampire - Google Art Project.jpg, by Musée d'Orsay, 2015. Wikimedia Commons (https://commons.wikimedia.org/wiki/File:Charles_N\%C3\%A8gre__The_Vampire_-_Google_Art_Project.jpg). In the public domain.

In the late nineteenth and early twentieth centuries, the increased publication of photography in journals, including in Alfred Stieglitz' Camera Notes, enabled the potential for the medium to channel artistic vision to be better understood. ${ }^{32}$ Busch discusses how this shift towards the expressive and experimental meant that architectural images were considered "not simply [for] the building, but the photographer's impression of it". ${ }^{33}$ British photographer Frederick Evans, working at the turn of the twentieth century, produced now famous images of English and French religious architecture. His photography (see Figure 4) demonstrates what Busch refers to above, by presenting a particular, perfectly illuminated architectural atmosphere without revealing the full extent of the place that viewers are being shown. While Evans emphasised

32 Nilsen, 2.

${ }^{33}$ Busch, The photography of architecture, 5. 
beauty and mood within historic settings, the development of modern architecture in the early twentieth century also provided photographers with generous opportunities for exploring a new photographic style.

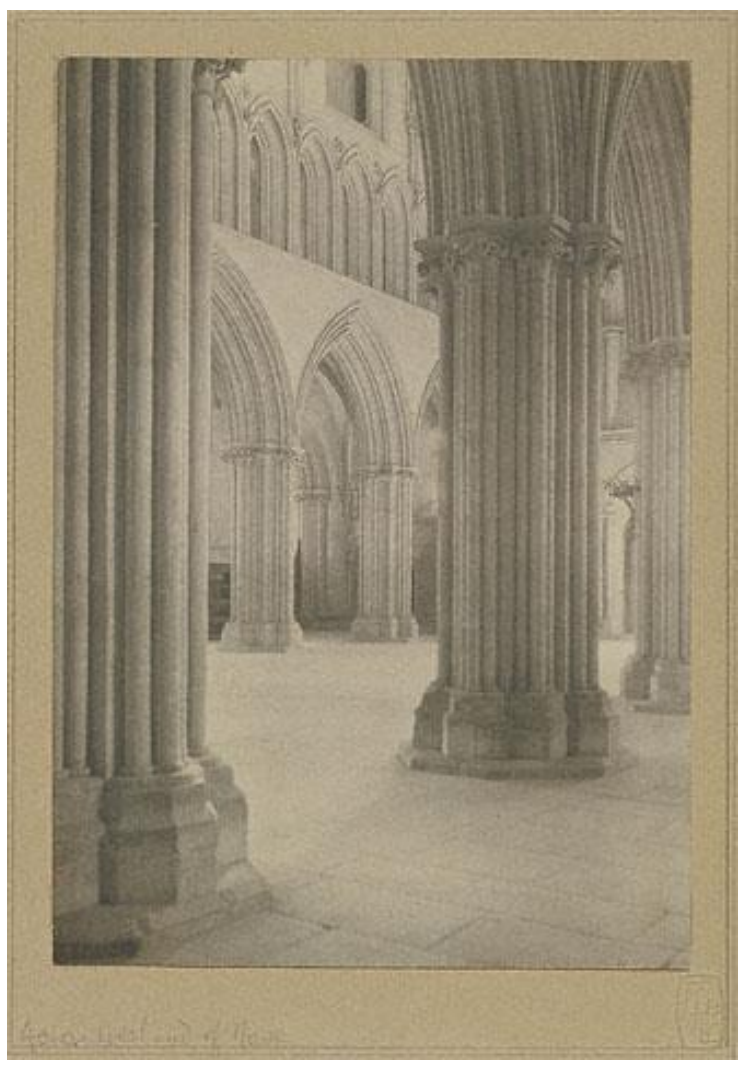

Figure 4: Frederick H. Evans, Wells Cathedral, 1903.From File:Frederick H. Evans Wells Cathedral.jpg. The J. Paul Getty Museum, 2010. Wikimedia Commons (https://commons.wikimedia.org/wiki/File:Frederick_H._Evans Wells_Cathedral.jpg). In the public domain.

Importantly, there is evidence of architects from this period confirming the multiple advantages of photography within their profession, as means for expanding their understanding of architectural precedent as well as recognising the value of documenting their own work. American architect Henry Hobson Richardson famously had a comprehensive collection of photographs of buildings from across the world which he would use as an educational resource for architectural students as well as a source of inspiration for his own practice, which incorporated characteristics of French, Italian and Spanish medieval architecture. ${ }^{34}$ It is thought that as cameras became more portable and accessible, architects became more involved in the process of photographing their buildings, travelling with photographers to ensure they captured

${ }^{34}$ Elwall, 55. 
buildings in specific ways. ${ }^{35}$ While many architects were starting to use cameras themselves, some were also sharing what they saw as limitations of architectural photography. For example, the interest of architects Le Corbusier and Adolf Loos in photography, and architectural media more generally, has been critically assessed by Beatriz Colomina. Colomina observes how similar the positions of these two European architects were on architectural photography. In 1908, Le Corbusier described architectural images as "always distorted and offensive" in relation to the first-hand experience of a place, while Loos, in 1910, declared with satisfaction that the interior spaces he designed were "totally ineffective in photographs". ${ }^{36}$ What this does indicate is that these architects understood that photography would be the means for which their buildings would be recorded and valued - even if they did not agree with the power that photography held.

As photographic conventions matured, the distinction between the amateur and the professional became more evident. Along the continuum of architectural photographers, amateur photographers were most often associated with documenting historic buildings while professional photographers generally attended to the new. ${ }^{37}$ Joel Smith discusses the development of new styles of commercial architectural photography from the 1920s, including the 'artful crimes' of depicting interior spaces as deceivingly spacious and well-proportioned, and thus testing viewers' belief in the photograph as truthful representation. ${ }^{38}$ The emergence of this more strategic approach to photography may be a product of the commercial photographer's desire to give prominence to their own cunning skills within an increasingly viable studio photography industry, as well as a realisation from the architecture profession and real estate industry of the lucrative potential that successful visual documentation of their projects could provide. Additionally, the shift in photography can be seen as a direct response to the emergence of the internationalist architectural style.

Founded in continental Europe, the modernist architectural philosophy promoted the use of man-made technologies, direct and conspicuous use of materials, and above all, a dedication to functionality. The means of representing modernism facilitated a new genre of photography, appropriately termed New Photography. ${ }^{39}$ New Photography encouraged focus on component architectural elements, texture, tonal contrasts, which strengthened the affinity between

\footnotetext{
35 lbid., 55.

${ }^{36}$ Colomina, Privacy and publicity: modern architecture as mass media, 101,104.

${ }^{37}$ Robinson, "Part three: 1930 to 1970", 110.

${ }^{38}$ Smith, The life and death of building: on photography and time, 61.

39 Elwall, 120.
} 
architecture and photography.$^{40}$ As part of its clear artistic intent, New Photography presented architecture with an abstract yet decidedly objective, clinical vision. László Moholy-Nagy (see Figure 5), an important proponent of New Photography, spoke of its ability to convey "a new spatial culture". ${ }^{41}$ This cultural representation would spread widely in the decades to come.

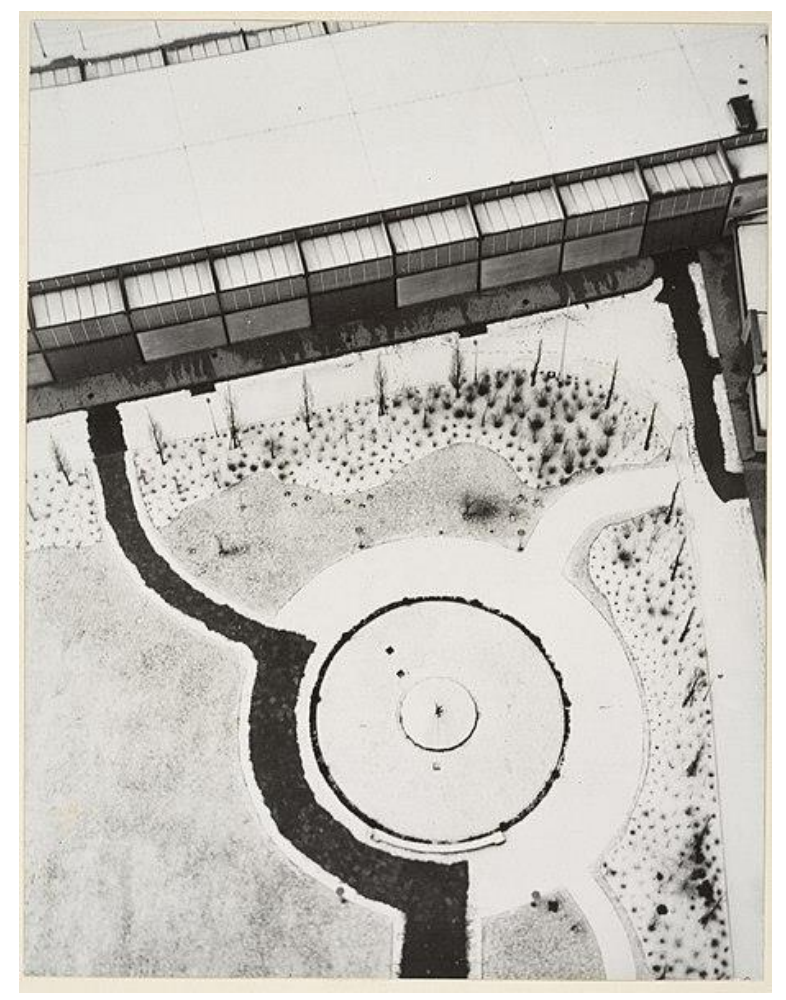

Figure 5: László Moholy-Nagy, From the Radio Tower, Berlin, 1928. From File:From the Radio Tower, Berlin MET DP146680.jpg, by Metropolitan Museum of Art, 2017. Wikimedia Commons (https://commons.wikimedia.org/wiki/File:From_the_Radio_Tower,_Berlin_MET_DP146680.jpg). In the public domain.

\section{0 s to 1970 s}

It was in the 1930s that the potency of architectural photography was truly realised. The discipline was well espoused in professional journals of this time. The Architects' Journal insisted "To no profession is a proper understanding of the whole creative and revelational scope of modern photography more important than our own" while in Architectural Review $(A R)$, P. Morton Shand contributed a seminal essay on architectural photography, praising New Photography for facilitating a revolution in architectural criticism, and successfully "put[ting]

40 Elwall, 120.

${ }^{41}$ Moholy-Nagy, A New Instrument of Vision, 36. 
across modern architecture". ${ }^{42}$ Even more importantly than communicating these sentiments in written form, journals were engaging leading photographers in their publications. From 1929 to 1946, AR employed the firm Dell \& Wainwright as its official photographer, a partnership that would prove to be widely influential in the promotion of modern architecture and the approach to photographing it. ${ }^{43}$ Carullo has acknowledged Dell \& Wainwright as fortifying the language of modern architectural photography. ${ }^{44}$

The mission of the studio photographer, to 'put on' (as Morton Shand termed it) modern architecture, cemented architectural photography as a commercial trade. The professionalism of the discipline presented new opportunities for photographers to be recognised for their unique contributions and perspectives. No one demonstrates this better than Julius Shulman, who remains arguably the world's most famous architectural photographer. Beginning in the 1930s, Shulman's career as an architectural photographer spanned more than six decades of documenting buildings in America for architects, publications and exhibitions. Shulman's savvy and highly controlled images, with their hallmark inclusion of people engaging with buildings (Figure 6), broadened the appeal of architectural photography. It did not simply sell architecture - it sold a modern way of living. ${ }^{45}$

\footnotetext{
42 Robinson, 118.

${ }^{43}$ Carullo, The Robert Elwall Photographs Collection at the RIBA British Architectural Library, 8.

44 Ibid., 8.

${ }^{45}$ Elwall, 161.
} 


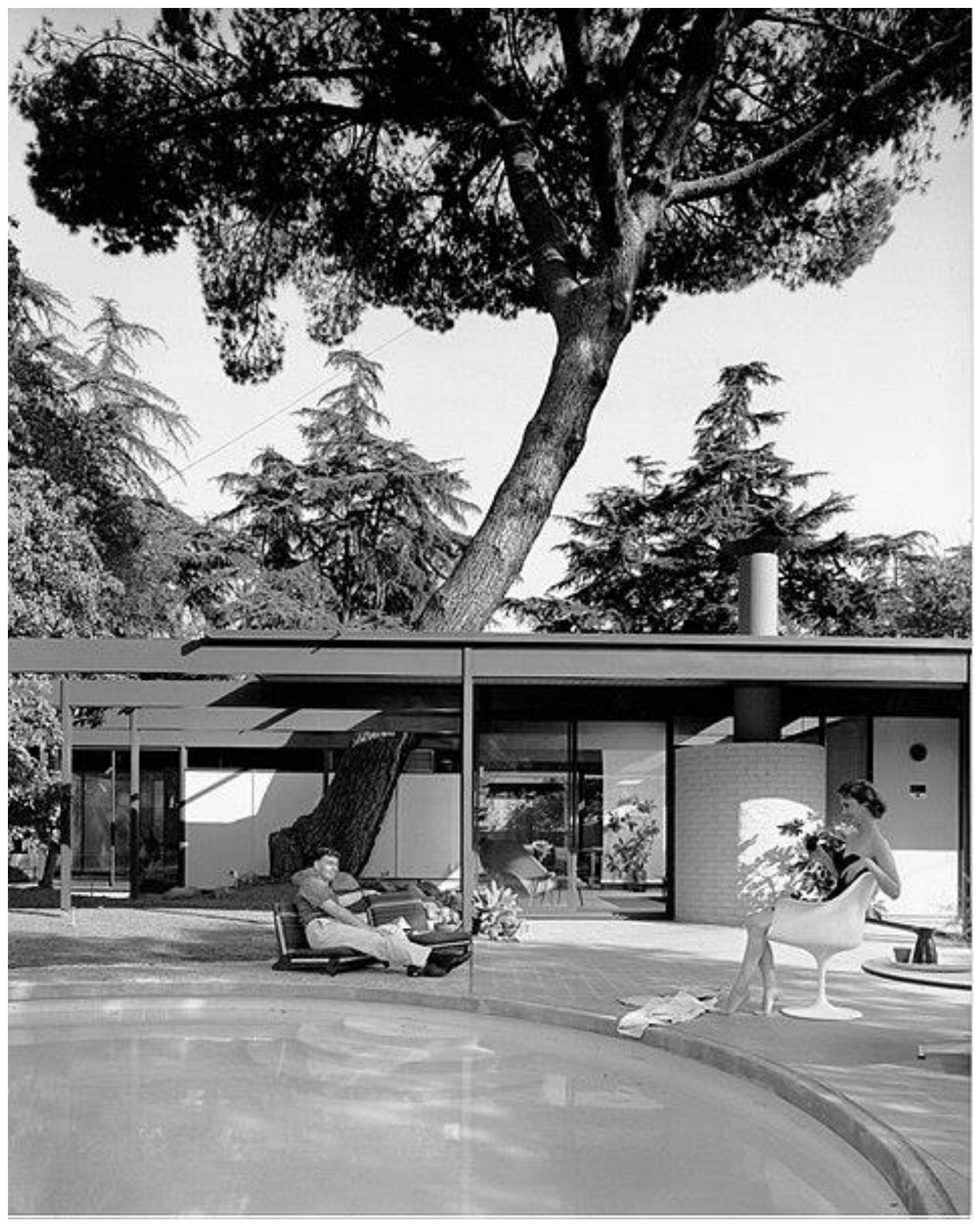

Figure 6: Julius Shulman, Bass House (Case Study \# 20), Buff, Straub \& Hensmen, 1956. From File:Bass Pool View.jpg, by Marchitecthistories, 2016. Wikimedia Commons

(https://commons.wikimedia.org/wiki/File:Bass_Pool_View.jpg). In the public domain. 
Photographers were not only choosing to document new buildings in novel ways, in some cases, they needed to. Over the first half of the twentieth century, skyscrapers were becoming more and more dominant across the urban landscape. In order to appreciate the skyscraper in full - the worm's-eye view emerged. This perspective allowed the photographer to be in close enough proximity to a tall building to capture the texture and pattern of its facade, while still showing the completeness of its built form. ${ }^{46}$ Access to skyscrapers also allowed aerial and bird's eye views to be more easily utilised. New York photographer Berenice Abbott took advantage of this access, capturing images atop skyscrapers and revealing unseen and dynamic perspectives of urban space (see Figure 7 ). ${ }^{47}$

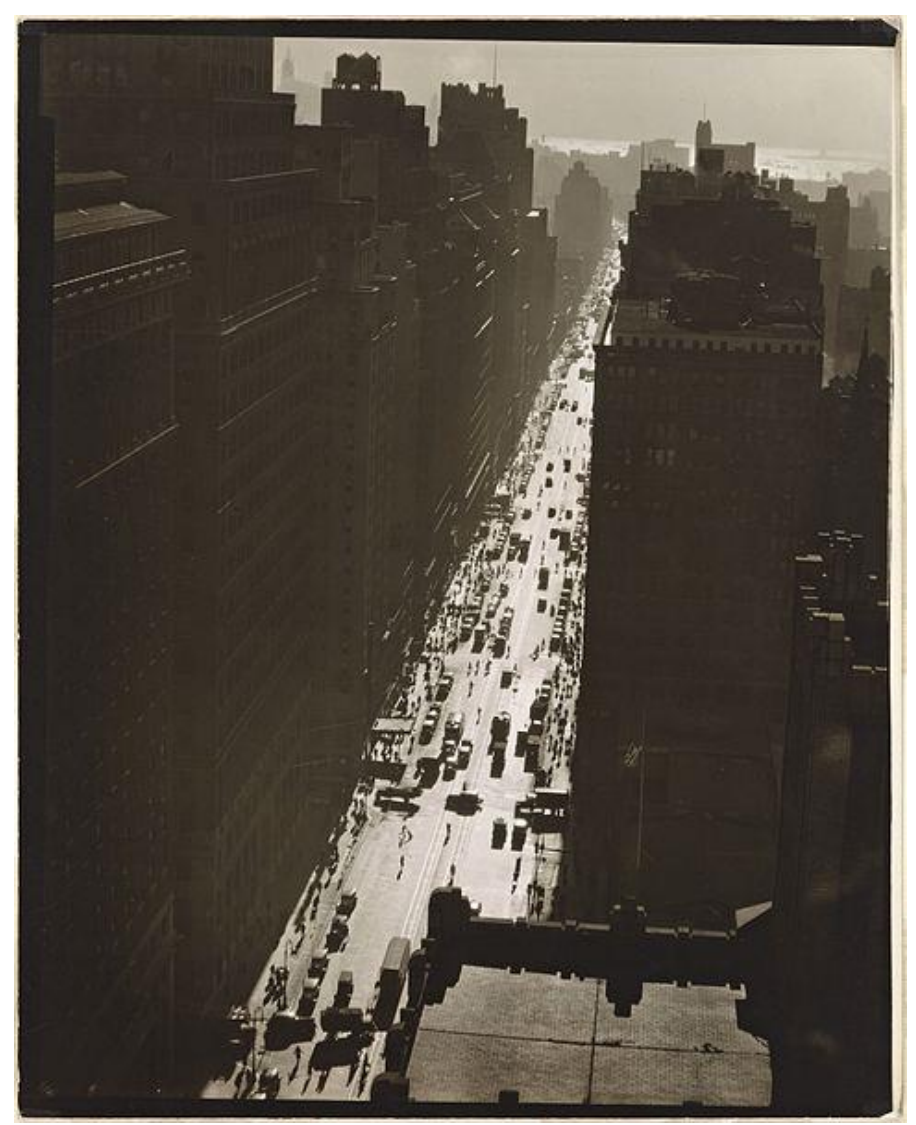

Figure 7: Berenice Abbott, Seventh Avenue looking south from 35th Street, Manhattan, 1935. From: File:Seventh Avenue looking south from 35th Street, Manhattan (NYPL b13668355-482802).jpg, by New York Public Library, 2016. Wikimedia Commons (https://commons.wikimedia.org/wiki/File:Seventh_Avenue_looking_south_from 35th_Street,_Manhattan_(NYPL_b13668355-482802).jpg). In the public domain.

\footnotetext{
46 lbid., 118.

47 Woods, Beyond the architect's eye: photographs and the American built environment, 49.
} 
In the post-war period, a new generation of photographers was documenting the built environment. More than ever before, photographers were likely to have trained in architecture, as opposed to their predecessors, who were largely trained in photography. ${ }^{48}$ Photographers trained in architecture were noted for their ability to apply their spatial understanding for photography. ${ }^{49} \mathrm{~A}$ prime example is Ezra Stoller, one of the most celebrated architectural photographers of the twentieth century, whose elegant imagery was recognised as calming public resistance towards the starkness of modern architecture. Stoller described his "architectural approach" to photo-making, which undoubtedly was informed from his time as an architecture student. ${ }^{50}$

That the architectural community increasingly produced its own photographers, such as Stoller and others, has been discussed as contributing to a division between architectural photographers and the greater photography establishment. ${ }^{51}$ This division may partly explain the sustained use of a single style of architectural photography throughout the mid twentieth century. In his 1961 Photography and Architecture, de Maré describes three categories of architectural photography. First is the factual 'Record', then the more expressive 'Illustration' and finally what de Maré suggests as the 'most creative and exciting', 'the Picture'. ${ }^{52}$ de Maré's groupings appear almost unchanged from the categories of photographs that Charles Nègre described almost a century earlier.

By the 1960s, the dominance of New Photography as a conduit for representing architecture was beginning to wane. Visual artists were experimenting with architectural photography in ways which democratised the discipline. An enduring example of this artistic engagement is the decades long typological enquiry by German photographers Bernd and Hilla Becher. The Bechers documented industrial structures including cooling and water towers and factories. Their photographs were taken head-on in with objectivity, and framed with orderly conventions that enabled presentation in grid formats. This presentation allowed viewers to see architectural taxon on mass, and derive their own meanings from them, rather than seeing what the photographer intended. This new breed of photographers found mainstream audiences in publications, notably in AR's 'Manplan' series of 1969-70. Photojournalists, not professional architectural photographers, were commissioned to document the state of British architecture

\footnotetext{
48 Elwall, 156.

49 de Maré, 20.

50 Busch, 14.

51 Elwall, 154.

52 de Maré, 25-26.
} 
and planning, with frank and humanising effect. ${ }^{53}$ The 'Manplan' series represents an historical moment, where an expanded possibility for architectural photography was showcased.

\section{Conclusion}

Reflecting on the history of architectural photography from the 1830s to the 1970s reveals a discipline positioned between an objective science and a subjective art. Advances in technology enabled it to develop in both directions, while successive architectural eras supported its creative application - and as an artistically motivated pursuit, it has proven to have enduring and inherent value. Of significance is the changing ways in which the architectural establishment has understood and valued photography. Over time architects and architectural theorists have found ever more reasons to reflect on not only the way that photography and architecture have influenced one another, but also how that relationship continues to impact the way we value, historicise, and understand architecture.

The knowledge of this history provides valuable context in which to consider Winder's post-war photography, and the ways in which it would have been produced and viewed.

53 Carullo, 9. 


\section{On the visual languages of New Brutalism and Townscape}

\section{Introduction}

In order to contextualise Duncan Winder's photography within the modernist project of the twentieth century, this section of the literature review revisits the post-war period in Britain from the 1940s to the 1970s, when emerging architectural philosophies were not only asserting influence on the design of new buildings, but were also establishing precedent for mainstream architectural representation. The post-war British architectural cultures of Townscape and New Brutalism can both be considered germane when assessing Winder's oeuvre, given the attention to which they considered the 'image' as critical to their spatial philosophies. While Townscape and New Brutalism positioned themselves as ideologically oppositional paradigms, contemporary historians contest the extent to which these movements should be read as conflicting. ${ }^{54}$ One means for assessing the relationship between Townscape and New Brutalism is their use of imagery. An examination of their approaches to imagery and specifically towards photographic representation provides an avenue in which to explore the two movements, and also act as context with which to interpret Winder's photographs later on in Chapter Three.

This section of the literature review is structured with concise overviews of both Townscape and New Brutalism and their distinct visual languages. This is followed by a comparison of their imageries.

\section{Overview of the Townscape movement}

Promulgated on the pages of $A R$, the Townscape movement was a didactic campaign most prominently espoused by planner and illustrator, Gordon Cullen. It sought to promote a way of seeing the built environment, through an aesthetic, inclusive and especially English lens. Its first explicit appearance in $A R$ in 1949 signified the beginning of a period of focused engagement on what Townscape meant for perceiving and designing urban environments.

The immediate post-war period coincided with $A R$ 's fiftieth anniversary. In January 1947, AR's editorial 'The second half century' acted as a manifesto, revealing the 'ever-present thread of policy' which underpinned the journal's model of architectural journalism. The editorial acknowledged $A R$ 's commitment to tracing the development of the modern architectural style and bringing attention to the significance of popular art and design, but of most interest was the admission that 'the endeavour running throughout the story (was) to re-establish the supremacy

${ }^{54}$ Calder, "Brutal enemies? Townscape and the 'Hard' Moderns", 200. 
of the eye' ${ }^{55}$ This was argued as an urgent objective given the ascendancy of large-scale urban planning and reconstruction projects and the concomitant perception that the built environment was being increasingly conceived of as 'one coordinated scene rather than a collection of buildings to be looked at individually, ${ }^{56}$ The $A R$ editors saw these trends as an opportunity to impart ways of seeing that were aligned with their affinity for historic precedent, and especially English precedent. The editors stated only one theory to support the identified opportunity: the relevance of the Picturesque tradition for responding to the twentieth-century urban landscape. ${ }^{57}$ This suggestion comes as no surprise, given $A R$ 's editorial team included art historian Nikolaus Pevsner. Pevsner, arguably the most prominent modern thinker on the Picturesque tradition and most determined to prove its twentieth century architectural applicability. John Macarthur and Mathew Aitchison argue that Pevsner's Picturesque revival facilitated a pedigree for Townscape. ${ }^{58}$

\section{Overview of Townscape's visual language}

Pevsner's theories on the Picturesque provide an appropriate entry point for considering the visual language of Townscape. Pevsner advanced theories about the Picturesque over a sustained period from the 1930s to the early 1970s. As a renowned art and architectural historian, he was ideally positioned to relate the Picturesque to modern architecture. He saw it as a distinctly English concept, rating it as England's greatest contribution to aesthetic theory. While Pevsner's mode of communication was keenly academic, he held that Picturesque was the first 'feeling-your-way' theory of art in European history indicating his confidence in its potential for mainstream comprehension and utility. Perhaps it is for this reason that he offered the Picturesque as a series of frangible qualities: intricacy, surprise, impropriety, variety, contrast, piquancy, incongruity, roughness, sudden variation and irregularity. With these qualities in mind, one can appreciate how Pevsner connected the Picturesque to the modernist project, a historical moment in which new buildings and groups of buildings were (at times, radically) challenging the established pattern and quality of the urban environment. On account of this potential spatial tension, Pevsner saw the Picturesque as an essential tool with which 'the town planner can defeat chaos'.

55 Parnell, "AR's and $A D$ 's post-war editorial policies: the making of modern architecture in Britain", 763.

56 Richards, Pevsner, Lancaster and Hastings, "The second half century", 36.

57 Ibid., 36.

58 Macarthur and Aitchison, "Pevsner's Townscape", 1. 
This set of qualities that Pevsner offered as a way to understand the Picturesque can also be considered as a guide to the visual language of Townscape, which Pevsner presented through photography. This is demonstrated in his 1942 manuscript (which he never saw published) on 'Visual Planning', a phrase which can be read as tantamount to Townscape. ${ }^{59}$ The manuscript, edited by Aitchison and published in 2010 , includes a series of photo-narratives predominantly depicting Picturesque planning in Oxford and Cambridge. Interestingly, Pevsner identifies photographs as limited in their ability to do justice to his Picturesque case studies. He suggests the 'visual merits of Oxford and Cambridge, which are not merely merits of sequences of buildings... can reveal their aesthetic qualities only to the roving eye'. ${ }^{60}$ Despite the camera's supposed limitations, Pevsner concedes that through his selection of images accompanied by a map to explain the relativity of the scenes depicted, it 'may be possible to convey their spatial significance'. ${ }^{61}$ This series of images emphasises variety and contrast in the built environments of Oxford and Cambridge, rather than focusing on any particular building.

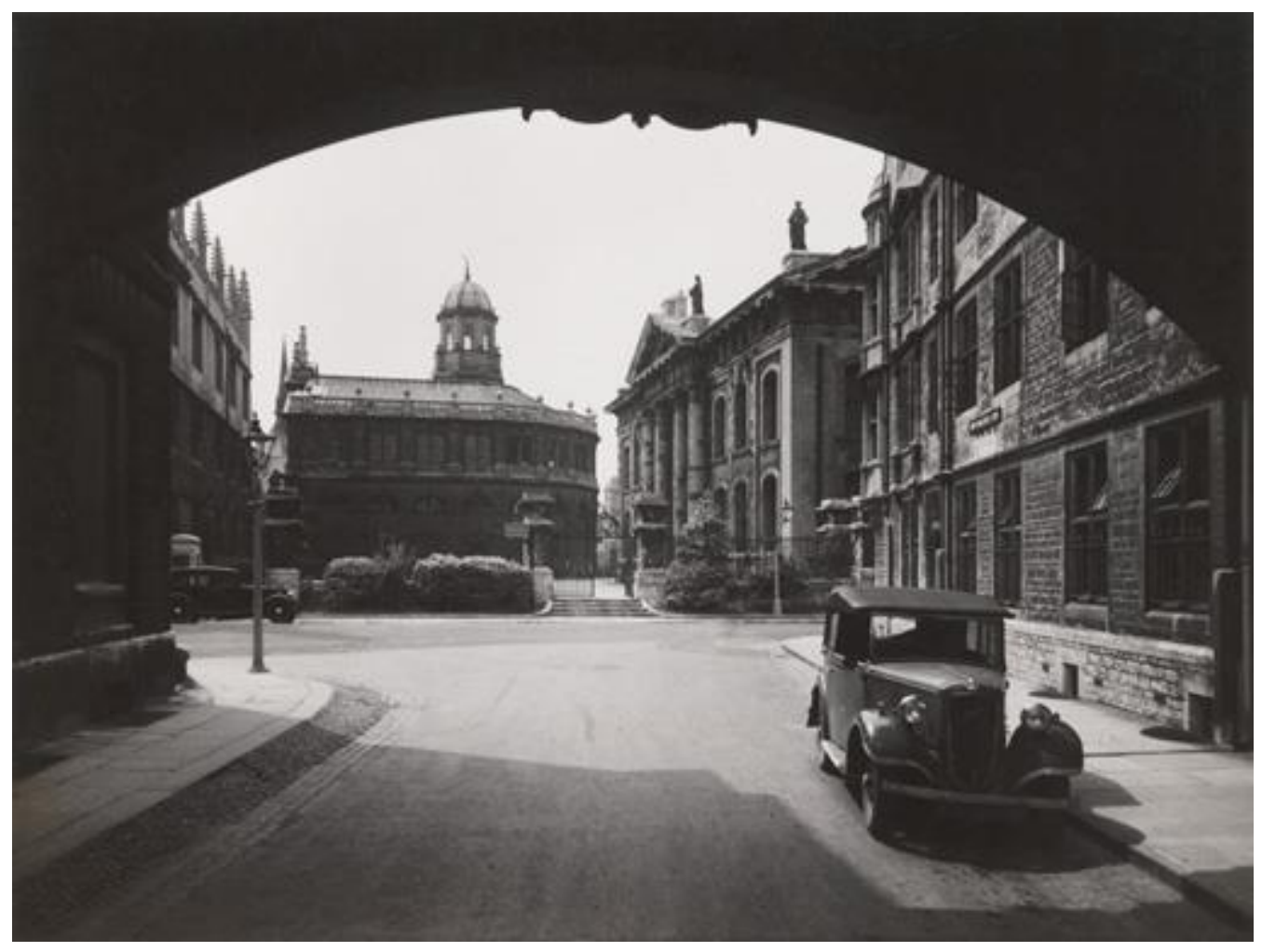

Figure 8: Helmut Gernsheim, Queen's Lane, Oxford. Courtesy the Gernsheim Collection, Harry Ransom Humanities Research Center, the University of Texas at Austin.

59 Pevsner, "C20 Picturesque", 229.

60 Macarthur and Aitchison, 9.

61 lbid., 9. 
One of the first published articles on Townscape used a similar approach to Pevsner to visually represent the movement. Townscape (penned by Ivan de Wolfe, the pseudonym for $A R$ 's editor Hubert de Cronin Hastings) appeared in the December 1949 edition of $A R$ (see Figure 9). The article is introduced with a single image, generously occupying almost a full page. It is the only visual representation in the essay. The image shows the detail of a footpath and cobbled street. Within the image, compositional priority is given to a stormwater grate, with its rounded openings appearing like passages of Morse code. The grate is positioned between contrasting cobble stone configurations. Slim rectangular stones shoot out to the right, and above, rays of square stones beam across the surface towards a central point - just out of view. Similarly, to the left of the image, the curb's edge curves out of frame - suggesting a path to follow, and the promise of a destination. Shadows cast over part of the image, which add rich tonal variations and dramatic abstractions to the image.

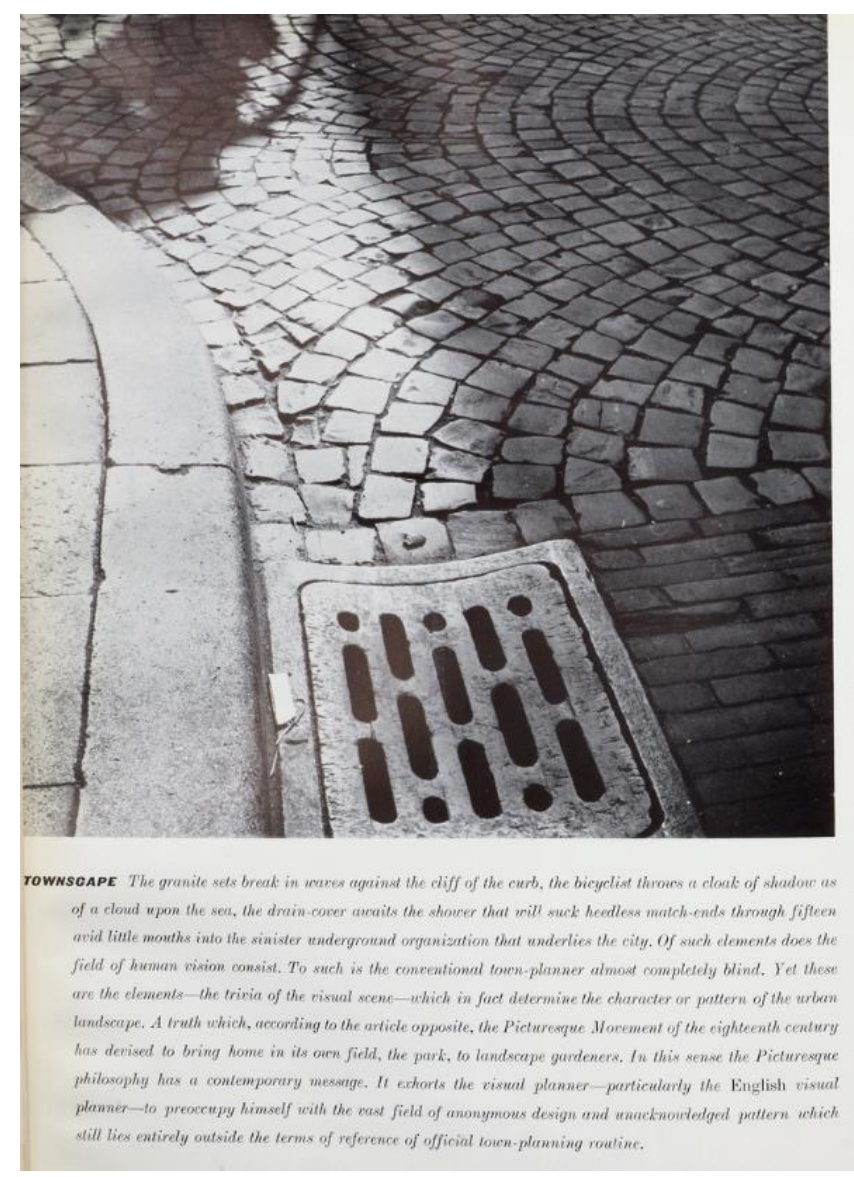

Figure 9: Cover page for the article Townscape by Hubert de Cronin Hastings (written under the name Ivan de Wolfe). AR, Volume 106, December 1949. 
Hastings' article sought to bring attention to the 'anonymous design and unacknowledged pattern within the urban landscape. It is an objective that can only be proven through imagery or 'perceived by the eye' - and the photograph of the stormwater grate elegantly achieves this objective.

The article that immediately followed Hastings' in the December $1949 A R$ also concerned Townscape, but used a different approach to its visual representation. This was written by Gordon Cullen. Trained (but never practiced) as an architect, Cullen initially worked as a draughtsman in London. In the late 1940s, Cullen joined $A R$, as assistant editor. ${ }^{62} \mathrm{He}$ was known predominantly for his writing on town planning and urban design, regularly complementing his writing with distinctive sketched illustrations. Cullen's first Townscape contribution to AR immediately followed Hastings' essay. Where Hastings theorised on the value of Townscape, Cullen attempted to put theory into practice. Across the pages of Cullen's feature, photographs are employed to express Townscape. Unlike Hastings' large-scale single Townscape image, Cullen's article is a panoply of images, fitting for a movement so embracing of richness and variety.

Cullen's article is presented in the form of 'specimen pages' each with a heading indicating a specific genre of vision required to perceive the built environment. ${ }^{63}$ Consistent with Charles Nègre's approach of explicitly photographing the same building differently, for different creative practitioners, Cullen's visual genres call for the 'eye as painter', 'as sculptor' and 'as poet'. ${ }^{64}$ Another of Cullen's genres, indicating the modernity of his Townscape, and perhaps the most demonstrative of his approach to imagery is the 'eye as movie-camera'. Cullen's approach to the visual representation of Townscape seems to acknowledge a similar belief to that held by Pevsner, that photography is an inferior means of understanding a built environment, relative to experiencing it first-hand. Despite this, Cullen's generous use of photography indicates an attempt to overcome, or at least minimise, the limitations of photography to communicate Townscape.

Cullen's 1949 article can be read as the first iteration of his Concise Townscape. Eventually published in 1961, Concise Townscape was Cullen's Townscape treatise and can be seen as the coalescence of his thoughts on the movement. In Concise Townscape, Cullen is more direct about the use of Townscape not only as a way of looking at the urban environment, but also as

\footnotetext{
62 Parnell, 763.

${ }^{63}$ Cullen, Townscape, AR, Volume 106, December 1949.

64 Ibid., 41.
} 
a guiding principle for designing new townscapes, 'manipulating the elements of town - so that an impact on the emotions is achieved'. ${ }^{65}$ In Concise Townscape, he also elaborates on his 'eye as movie-camera' concept through discussion of serial types of 'vision', the phenomenon of the built environment being 'revealed in a series of jerks or revelations'. ${ }^{66}$ Cullen asserts that within serial vision, views can be described as either 'existing' or 'emerging', further enforcing his interest in Townscape as continuing and connected series of vistas. ${ }^{67}$ Interestingly, Townscape appears as much about a person's ability to move through space as it does about aesthetics. Concise Townscape is richly illustrated, predominantly with photographs as well as lively sketches (see Figure 10). Text is predominantly presented in caption form, giving the publication the provisional quality of a scrapbook or photo album. In many instances Cullen's captions feel obsolete, given the immediacy with which the photographs communicate his intentions. This reliance on text, however, accords with the views of Cullen and Pevsner that photography alone is limited in its ability to represent Townscape.

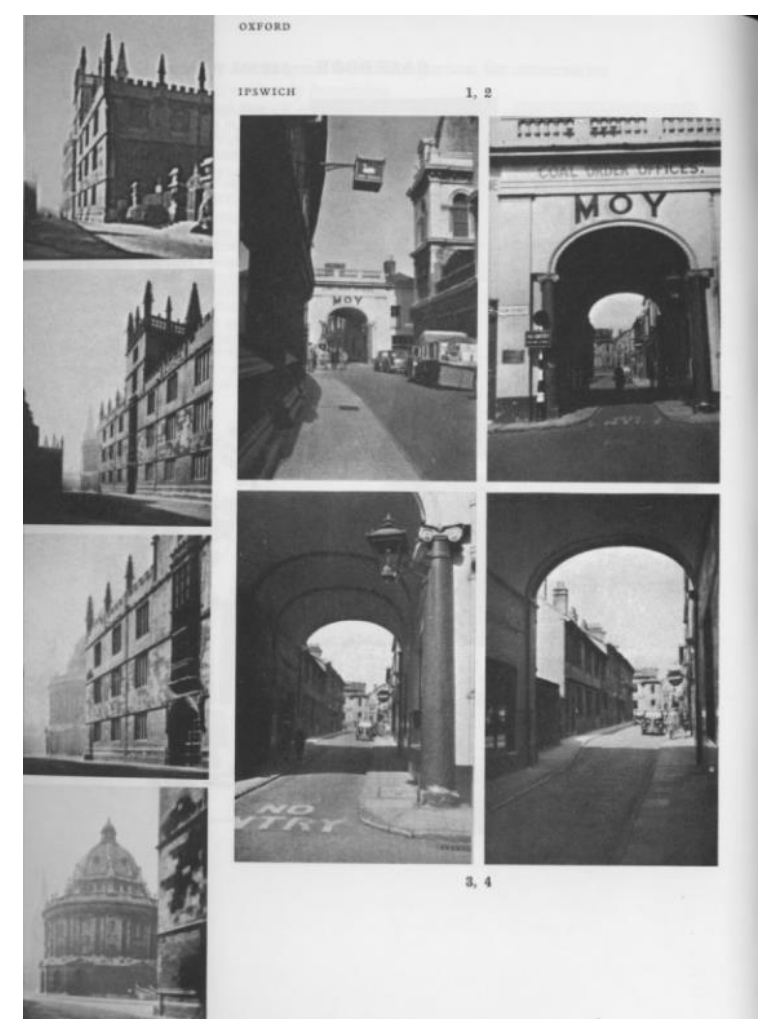

Figure 10: (no photographer credited). Excerpt from Gordon Cullen's Concise Townscape. London: Architectural Press, 1961.

${ }^{65}$ Cullen, The Concise Townscape, 8.

66 Ibid., 9.

67 lbid., 9. 


\section{Overview of New Brutalism}

The term New Brutalism was first recognised in the December 1953 edition of Architectural Design. Considering their design for the Soho House, a private residence that had no internal finishes, Alison and Peter Smithson noted 'had this house been built, it would have been the first exponent of new brutalism'. ${ }^{68}$ In interviews decades later, Peter Smithson would return to further reflect on the intended ideas of the Soho House. Smithson stated 'brutalism to us meant 'direct'... necessary to suit the situation'. ${ }^{69}$ While the Soho House was never realised, the Smithson's first built project, Hunstanton School would become the touchstone of New Brutalism, not only in its design but also in its photographic representation, and would become an important case study for Reyner Banham to advance thinking about New Brutalism.

\section{Overview of New Brutalism's visual language}

During the time in which the Smithsons were designing the Hunstanton School (1949-1954), they were engaged with the Independent Group. This was a group of painters, sculptors, architects, writers and critics who met at the Institute of Contemporary Arts (ICA) in London, England, from 1952 to 1955, and wanted to challenge prevailing modernist approaches to culture. ${ }^{70}$ This interest of the Independent Group on mass culture helps to understand the way that the Hunstanton School was photographed. The way in which Hunstanton School was photographed was seminal for asserting New Brutalism's visual language. Visibly inspired by the architecture of Mies van der Rohe, Hunstanton School was a revelation for the extent to which the building's structure and services were left exposed. In this way, it resolutely displays the directness to which Peter Smithson stated as critical to New Brutalism. In fact, its directness is so concentrated that Claire Zimmerman has discussed how the building's architectural qualities can hardly be 'distinguished from its imagistic ones'. ${ }^{71}$ Multiple photographers took images of Hunstanton School at the time of its construction and completion. Most attentive to its New Brutalist categorisation, Nigel Henderson took photographs of the school during its assembly (see Figure 11). Henderson's images defy conventions of commercial modern architectural photography, for their emphasis on the building's status as part of a process, rather than as the ideal. Andrew Higgott describes this as at the heart of New Brutalism, focussing on

\footnotetext{
68 Parnell, 766.

69 van den Heuvel, "Between Brutalists. The Banham Hypothesis and the Smithson Way of Life", 294.

70 Ibid., 293.

71 Zimmerman, "Photographic Images from Chicago to Hunstanton", 206.
} 
appreciating the everyday qualities of the modern world, without seeking to dictate a uniform aesthetic from that appreciation. ${ }^{72}$

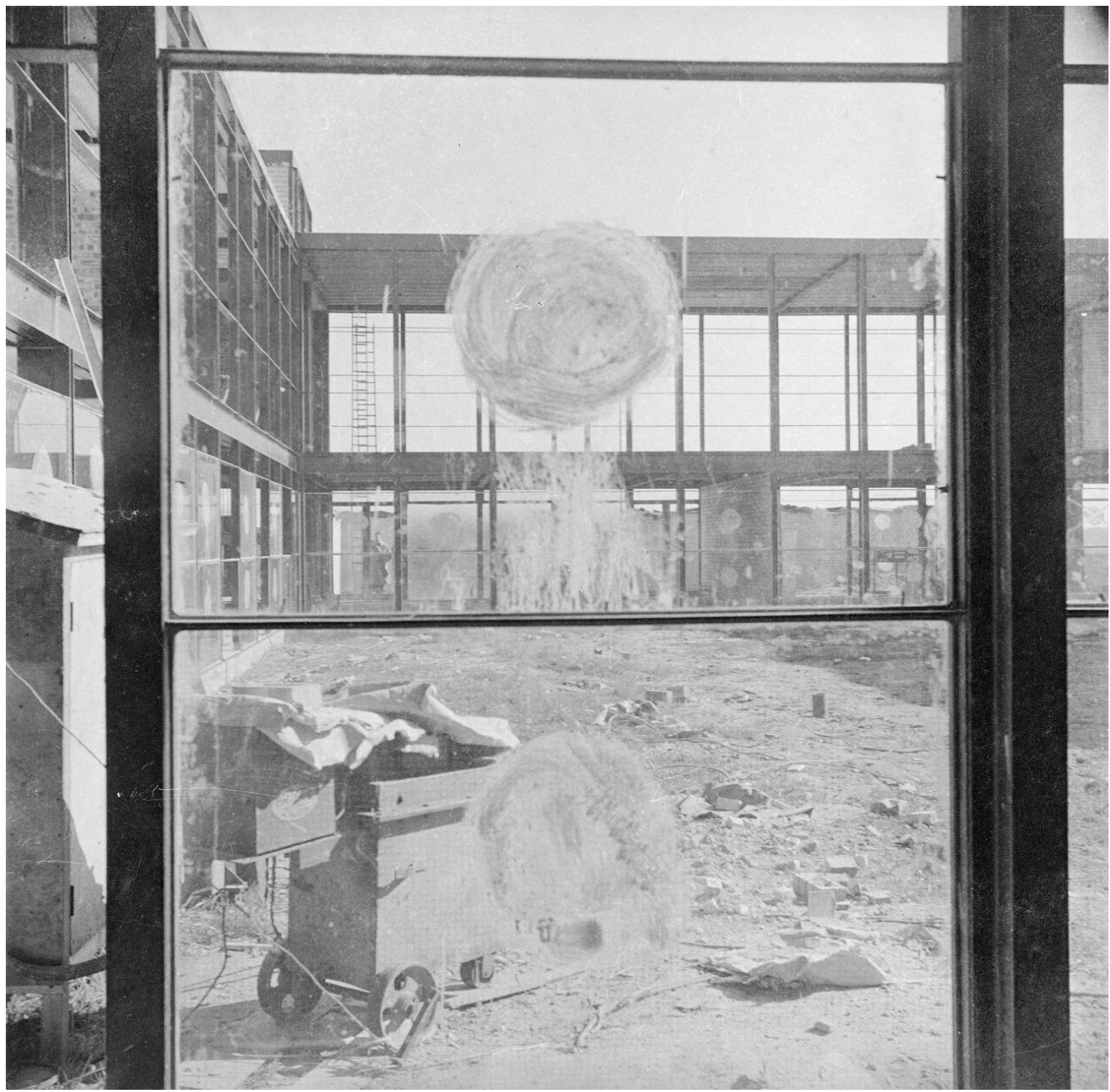

Figure 11: Nigel Henderson, Photograph showing Hunstanton Secondary Modern School, Norfolk, during construction, [c.1949-c.1956]. Tate Archive, and Nigel Henderson Estate. Image released under Creative Commons CC-BY-NC-ND (3.0 Unported).

72 Higgott, 285. 
It is interesting to consider the Smithson's act of having the furniture removed from the completed Hunstanton before it was photographed for publication. Conscious of photography as the language in which buildings were primarily communicated, the sparse interiors enabled the clear articulation of the building's direct legibility. What is more, the Hunstanton School provides a useful study of a building whose architecture has been affected by photography. Peter Smithson described his exposure to photographs of van der Rohe's Illinois Institute of Technology (IIT) as life changing. ${ }^{73}$ van der Rohe's interest in fabricated repetition, visible through the imagery of IIT, was of primary influence on the Smithsons. Zimmerman has acknowledged that while there is a sympathy between images of the two buildings, in reality, their architectures are fundamentally different. ${ }^{74}$ What this difference reveals is the ability for the image to convey a design philosophy that transcends spatial truths.

Even before the Hunstanton School was completed, the Smithsons were involved in another project which confirmed how formative the early 1950s was for the shaping of New Brutalism. In 1953, members of the Independent Group, namely the Smithsons, alongside Henderson and Eduardo Paolozzi, staged what they intended to be a seminal exhibition at the ICA. In fact for the Smithsons, the exhibition intended to usher in the 'second great creative period' of modern architecture. ${ }^{75}$ They argued that during the first great period, architecture was the synergistic composition of simple elements, which alone had no inherent identity and could only be understood contextually. The Smithsons saw the act of establishing inherent definition and complexity for those contributing elements, while still retaining the clarity of the overall architecture, as the cultural challenge of the 1950 s. $^{76}$

Reflecting on the original title for the exhibition, Sources, provides a useful entry point to understand its objectives, and what kind of visual language it attempted to convey. The Smithsons stated that "art results more from the act of selection than from the act of design", and for the exhibition 122 images were carefully selected. ${ }^{77}$ While the selected images accorded to eighteen different categories (including anatomy, architecture, art, calligraphy, landscape, movement, nature, primitive and stress), their seemingly random spatial installation across the ICA gallery space enabled imaginative connections, free from categorical discrimination, to be made between images. The exhibition, eventually titled Parallel of Life and Art, represented an

\footnotetext{
${ }^{73}$ Zimmerman, 207.

74 Ibid., 208.

75 Lichtenstein, As Found: the discovery of the ordinary, 38.

76 Ibid., 38.

77 lbid., 31.
} 
atlas of collaged background material with which a modern and inclusive visual sensibility could be fostered. In this way, there was no singular statement to be deduced from the exhibition, but instead, an endless number of visual weavings which all spoke to the organisers' wish to see a union of vision for the realms of art, science, the organic and the man-made.

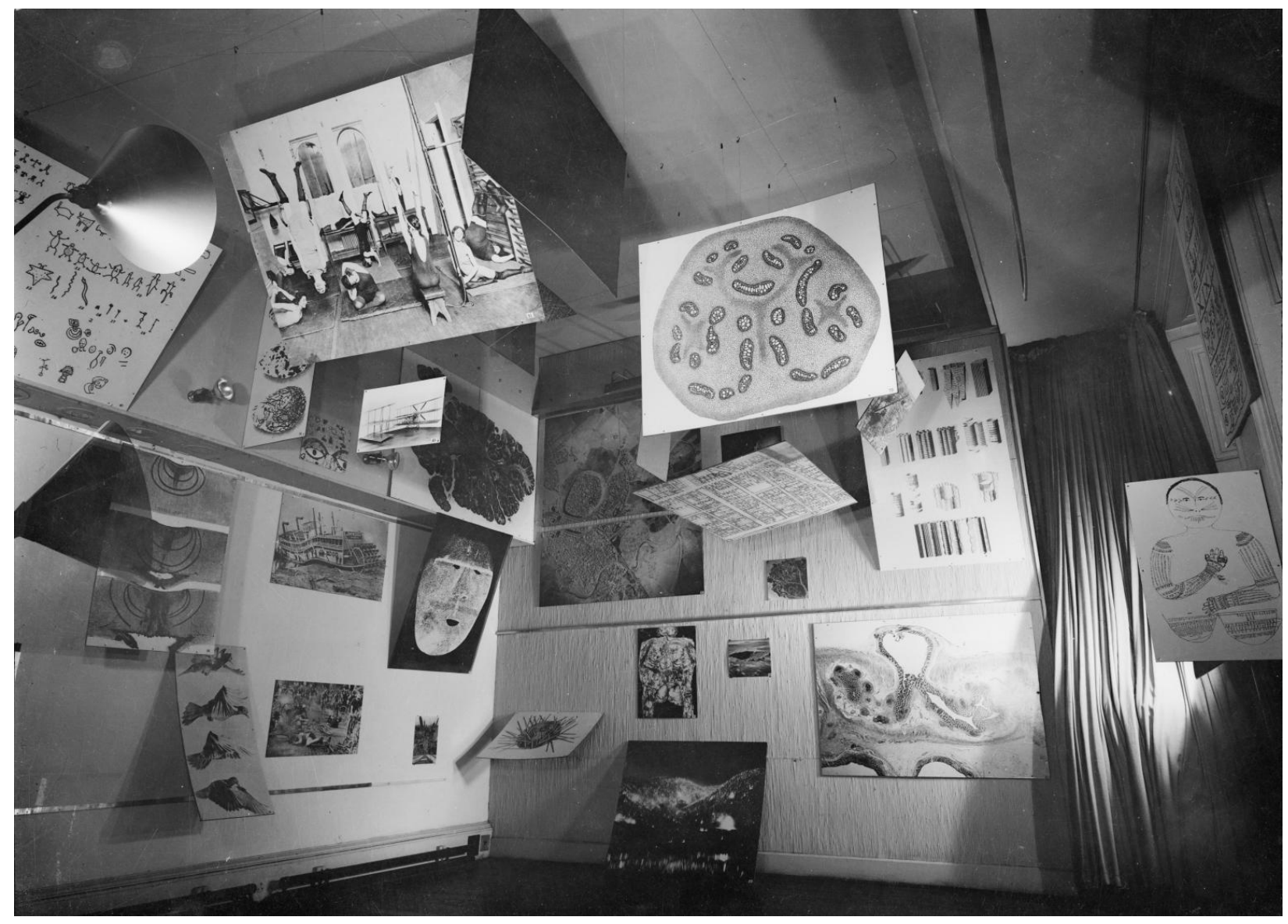

Figure 12: Nigel Henderson, Photograph of installation view of Parallel of Life and Art exhibition, 1953. Tate Archive and the estate of Nigel Henderson.

While it could be argued that the Parallel of Life and Art images can be described as brutalist, it is perhaps more useful to consider that they illuminate a brutalist approach to perceiving image, one conscious and accepting of form, material and texture - this is what the Smithson's termed 'as found'. ${ }^{78}$ The "as found" concept has a noteworthy relationship to photography, as the Smithsons named the concept after viewing Nigel Henderson's photographs of his home and

\footnotetext{
78 van den Heuvel, "As Found: The Metamorphosis of the Work of Nigel Henderson, Eduardo Paolozzi,
} and Alison and Peter Smithson (1953-1956)", 58. 
seeing a "perceptive recognition of the actuality around his house". ${ }^{79}$ The Smithsons saw 'as found' as a way of "rethinking architecture" and invigorating their creative output. ${ }^{80}$

The 'as found' aesthetic was also considered by Reyner Bahman in his commentary on New Brutalism. Banham proffered a most definitive understanding of New Brutalism in the post-war period, through his 1955 essay published in AR, The New Brutalism: Ethic or Aesthetic.

Reading Banham's essay with a particular concern for architectural photography is instructive for Banham's emphasis on the 'image' dominates his definition of New Brutalism. Banham outlines three criteria for New Brutalism, the first of which is 'memorability as an image'. ${ }^{81}$ As Alex Potts notes, Banham uses the term image not to refer to representation, 'but to describe a material configuration that is immediately striking for visual qualities that are not reducible to formal logic' ${ }^{82}$ Banham suggests a New Brutalist building must be immediately apprehensive as a visual entity to the eye, and that the perceived form can be 'confirmed by experience of the building in use'. Given the interest of New Brutalism's founders (including Banham) in American advertisements for their realist and direct qualities achieved through photography, it can be posited that 'memorability as image' could be experienced through a photograph - and only later, as Banham requires, confirmed through first-hand spatial experience. Banham's essay is introduced with seven photographs of Le Corbusier's chapel at Ronchamp (see Figure 13), these vignettes declare an especially pronounced 'image' of the chapel, communicated on the page.

\footnotetext{
79 lbid., 60.

80 lbid., 60.

81 Banham, "The New Brutalism: Ethic or Aesthetic", 20.

82 Potts, "New Brutalism and Pop", 35.
} 


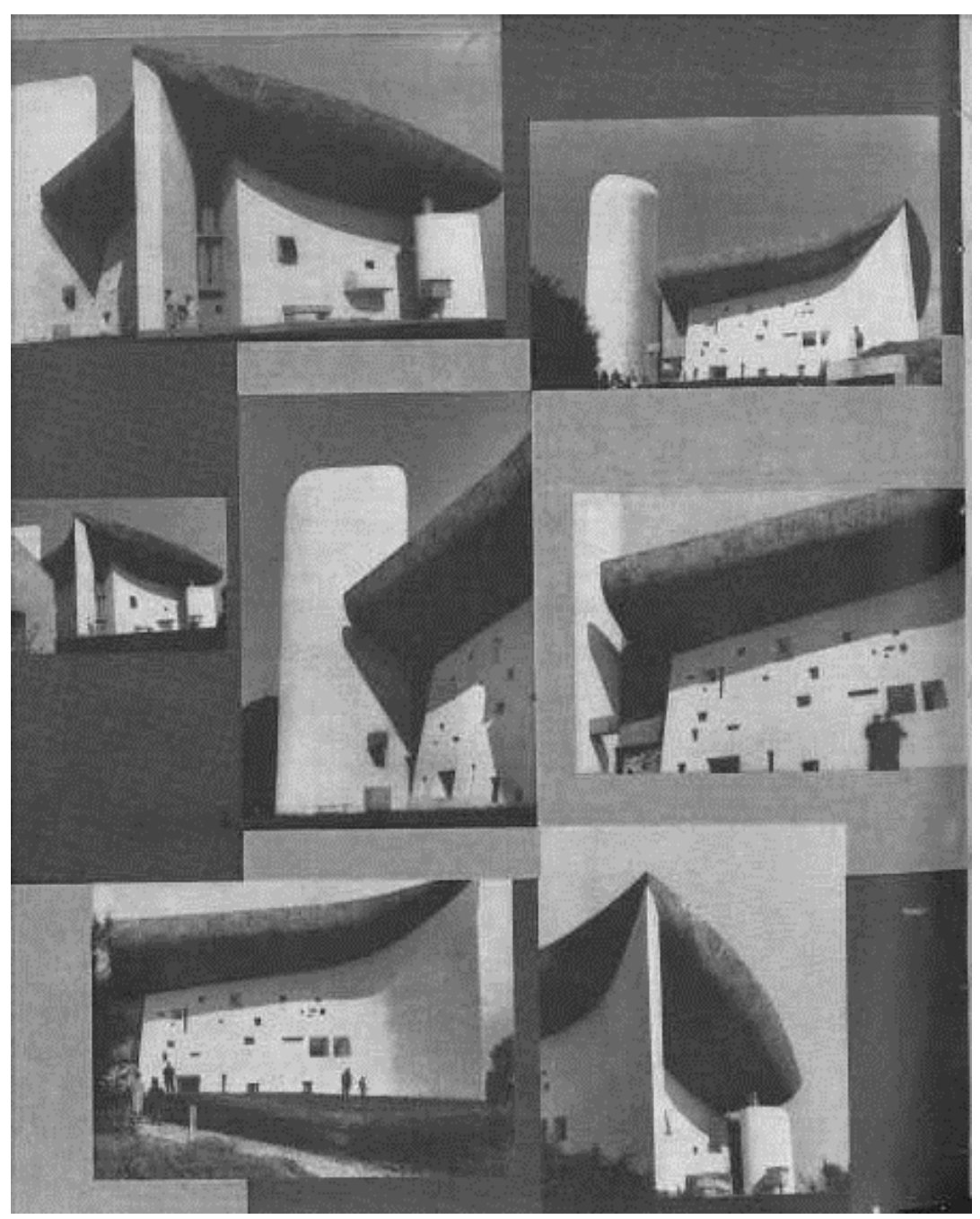

Figure 13: Cover image for Reyner Banham's essay The New Brutalism. Architectural Review Volume 118, December 1955. Reproduced in accordance with the fair dealing (criticism and review) provisions of the Copyright Act 1994.

Banham's second tenet of New Brutalism, 'clear exhibition of structure' also relates to the visual elements of buildings. ${ }^{83}$ It can be interpreted as an extension of 'memorability as an image', in that it implores architecture to be plainly comprehendible - for its true tectonics. At the time of the essay's publication, Hunstanton School was seen as the exemplar for how a building could clearly exhibit its structure and use photography to evidence this exhibition. Its photography saw the building stripped of all furniture to eschew distraction away from the structural elements and materiality. Banham's 'clear exhibition of structure' criteria is, therefore, relevant not only to architecture but also its photographic representation.

${ }^{83}$ Banham, 20. 
'Valuation of materials as found' is Banham's final New Brutalism criteria. ${ }^{84}$ The term, of course, coined by the Smithsons. ${ }^{85}$ Perhaps at the time of Banham's essay, this quality was best demonstrated not by a building, but through the Parallel of Life and Art exhibition, where material details from all aspects of ordinary life were indiscriminately presented, and embraced together.

\section{The Functional Tradition}

Before comparing Townscape and New Brutalism, it is useful to acknowledge the related concept of the 'Functional Tradition', which is pertinent for its distinctive visual language. Popularised by post-war architectural photographer Eric de Maré, ‘Functional Tradition' imagery shared similarities with both Townscape and New Brutalism. de Maré's photographs (Figure 14) of early industrial buildings and structures, such as lighthouses, bridges, and kilns, provided a means to "show the past, denote human use, and stand outside the historical traditions of architectural perfection of form" ${ }^{86}$ These distinctive images became influential for a generation of architects, due to their inclusion in late 1950s $A R$. Similar to the exponents of Townscape, de Maré recognised photography's role in facilitating "visual re-education" and new ways of looking at man-made environments. However, while Townscape imagery had a realistic picturesque quality, Functional Tradition imagery tended more towards an abstract picturesque. de Maré noted that "the photographer can discover and reveal architecture where none was intended by creating abstract compositions of an architectonic quality" which demonstrates a broader "way of seeing' which is more aligned with the New Brutalist 'as found' concept, than with Townscape. ${ }^{87}$

\footnotetext{
84 lbid., 20.

85 Lichtenstein, 8.

86 Higgott, "Eric de Maré: between the functional and the beautiful", 873.

87 Ibid., 874.
} 


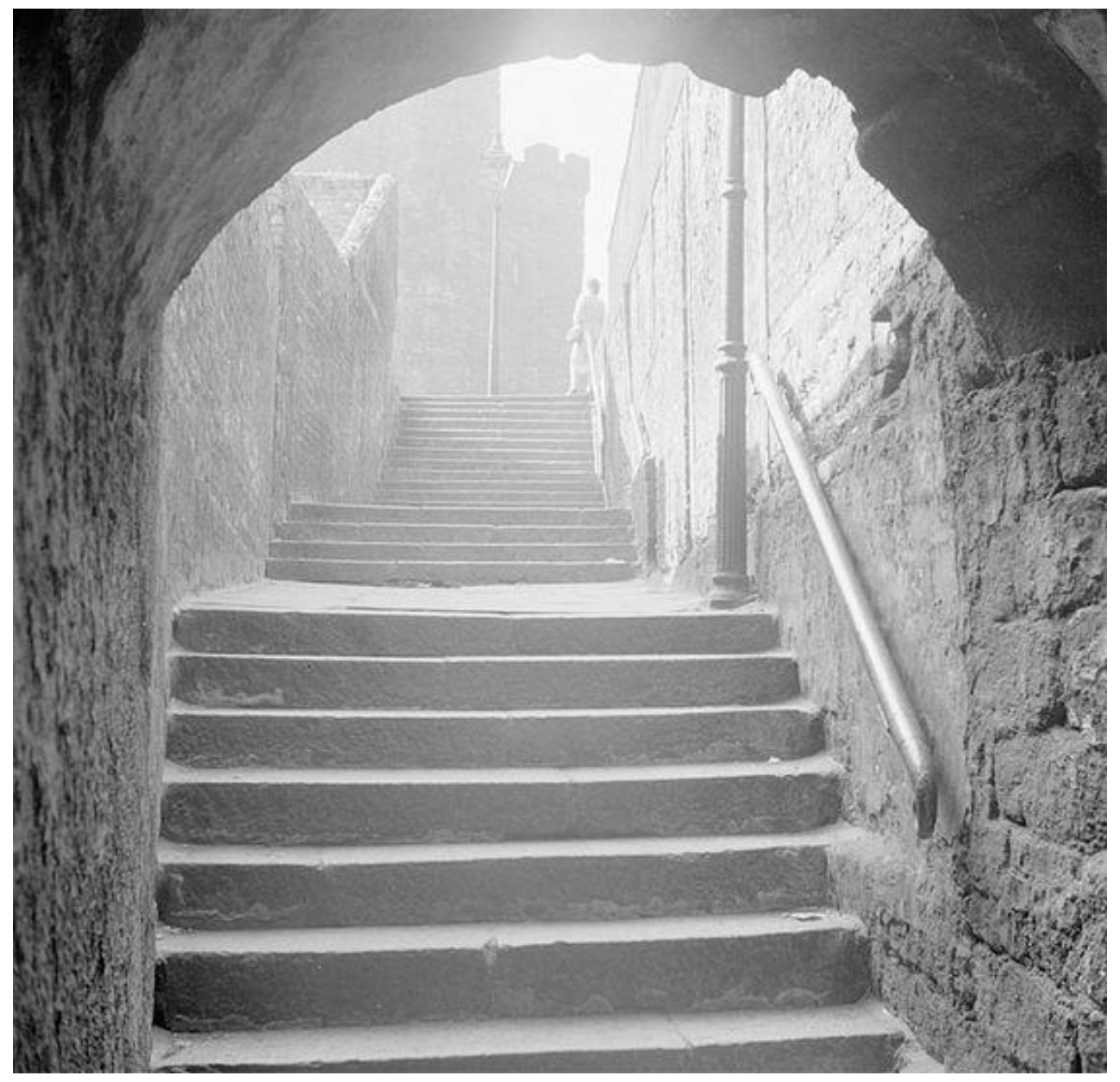

Figure 14: Eric De Maré, General view showing steps leading up to the castle in Newcastle-upon-Tyne, 1945. Historic England Archive, n.d.

\section{Townscape and New Brutalism compared}

While Banham's essay advanced the concept that New Brutalism was an ethic, rather than an aesthetic, his criteria were overwhelmingly materialistic, concerned with architecture's ability to be visually communicated, as well as its composition and texture. This visual focus provides an interesting comparison to Townscape, which also valued 'ways of looking' at the built environment. Despite their distinct foundations and the efforts of the proponents of Townscape and New Brutalism to outwardly position the concepts as mutually exclusive, there are similarities in their visual sensibilities that are worth considering. Barnabas Calder observes that the compositional qualities of Townscape and New Brutalist images are similar, sharing emphases on texture, simple and robust detailing, and unpopulated spaces shot from low 
down. ${ }^{88}$ Calder also acknowledges that, in terms of photography, the two movements did both employ 'moody, high-contrast black and white photography' indicating the dominance and limitations of this photographic style within the post-war context. ${ }^{89}$ Beyond these formal qualities, comparisons can be made between the imagery of the two movements which relate to the embrace of realism and the extent to which images were seen as capable of communicating spatial realities.

Townscape's nostalgia for the aesthetics of the English urban settlement demonstrated a commitment to realism, seeing a legitimate art in the concrete world. This was a sentimental realism which sought to strengthen and progress ideas of national identity. ${ }^{90} \mathrm{New}$ Brutalist imagery also embraced realism, albeit a separate one. This was a strongly commercial realism, inspired by the possibilities of commercial media. Brutalist realism was not picturesque, instead it actively asserted the qualities of advertisements - emphasising the building as a commercial product. This was fundamentally different to Townscape which did not seek to isolate single features of the built environment but instead present an inclusive, contextualised image. These different expressions of realism can explain why Townscape images were regularly composed to elicit optimal drama and effect for viewers, while brutalist images conformed to a more direct, objective format.

It is revealing to consider the extent to which the photograph was valued by proponents of Townscape and New Brutalism to communicate their ideas. It is evident that photographs were used extensively to discuss both concepts, however, this occurred in different ways. For Townscape, photographs were supporting pieces of evidence and always explained through text. Townscape proponents regularly expressed the limitations they saw in photography, citing that only first-hand spatial experience could reveal the reality of Townscape. Perhaps this explains Cullen's overcompensation of imagery through photographic narratives of multiple images presented in sequence, as if on a film reel, suggesting that a single image could not convey his Concise Townscape. This was not the case for New Brutalism. Banham's seminal definition of the movement as 'memorability as an image' specifies that buildings must be immediately understandable as an image. Here the 'image', and laterally, photography is entrusted as offering direct, primary evidence of Brutalism. As Zimmerman reflects, 'post-war conditions shifted the balance between the image and the object to increase the importance of

\footnotetext{
${ }^{88}$ Calder, "Brutal enemies?", 206.
}

89 Ibid., 206.

90 Boyer, 159. 
the former to an unprecedented degree'. ${ }^{91}$ The levels of importance that followers of Townscape and New Brutalism placed on the photographic image, therefore, does reveal fundamental differences in their visual philosophies.

'The word 'image' is ... one of the most intractable and the most useful terms in contemporary aesthetics, and some attempt to explain it must be made,92

Both Townscape and New Brutalism emerged from a period of architectural history notable for vigorous and original attempts at 'visual re-education', so often preoccupied with the 'image'. This didactic exercise produced memorable and distinctive architectural photographs, framed within ideological positions on how to perceive architecture and the built environment. Importantly, while 'a sense of opposition' was important for the self-definition of both Townscape and New Brutalism, their ways of seeing shared commonalities. ${ }^{93}$ Both visions attended to the realities of the pre-existing world and learnt from a range of other art forms to develop considered ways of looking at architecture. We can understand the photographic representations of Townscape and New Brutalist through their expression of specific architectural cultures and theories. Beyond this, we can also interpret their styles of photography more inclusively through an appreciation of the unprecedented value that was placed on the architectural image during the post-war period, and the aspiration and faith with which photography employed during that time to articulate the meaning and potential of architecture.

91 Zimmerman, 207.

92 Banham, 20.

93 Calder, 213. 


\section{On the development of architectural photography in New Zealand, 1930 -1970}

\section{Introduction}

It is advantageous that the development of architectural photography in New Zealand has been recorded as a visible history. Successive pages and volumes of our architectural publications chart the increasing attention afforded to the photography of buildings over the twentieth century and the growing local professionalisation of this branch of photography. Collectively the images within New Zealand architectural publications represent an important source of evidence of an evolving domestic architectural culture that drew on a range of international influences in the process of documenting our built environments. Interpreting this body of work provides a means of appreciating the specific influences that contributed to the way that modern New Zealand architecture was visually communicated to and understood by public and professional audiences.

This chapter considers New Zealand's own history of architectural photography, bringing together the two previous sections of the literature review. It reflects on how the international developments of the discipline influenced local practice, as well as the ways in which British architectural movements of New Brutalism and Townscape affected approaches to architectural photography in post-war New Zealand. Analysis begins in the 1930s, when local journals first began to regularly publish architectural images, and continues until the completion of the 1960s, in alignment with the end of Duncan Winder's period of production as an architectural photographer in New Zealand. Photographs by a number of architectural photographers that contributed images to the Journal of the NZIA (and its later titles), Home and Building, and Design Review illustrate this chapter and provide the basis of the argument for a burgeoning practice of architectural photography in mid-twentieth century New Zealand.

The 1930s - influences of New Photography and European émigrés

As discussed earlier in the literature review, internationally the 1930s represented a lively time for architectural photography. In contrast, New Zealand's architectural photography culture appeared embryonic. At the beginning of the decade, the Journal of the NZIA was the only publication explicitly concerned with New Zealand architecture and architectural practice. Photography was a rare inclusion on the pages of the journal and was often reserved for buildings that the NZIA had recognised with awards. The image, 'Flats, Wellesley Street, Auckland' (Figure 15 over page) of Hampton Court, the 1930 Gold Medal winner for architect 
Surrey S. Alleman, is a representative example of the quality of the journal's early 1930 s published photography.

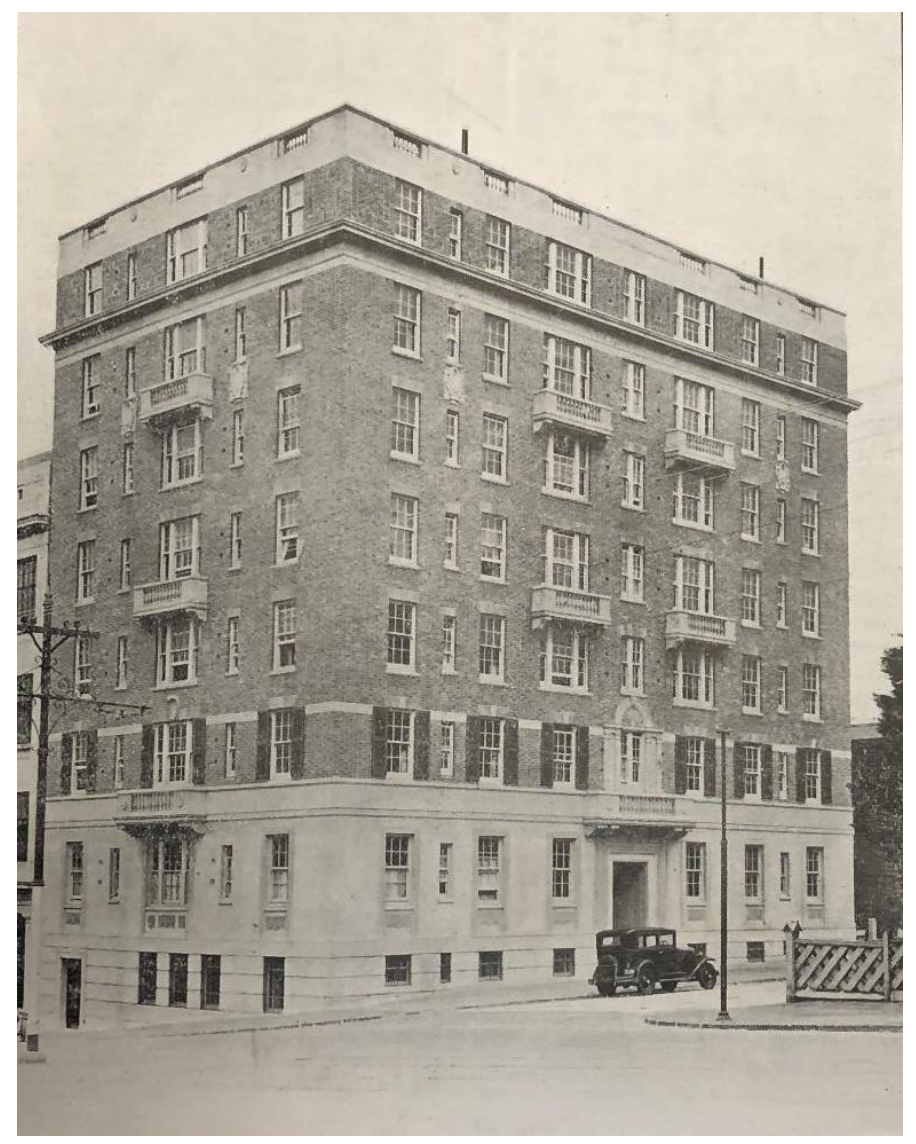

Figure 15: Flats, Wellesley Street, Auckland, S. S. Alleman, A.N.Z.I.A., Architect (no photographer credited). Journal of the NZIA, Volume 10, August 1931.

It has a straightforward composition that captures as much of the rectangular building as is possible in a single photograph. The image stands alone and takes up a full page of the journal, unconnected from any article. In order to maximise the visibility of the building, the photographer (unacknowledged in the journal) is distanced far enough away that the texture of the brick facade is difficult to appreciate - contributing to the photograph's general flatness. The Rolls Royce stationed by the building's entrance is a useful means of placing this otherwise generic image in the 1930s.

Later in the decade, opportunities for architectural photography publication were expanded significantly with the introduction of Home and Building, a new publication produced by the Auckland branch of the NZIA. Unlike the Journal of the NZIA, Home and Building had broad, public appeal and a magazine format that lent itself naturally to photography. Home and 
Building profiled modern building projects across New Zealand, which necessitated architectural photographers to be located wherever the work was. Due to the range of photographers that were contributing to Home and Building, the publication did not have one defined approach to photography.

Volumes of Home and Building from the 1930s reveal that there was only a small network of photographers who were documenting buildings. These photographers worked in different geographic areas and all had work published regularly. Due to the smallness of the architectural community, photographers inevitably fostered close relationships with architects and many architects consistently collaborated with the same photographer. One such partnership was that of architect Vernon Brown and photographer, Frank Hofmann. Hofmann's interior vignettes of Brown's 1938 house in Takapuna are artful representations that appear fresh with originality and the benefit of an expert eye. An example is Figure 16, which centres around a staircase in a way which heightens the interest in its stepped form, cleverly accentuating the relationship between the patterns of the solid balustrade and corresponding lines on the interior wall. While focused on this one aspect of the interior, Hofmann's images remain strongly architectural emphasising the abstracted geometry of the structure, signalling an evolution from the more conventional approaches to interior photography seen in Journal of the NZIA from this time.

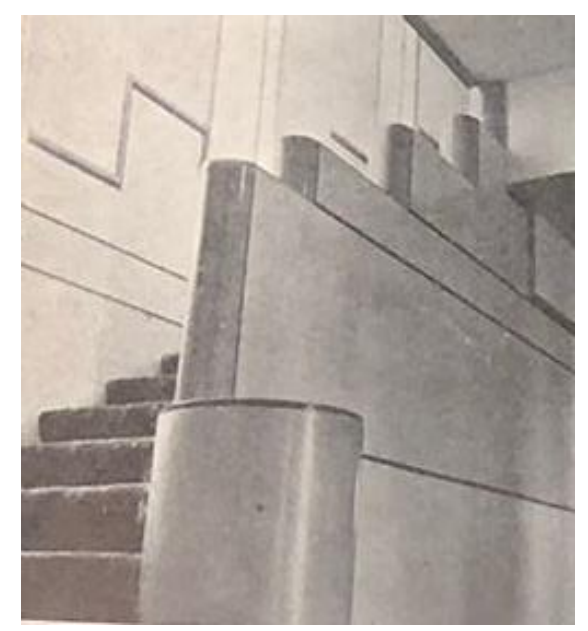

Figure 16: Frank Hofmann, Takapuna House. Home and Building, Volume 3, Number 5, May 1939.

It is in Home and Building that the impact of European émigrés, including Hofmann, who came to New Zealand had on local architectural photography in the 1930s can be recognised. While Hofmann was the most prolific of the émigré photographers, several others were also published in Home and Building. This includes Irene Koppel (Wellington), Franz Barta (Dunedin) and Maja 
Blumenthal (Auckland). ${ }^{94}$ Len Bell has discussed how these European photographers brought first-hand understanding of the interwar New Photography approach to New Zealand, and how, Hofmann especially, championed the possibilities for the type of art that could be made with a camera. $^{95}$

\section{The 1940s - new photographers and publications}

For architectural photography in New Zealand, the 1940s was a stable period in which local photographers strengthened their proficiency with the interwar-New Photography aesthetic approach. In general, images published in the local architectural media were not fundamentally different to those of the late 1930s, but did appear crisper and more defined - thanks to developments in camera technology and print publishing. For most of the decade, Home and Building was the single forum that architects could rely on for architectural photography. Over time, the publication was able to draw upon an extended network of photographers engaged in documenting buildings. Increasingly, architects were also making photographs and these were also published in Home and Building. This is consistent with international experiences, with the most prominent American architect-cum-photographer, Ezra Stoller, beginning his career as a photographer around the beginning of the 1940s. ${ }^{96}$ While New Zealand did not have any architects who went on to have such an illustrious photography career as Stoller, many were clearly highly competent photographers.

There are multiple examples of architect-photographers during this period, including James Walter Chapman-Taylor and Gerald Edgar Jones. Jones took photographs over a period of four decades, from the 1900s to the 1940s. Jones' 1940 images of Dominican Convent in St Mary's Bay, Auckland (Figure 17) demonstrate his photographic capability and pictorialist tendencies. The drama of the clouded sky provides a stirring setting for the convent building, and lends the images a sense of gentle intrigue. The almost indiscernible power lines that float above the building remind the viewer of the urban context in which the building is sited, while not shifting any focus away from solid built structure.

\footnotetext{
${ }_{94}$ Bell, Strangers Arrive: Emigres and the Arts in New Zealand, 1930-1980, 57.

95 Ibid., 48.

${ }^{96}$ Busch, 14.
} 

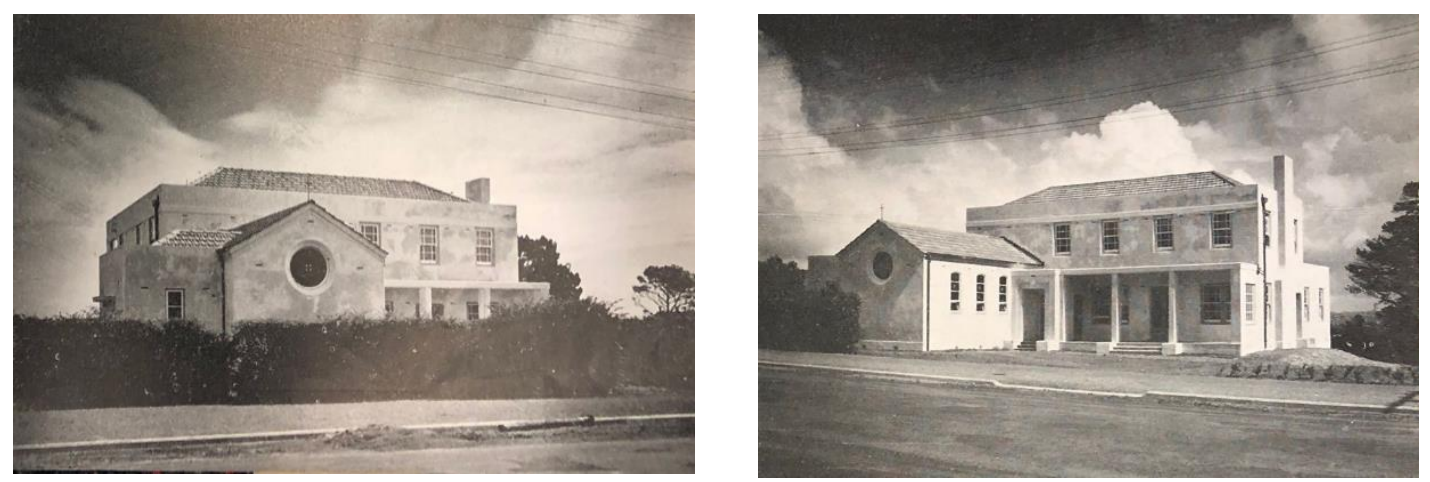

Figure 17: Gerald Edgar Jones, New Dominican Convent. Home and Building, Volume 4, Number 2, March 1940.

Another architect whose photographs were published in Home and Building was Paul Pascoe of Christchurch. Pascoe's images of a bach interior highlight how even the same photographer would draw on different styles of photography for documenting a single architectural site. His straightforward images of the building's interior appear quite removed from the particular shot (Figure 18) of a chair positioned towards an open window overlooking a New Zealand landscape. In this image, the frames of the window and chair define a sense of interiority, demarcated by shadow spread across the floor of the building. The carefully arranged image showcases what Pascoe strived to celebrate about New Zealand bach architecture; simple, sparsely furnished domestic spaces that open up to, and embrace, their natural surroundings. Pascoe's photograph suggests the architect's interest in using photography to evoke the sense of a place, rather than simply documenting it.

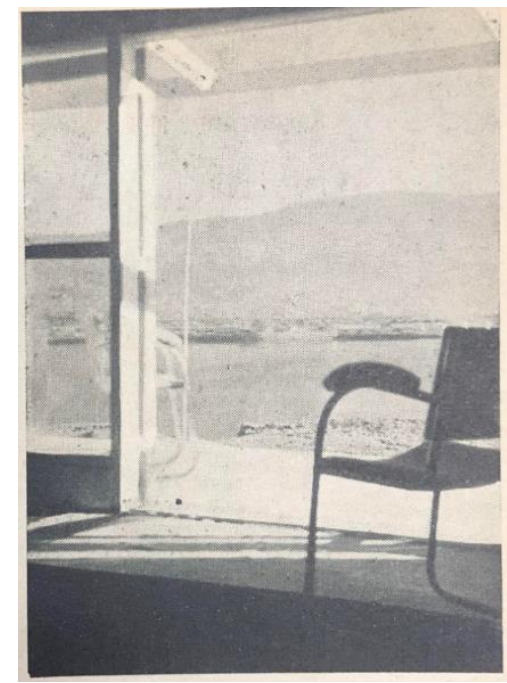

Figure 18: Paul Pascoe, Looking through the terrace, over the harbour, Home and Building, Volume 5, Number 4, December 1941. 
While the 1940s did see an increased number of photographers contributing images to Home and Building, none were as prolific as Arthur George William Sparrow (known as Bill Sparrow). Sparrow established Sparrow Industrial Pictures in 1939 following a career working for an advertising agency and later as sales executive for the Auckland Star. ${ }^{97}$ In the early years of his venture, Sparrow worked alone. He would, however, go on to employ several successful photographers who helped to refine a signature "Sparrow style". ${ }^{98}$ Sparrow's images were undeniably professional, and display his awareness of how to position the camera for effective impact. His images of Symonds Street Flats (Figure 19) in Auckland conveniently use a similar low angle and high contrast to capture both the exterior and interior of the flats.

Despite the interesting perspectives presented in Sparrow's images of the flats, their publication in Home and Building did not always showcase this with generosity - the photographs were printed at a small scale and were economically arranged. These editorial choices were symbolic of the challenges of publishing during wartime, where rising costs and shortages of supplies meant that Home and Building reduced the quality of its paper stock, as well as reducing margins and white space..$^{99}$ The result was a pragmatic means of maintaining the amount of content, including photography, in each edition, however, the quality of photographic reproduction was impacted as a consequence.
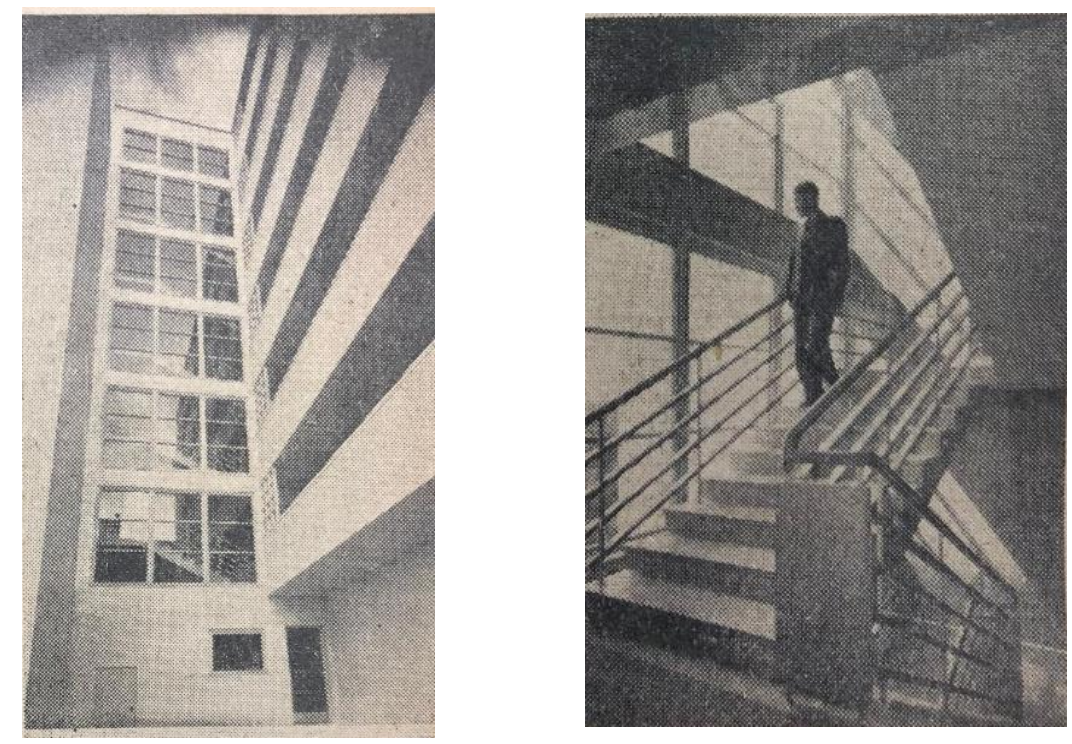

Figure 19: Sparrow Industrial Pictures Ltd. Symonds Street flats. Home and Building, Volume 10, Number 2, January 1948.

\footnotetext{
97 Lloyd Jenkins, "Early bird", 95.

98 Ibid., 96.

99 Ibid., 97.
} 
Towards the close of the decade, a new local, architectural publication was founded. Design Review, a bi-monthly journal produced in Wellington by the Architectural Centre. Clearly influenced by $A R$, it featured contributions on a broad range of design disciplines and scales including visual and applied arts, town planning, graphic design, and industrial design, as well as its firm focus of commentary on New Zealand architecture. As an advocacy organisation, the Architectural Centre had only a limited budget to produce Design Review, and the early editions did not boast the level of photographic quality as seen in contemporaneous editions of Home and Building. Like $A R$, Design Review recognised the interrelations between architecture and photography, and carried advertisements for local photography studios.

The 1950s - evidence of new international influences

The 1950s saw a greater diversity of architectural photographers operating within New Zealand. It could be argued that it was only in the 1950s that architectural photography developed sufficiently to be considered an industry in New Zealand. The expansion of the Sparrow Industrial Pictures, employing several talented photographers, was evidence of the growing demand for quality architectural photography and the viability of commercial architectural photography endeavours. In addition, it was in the 1950s that commentary about the overall standard of architectural photography was published. While commentary such as the 1950 Design Review critique of local architectural photography noted it was poor and that photographers did not use their equipment fully was plainly negative, it did demonstrate an awareness of architectural photography as a valid profession and that there were specific skills required of those that engaged in it. ${ }^{100}$

The cartoon (Figure 20), drawn by John Holmwood, published to support an editorial for Home and Building in 1951 shows a new attention that publications were showing towards photography. In the cartoon, the involved process of capturing a Home and Building cover story is illustrated. Bill Sparrow is seen directing the photoshoot, while two technicians are working on either side of the photographer to ensure the conditions are right to produce a high-quality image.

100 Clark and Walker, Looking for the Local: architecture and the New Zealand modern, 21. 


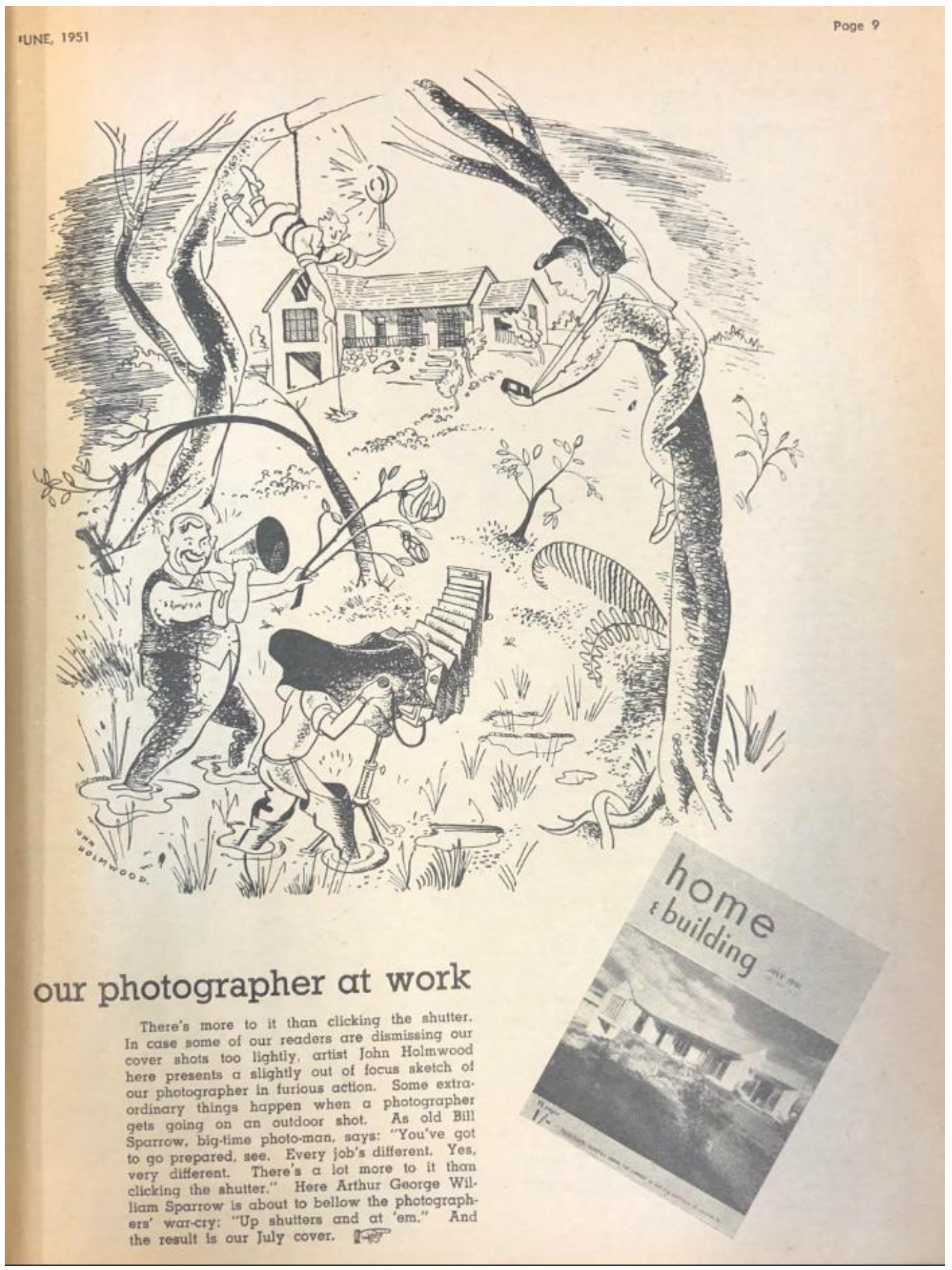

Figure 20: John Holmwood, Our photographer at work. Home and Building, Volume 14, Number 1, June 1951. 
Developments in the 1950s demonstrate the evolving way in architectural photography was used in New Zealand, not only to document modern architecture, but also to advance 'visual reeducation' campaigns, similar to those seen in $A R$. This is most clearly visible in the February/March 1950 edition of Design Review, which included a page titled "Worth looking at' (Figure 21).

\section{WORTH LOOKING AT}

Three-dimensional pattern

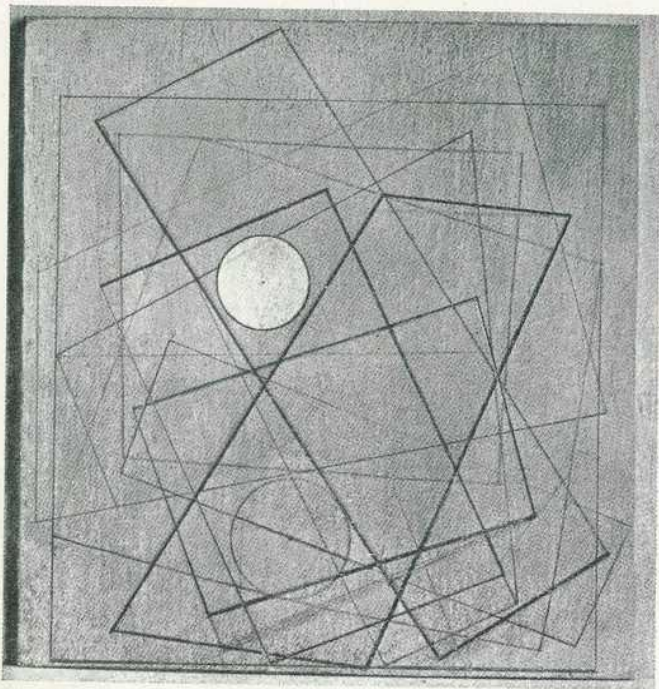

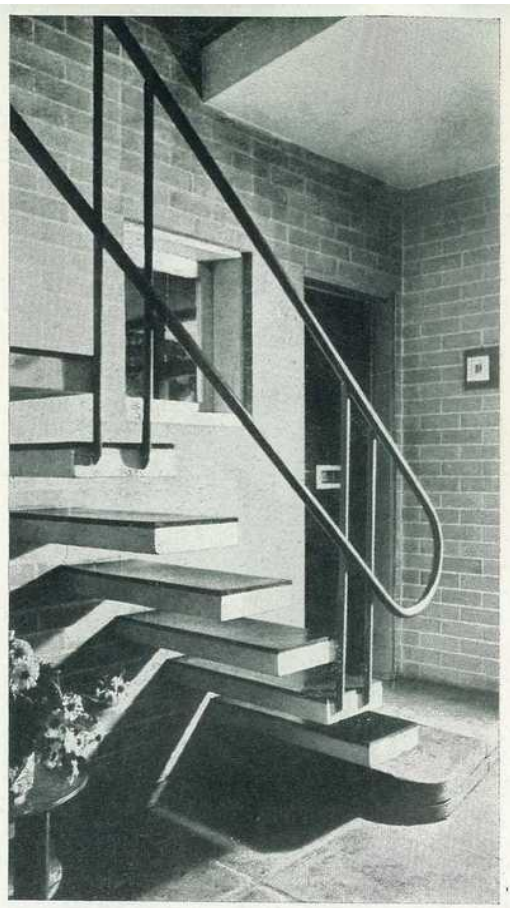

ABOvE-Ben Nicholson, Project 1945

TOP / RIGHT - Cantilever Stair, Architect M. Furniss

RIGHT - Aerial Photo, Rotation of Crops in Canterbury

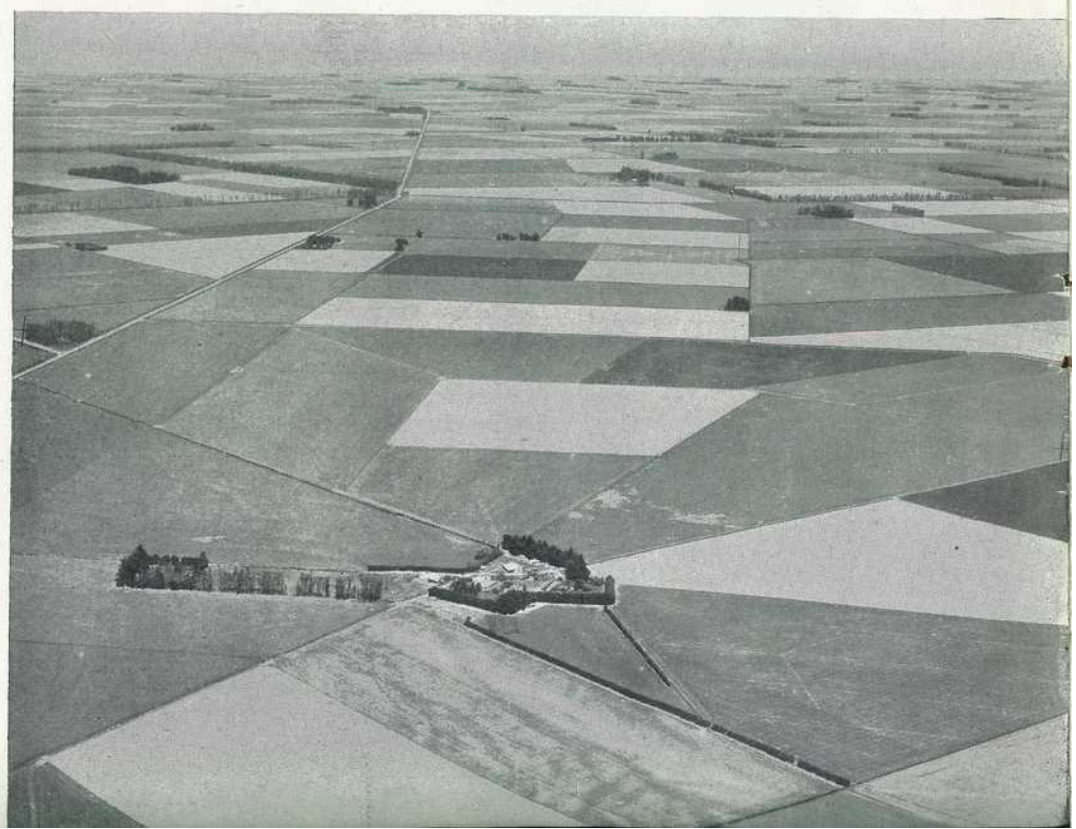

Figure 21: Worth looking at. Design Review, Volume 2, Number 5, February/March 1950. 
Here photography serves a specific purpose. It is not intended as a form of documentation, instead it is didactic - a training in understanding composition and aesthetics. Perhaps the most useful way in which to consider this page from 1950 New Zealand, is within the context of the landmark Parallel of Life and Art exhibition which occurred three years later in London. Both sought to bring attention to the endless visual connections that exist between the realms of art, science, the organic and the man-made. There is no singular argument put forward by this grouping of images 'worth looking at'. Instead, viewers are presented with an opportunity to reflect on the occurrence of similarly abstract patterns found in crop fields in Canterbury, forms in modern painting, and in the photograph of a domestic interior.

This page represents a fundamental evolution in the use of photography in a New Zealand architectural publication, and an acceptance of photography's expanded potential to develop new ideas about visual culture. It also illustrates the way in which post-war architectural cultures in Britain were widely disseminated, and found their way into New Zealand publications.

In addition to these 'visual re-education' developments, the 1950s also saw architectural photography used more commercially in New Zealand, with more obvious staging and styling. This was consistent with the international trends which favoured staged, 'lifestyle' approaches to architectural photography. Increasingly these kinds of images can be seen in Home and Building during the 1950s. This includes images taken at night-time. Up to this point, architectural photographs taken at night had rarely been seen in the publications that this chapter has analysed. This is, of course, not surprising given the importance of light and shadow in photography - and the difficulty of mastering these qualities at night. An issue of Home and Building from 1957 featured two memorable images taken at night. The first image (Figure 22) shows a model house, presented at an "Architecture and Building" exhibition in Auckland, 1957. A model house can be thought of as an architectural ideal, therefore, its photographic representation becomes equally important in communicating its intended aspiration. The image of the model house is taken at a distance which allows analysis of both the house's interior and exterior. The camera is at a slight elevation from the house, which allows for a greater vantage into the well-lit living spaces. The internal lighting clearly draws attention to the building, however, this is not achieved as successfully as in the photograph, again by Sparrow Industrial Pictures, of the house in Titirangi (Figure 23). In this image, the composition is much tighter, and solely on the house. The skilful lighting on the house, the low angle of the camera, and the near-black surrounds all contribute to the photographer's intention 
that this building is to be viewed as significant. The bush context of the house is effectively gestured at, by the silhouette of vegetation framing the image.
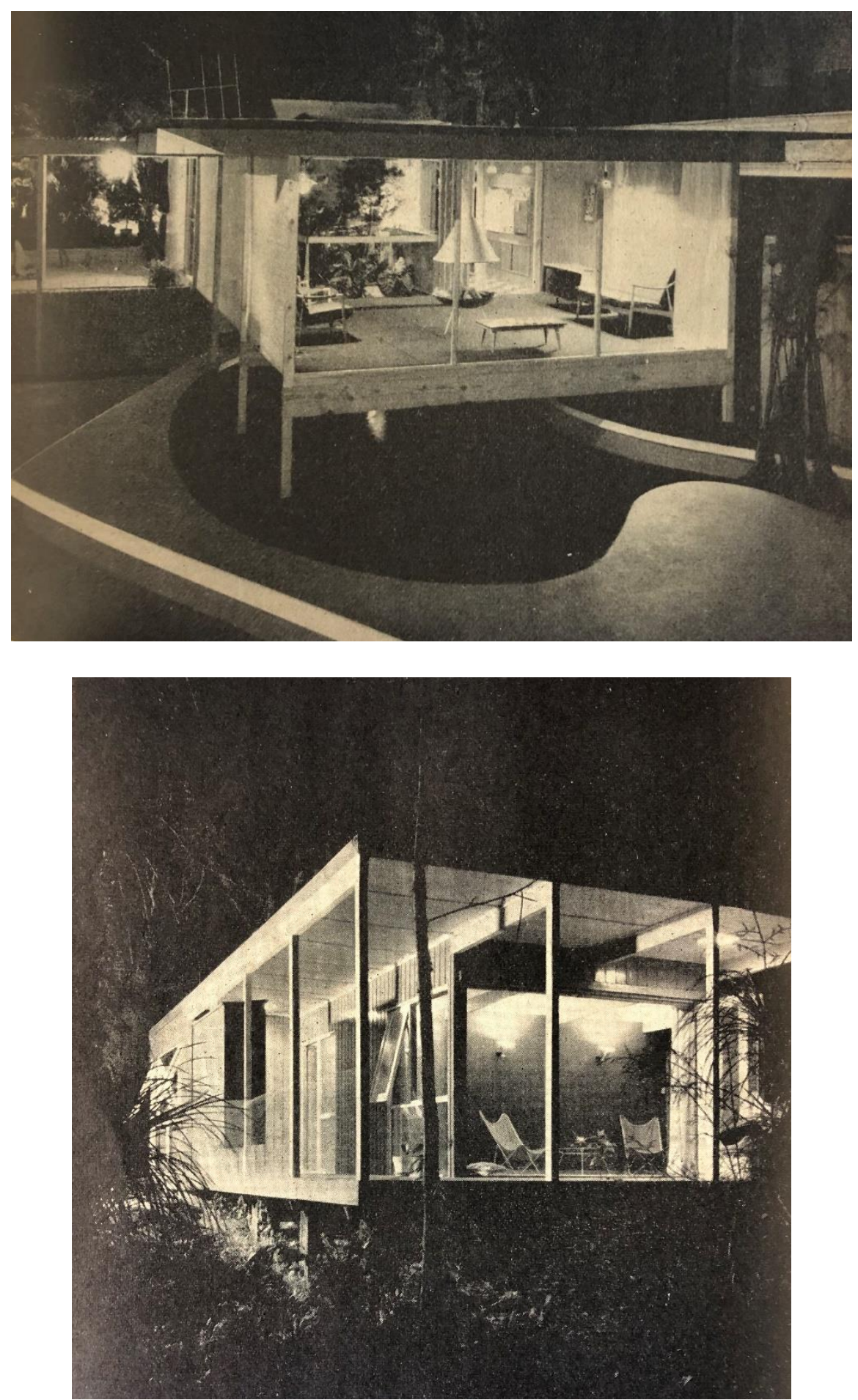

Figure 22 (top) and Figure 23: Sparrow Industrial Pictures Ltd. The theme house. Home and Building, Volume 19, Number 10, March 1957, and Sparrow Industrial Pictures Ltd. A house for the sub-tropics. Home and Building, Volume 19, Number 10, March 1957. 
The increasing commercialisation of architectural photography during the 1950s saw more visibly staged and styled images, regularly featuring people. An example is this image (Figure 24) from Home and Building, December 1955. The image is perhaps less related to architectural photography, as it is to lifestyle marketing. It follows an American approach of documenting and staging architectural spaces - where the structures themselves are less important than the lifestyle in which they appear to facilitate (consistent with the photography of Shulman, in Figure 6). Here, a fashionable woman appears comfortable in a modern courtyard environment. Within the context of New Zealand architectural publications, this is an image that could have only been published in Home and Building, given its broad, public readership and focus on the domestic, as opposed to the Journal of the NZIA or Design Review which were more targeted at those engaged in architecture and design professions.

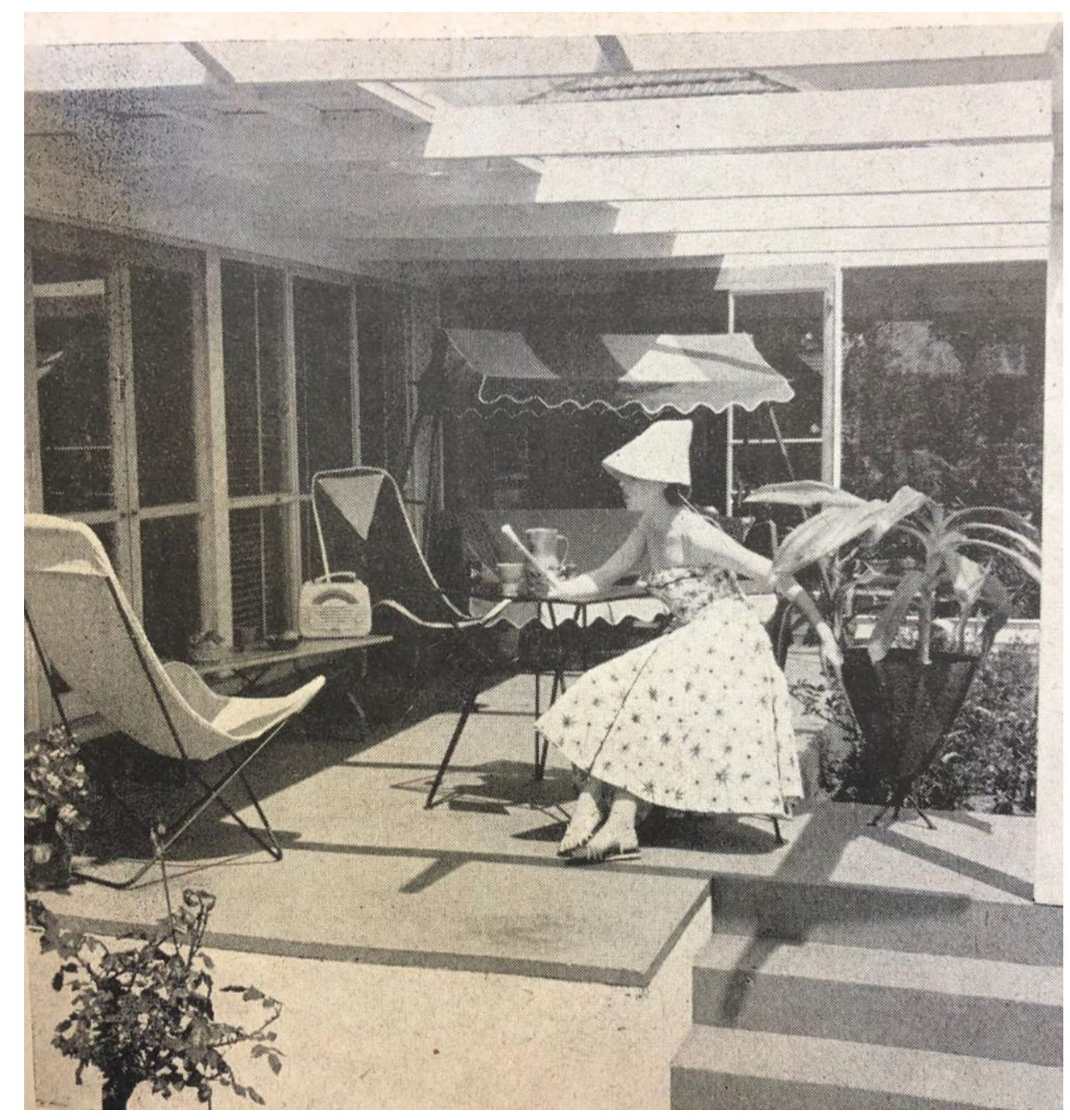

Figure 24: Sparrow Industrial Pictures Ltd. Terrace at Mr. and Mrs. C M Ponder's home, Parnell. Home and Building, Volume 18, Number 7 December 1955. 
As well as evidence of commercial architectural photography and 'visual re-education' imagery, New Zealand architectural media of the 1950s was also beginning to employ aspects of Townscape's visual language. A useful example in seen in this image (Figure 25) from the Christchurch photography studio Mannering and Donaldson of the Paul Pascoe-designed home, which appeared in Home and Building. The framing of this image is worth considering. The concrete fence and decorative gate on the left firmly place this building in a suburban context. While some photographers may have opted to omit these property features from an architectural shot, here they impose a sense of containment for the building, while the traditional wrought iron gate offers an ornate contrast to the modern architecture of the house. The inclusion of the gate and fence is clearly intentional, and the fence appears in neat parallel to the roofline of the house. Overall, this image evokes a sense of Townscape given its composition which brings an interesting sense of drama to an otherwise ordinary, suburban scene.

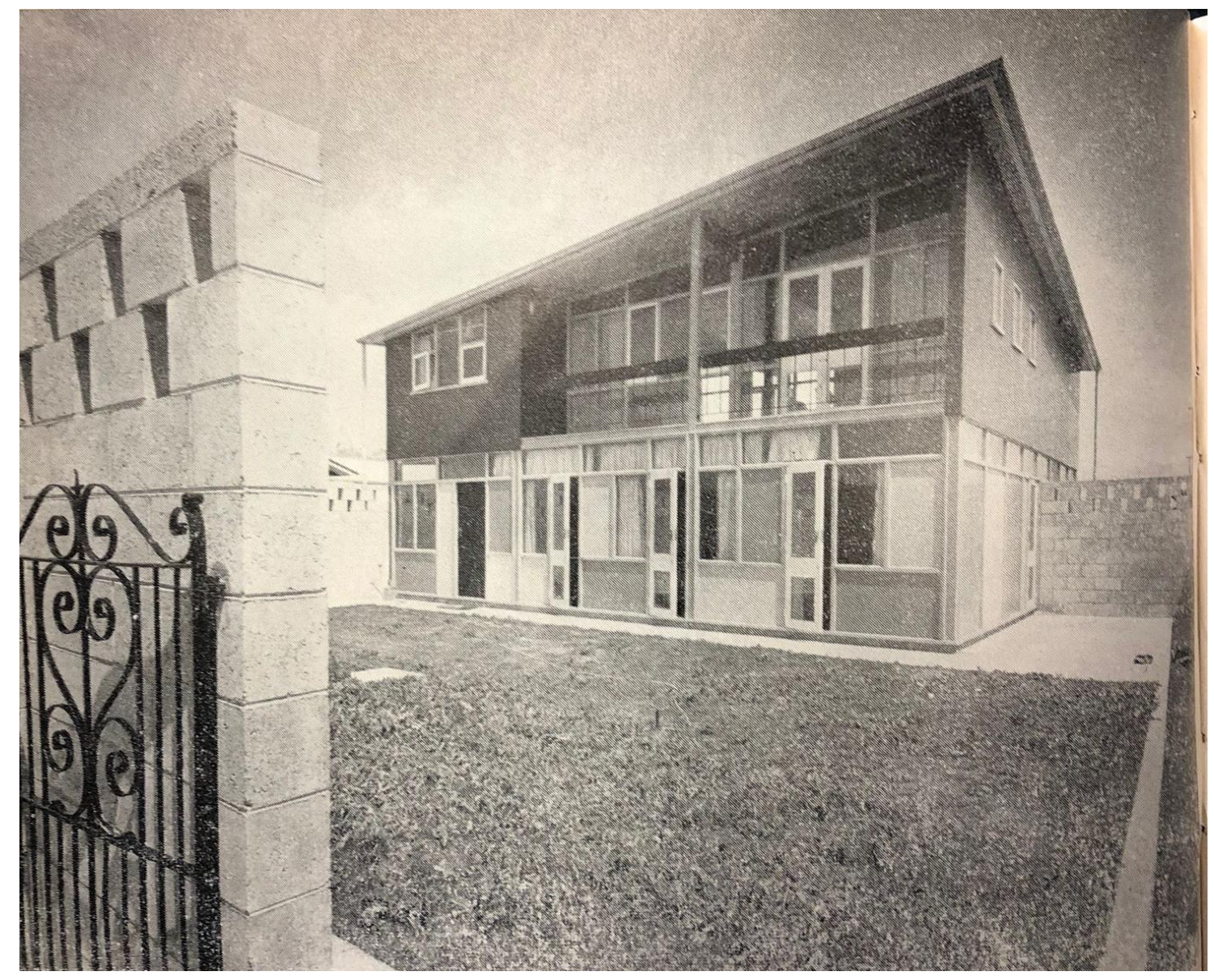

Figure 25: Mannering and Donaldson. Seaside house with a "hypoid" roof. Home and Building, Volume 21, Number 5, October 1958. 
While much of this 1950 s analysis has focused on Home and Building, significant changes in the use of architectural photography were happening at the Journal of NZIA. The following image (Figure 26) appeared in the final Journal of NZIA issue of the 1950s. It represents an increased, if not belated, evolution in the journal to include high quality architectural photography on a regular basis. This evolution recognised that the capability for high quality architectural photography had increased over the last decade in New Zealand. The balance of light and shadow across the entrance of the Dental Clinic is precise and is evidence of the detailed composition of the photograph. The inclusion of the full walkway and clinic building provides interesting vertical and horizontal subject matter.

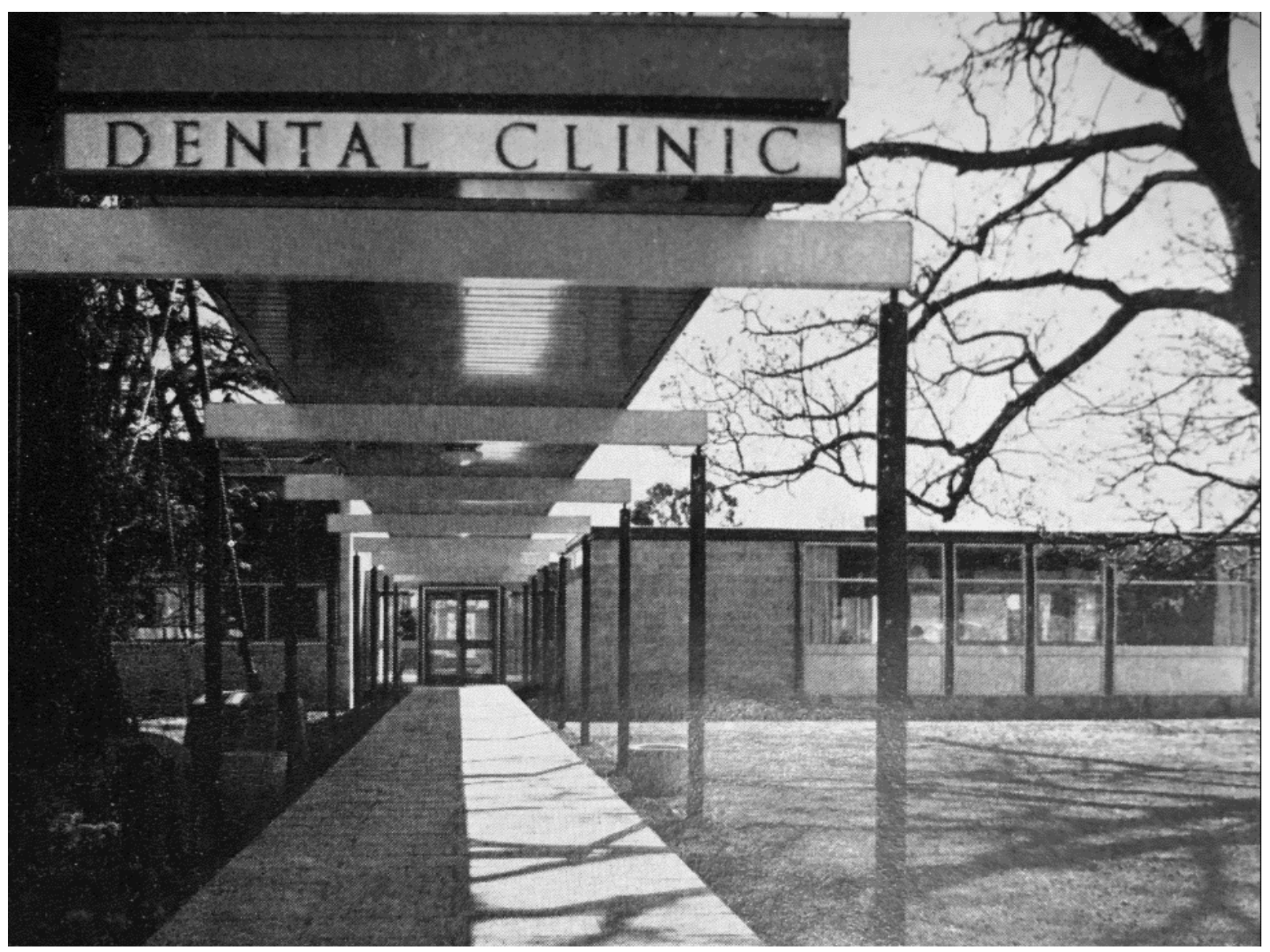

Figure 26: Mannering and Donaldson. Christchurch Dental Nurses' Training School. Journal of the NZIA, Volume 26, Number 10, November 1959. 
The 1960s - a diverse architectural photography field

Owing to the expanded field of architectural photographers practicing in New Zealand, the 1960s saw further diversification and original approaches to photography. This was consistent with international trends of the time, which saw more artistic as well as photojournalistic approaches to architectural photography gain popularity and visibility.

It is useful to note that within New Zealand, many of the differences in approaches seen in the 1960s could be considered regional given the dispersed network of photographers operating around the country, largely staying within their own regions. In the 1960s, several of the photographers who worked for Sparrow Industrial Pictures, and had helped define its style, left the studio to work independently. This included Barry McKay, and it is worth looking at McKay's images, in the context of the signature Sparrow style.

After working for Bill Sparrow, Barry McKay established his own successful photography practice, Barry McKay Industrial Photography (which in 1966 merged with Sparrow Industrial Pictures). It is clear from the following images (Figures 27 and 28) that McKay was able to achieve, and likely helped to define, the Sparrow style for architectural photography in New Zealand, which employed tonal contrasts and off-centre compositions to heighten the drama within images.

The photograph of the Dadly Foundation building may represent the zenith of the Sparrow style. It is a highly constructed image that is striking because of the light which the building appears to bask in. The low angle of the photograph seems to align closely to the slope of the ramp which curves through the photograph and guides the viewer's attention toward the front entrance of the building. While the composition does not include the full extent of the building, it instead captures an optimistic and dramatic moment of modern architecture. The photograph of the Bank of New South Wales (taken five years later) suggests a shift in McKay's approach away from the signature Sparrow style. Instead of solely privileging the modern bank building in his image, McKay has employed a perspective which emphasises the variance in architecture between the bank building and its Victorian neighbour. Furthermore, the tonal contrasts are much less pronounced than in the image of the Dadly building. These photographic decisions result in a more restrained and objective image, which ultimately has a greater affinity to Townscape than many other Sparrow style photographs. This suggests that the photographers 
who worked for Bill Sparrow did transition away from the specific style he had espoused in previous decades.
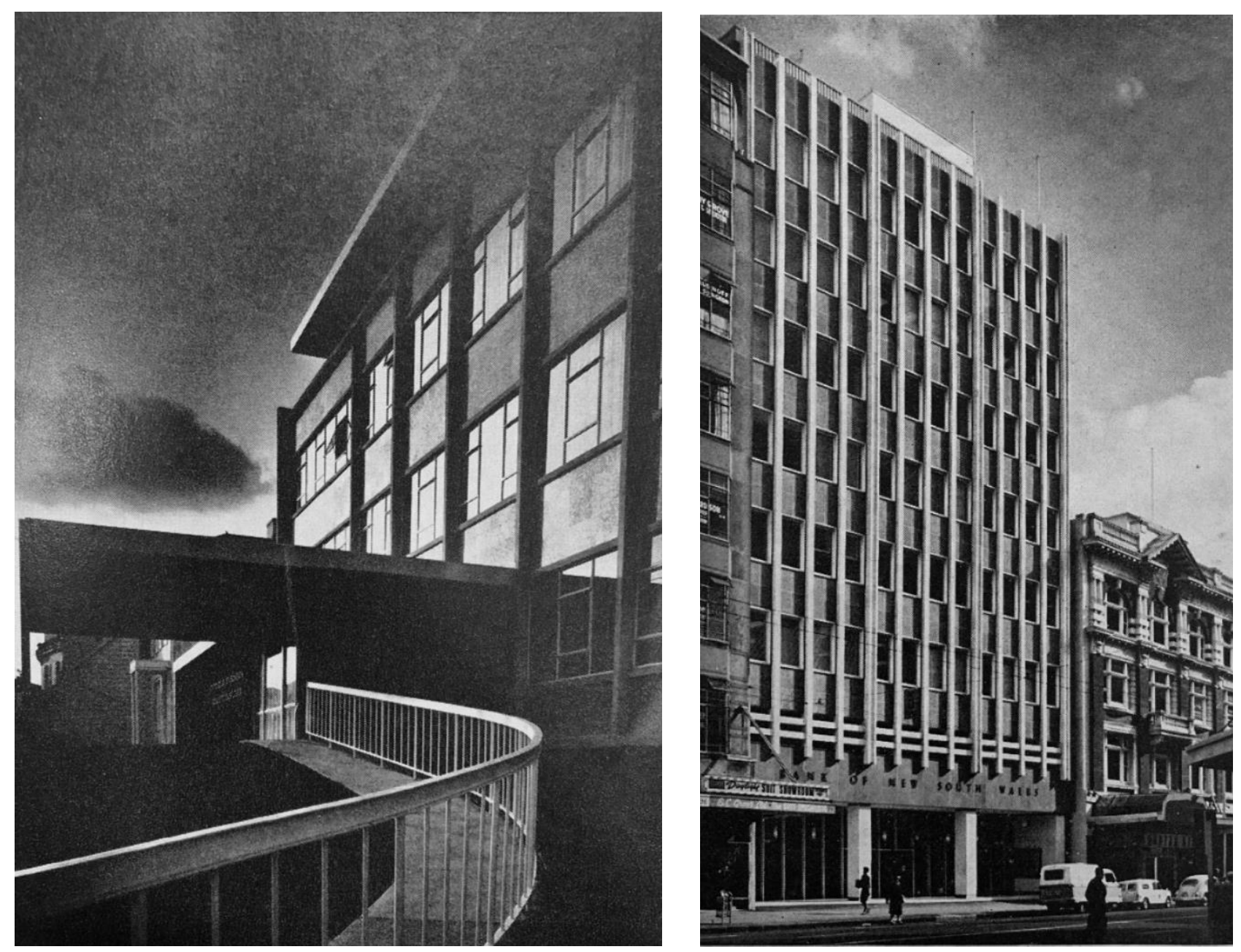

Figures 27 (left) and Figure 28 (right): Barry McKay Industrial Photography Ltd. Dadly Foundation for crippled children, NZIA journal, Volume 31, Number 2, March 1962, and Barry McKay Industrial Photography Ltd. Bank of New South Wales, Queen St., Auckland. Home and Building, Volume 29, Number 5, May 1967.

In the 1960s, there was increasing local evidence of Townscape principles applied to photography. This photograph (Figure 29) by Martin Barriball provides an excellent example. Interestingly it was included in a profile of the recently erected building visible in the distance, between the two older buildings closer to the camera. This photograph, therefore, is clearly attempting to illustrate how the new building relates to its immediate environment. There are multiple signature Townscape qualities present in this image. The first is the passageway which commands focus. Second is the inclusion of spires, which literally heighten the visual interest 
contained in the photograph. The third is the inclusion of smaller-scale street features, in this case, a public clock and a vine growing over one building surface, which add to the richness of the photograph. While some photographers of this period strove to capture refined perspectives - others enjoyed the irregularity and contrast that a Townscape sensibility promoted - as is evident here.

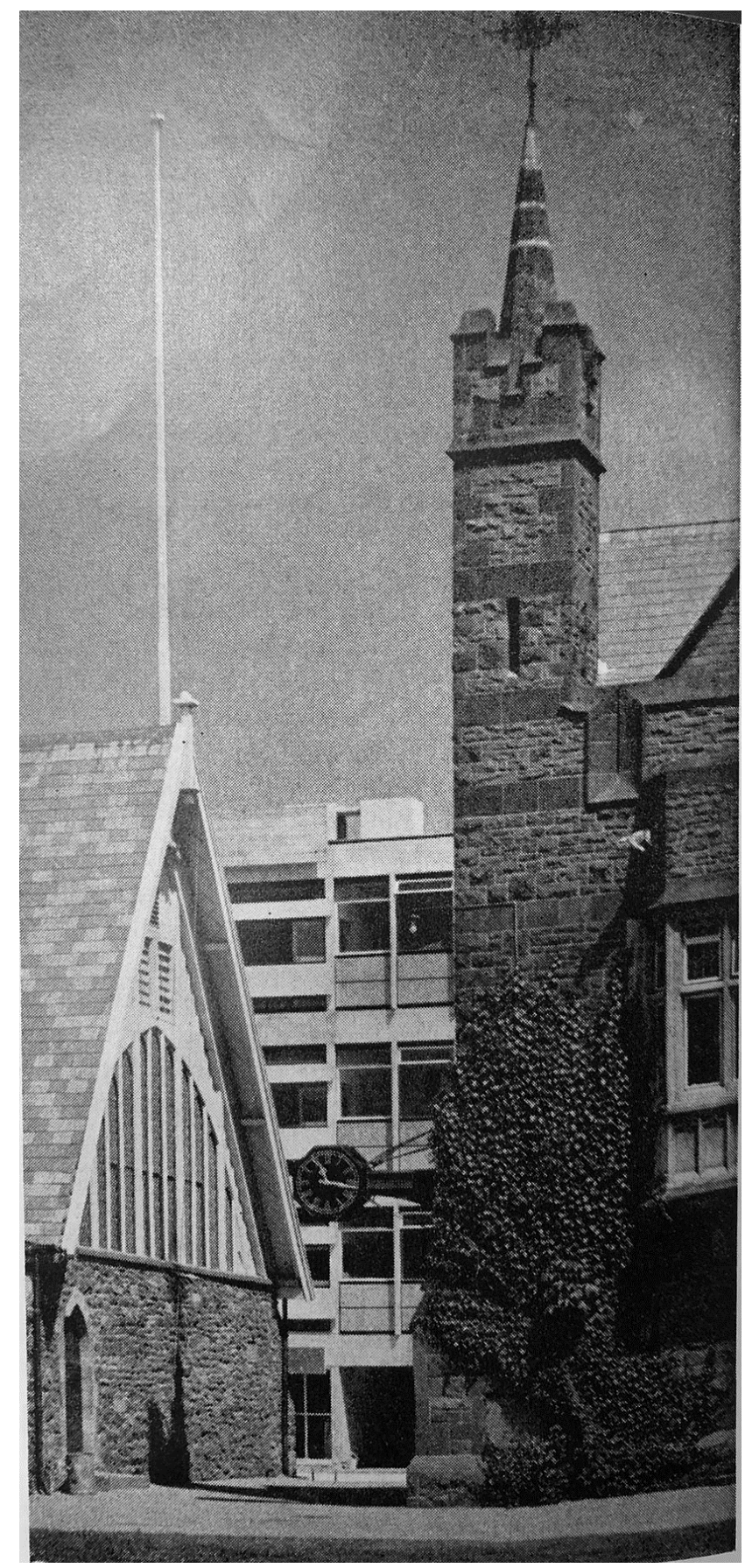

Figure 29: Martin Barriball Ltd. Streetscape view. Home and Building, Volume 23, Number 10, March 1961. 
Townscape imagery was not only seen in Christchurch, there are examples of its application across the country. This image (Figure 30) of the Auckland Transport Office bears close similarity to classic Townscape representations, captured by Pevsner and Cullen decades earlier, which New Zealand architectural photographers would have seen in the pages of $A R$ and in seminal publications such as Concise Townscape. Here, we view the building within the frame of a neighbouring historic portico. The arch of the portico creates a perfect context for the Transport Office to occupy, suggesting it is a complementary addition to the street. While the image has a commanding composition, some details appear less refined. The symmetry of the portico frame is not entirely even, and the branches masking the building's facade distract from its stratified design.

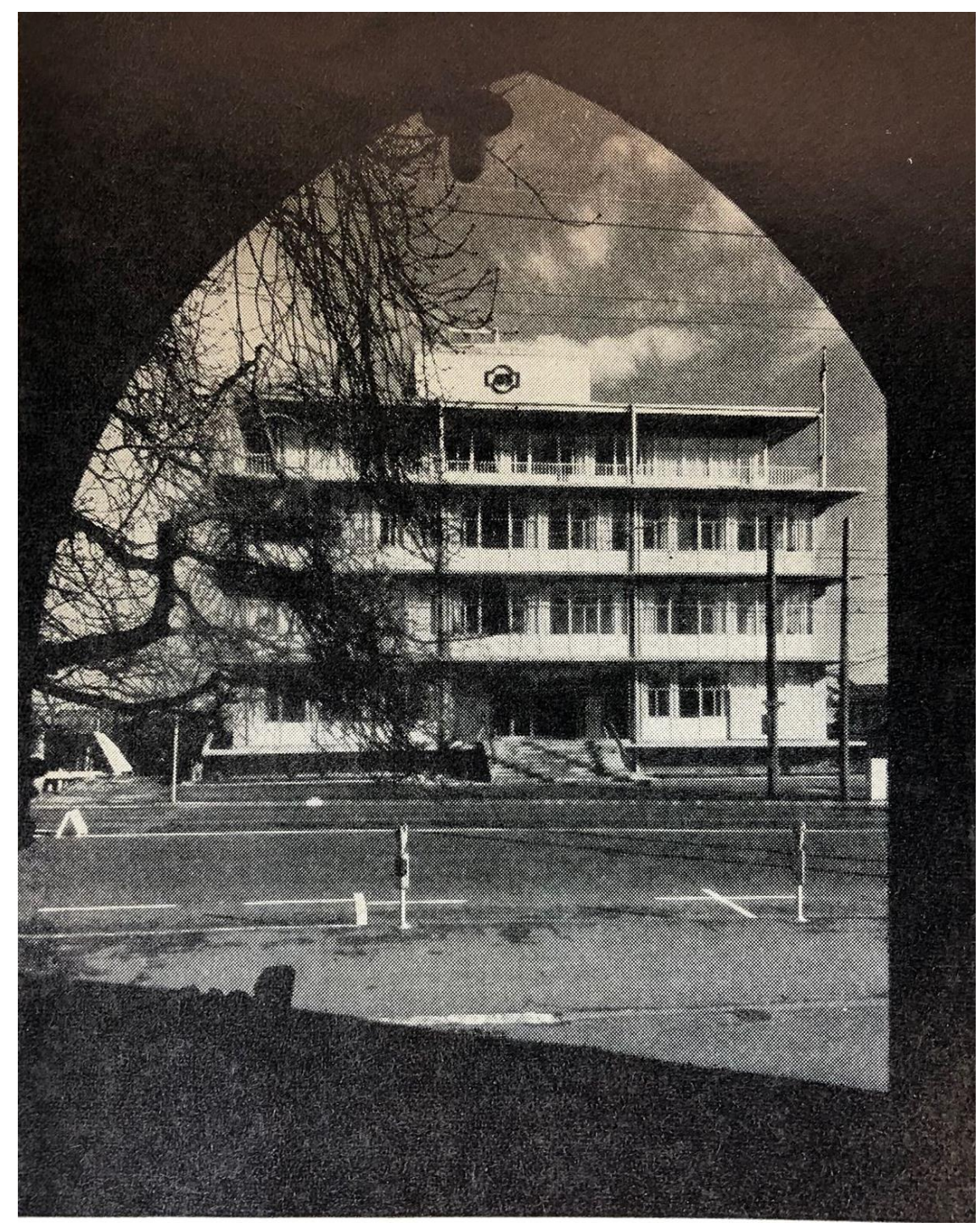

Figure 30: Studio 57. Auckland Transport Office. Home and Building, Volume 23, Number 6, November 1960. 
Related to the influence of Townscape imagery on local architectural media was a similar borrowing of the Functional Tradition style of photo-documentation. During the 1960s, the NZIA Journal (the Journal of NZIA was renamed the NZIA Journal in 1963) ran a series of photo essays on the Functional Tradition, with images taken by G. G. Thornton. ${ }^{101}$ In this series (which continued into the 1970s), maritime buildings were documented in a way which gave them compositional priority - elevating their status from functional buildings to sculptural forms of note. In the following image (Figure 31), a dramatic sky provides the backdrop to a lighthouse at Lyttelton. The front-on perspective of the lighthouse placed in the centre of the photograph presents the structure with a sense of grandeur.

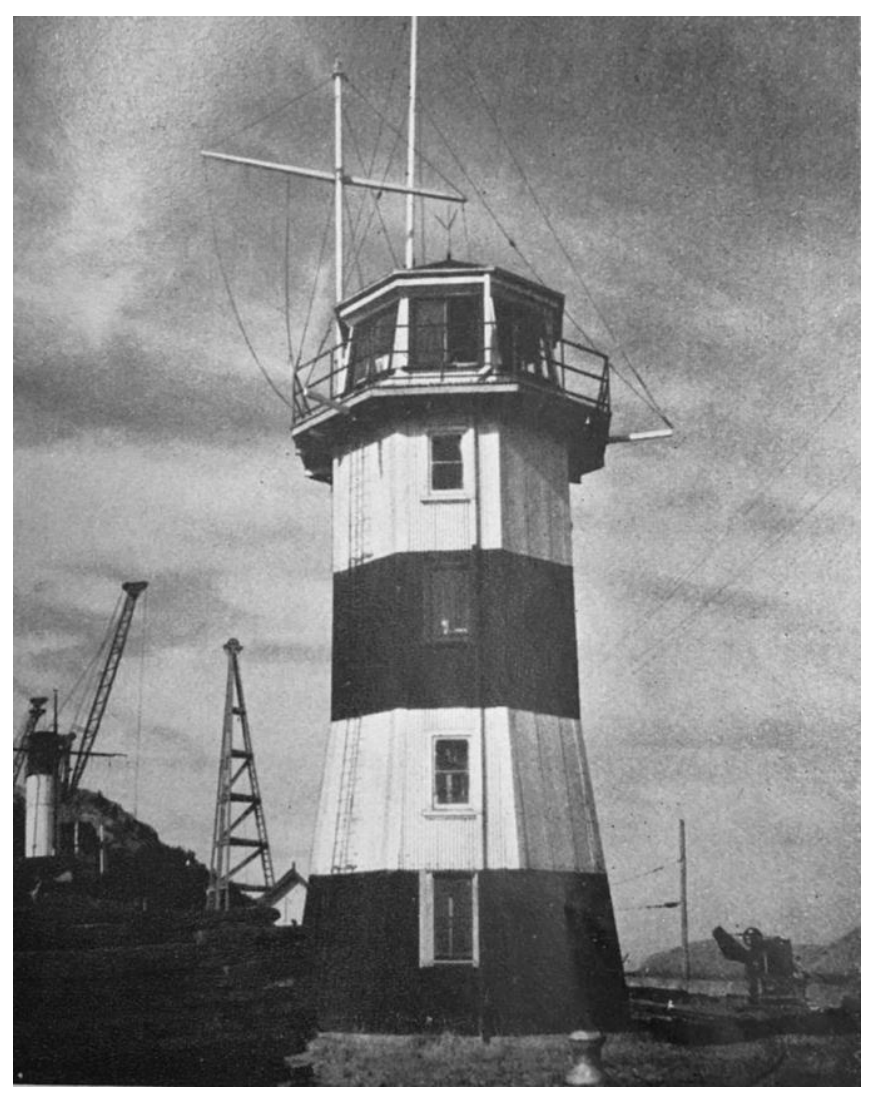

Figure 31: G. G. Thornton. Beacon on the mole, Lyttelton. NZIA journal, Volume 30, Number 2, March 1963.

While there was evidence of Townscape and Functional Tradition imagery in 1960s architectural photography, there was also evidence of photographers utilising more locally-responsive approaches to their architectural photography. The photograph by Mannering and Donaldson, of

101 Brookes, Index to the Journal of the New Zealand Institute of Architects, 1912-1980, iii. 
the Harewood Memorial Gardens Crematorium building (Figure 32) in Christchurch, is a noteworthy example to discuss. This is strong modern image, using tone to great effect. Components of the image are carefully balanced. The smooth grey sky provides a clean backdrop for the architecture, and allows the tonal contrast of the architectural elements to be heightened against the neutral sky. The front-on capture of the building means there is a remarkable flatness in the structure, giving it the appearance of a two-dimensional sculpture. The solidness of the crematorium building is nicely contrasted by the fineness of the tree foliage. Dark and light, hard and soft - all captured in one image.

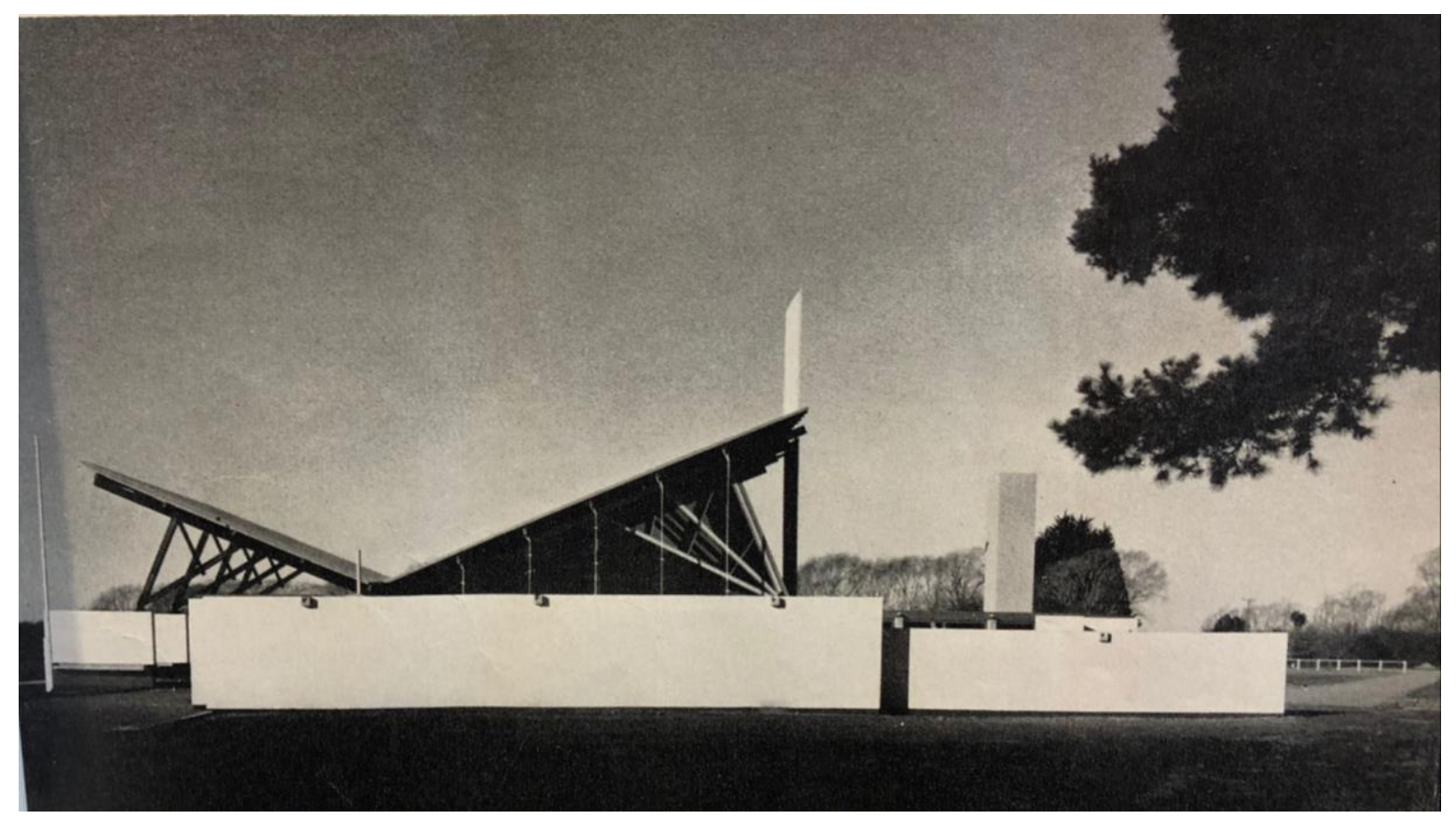

Figure 32: Mannering and Donaldson. Harwood Memorial Garden Crematorium. NZIA Journal, Volume 31, Number 2, March 1962.

It is appropriate that the final image of this chapter signals another development in architectural photography. This image (Figure 33) featured in NZIA Journal is unlike any other featured in previous volumes of the publication, which profiled individual buildings and largely omitted their surroundings. This Wellington streetscape contains much architectural interest, yet the focus is not on any particular structure or detail. Instead, we are shown a celebration of urban life in all of its richness and activity. In the foreground of the photograph, a pedestrian is seen crossing the car-filled street. In many ways, this image can be read as an attempt to convey the thinking that drove the Townscape movement. It was a call to think holistically about the built environment and embrace irregularity, texture and visual appeal. This image contains all of those qualities, layering them at every level within the frame. 


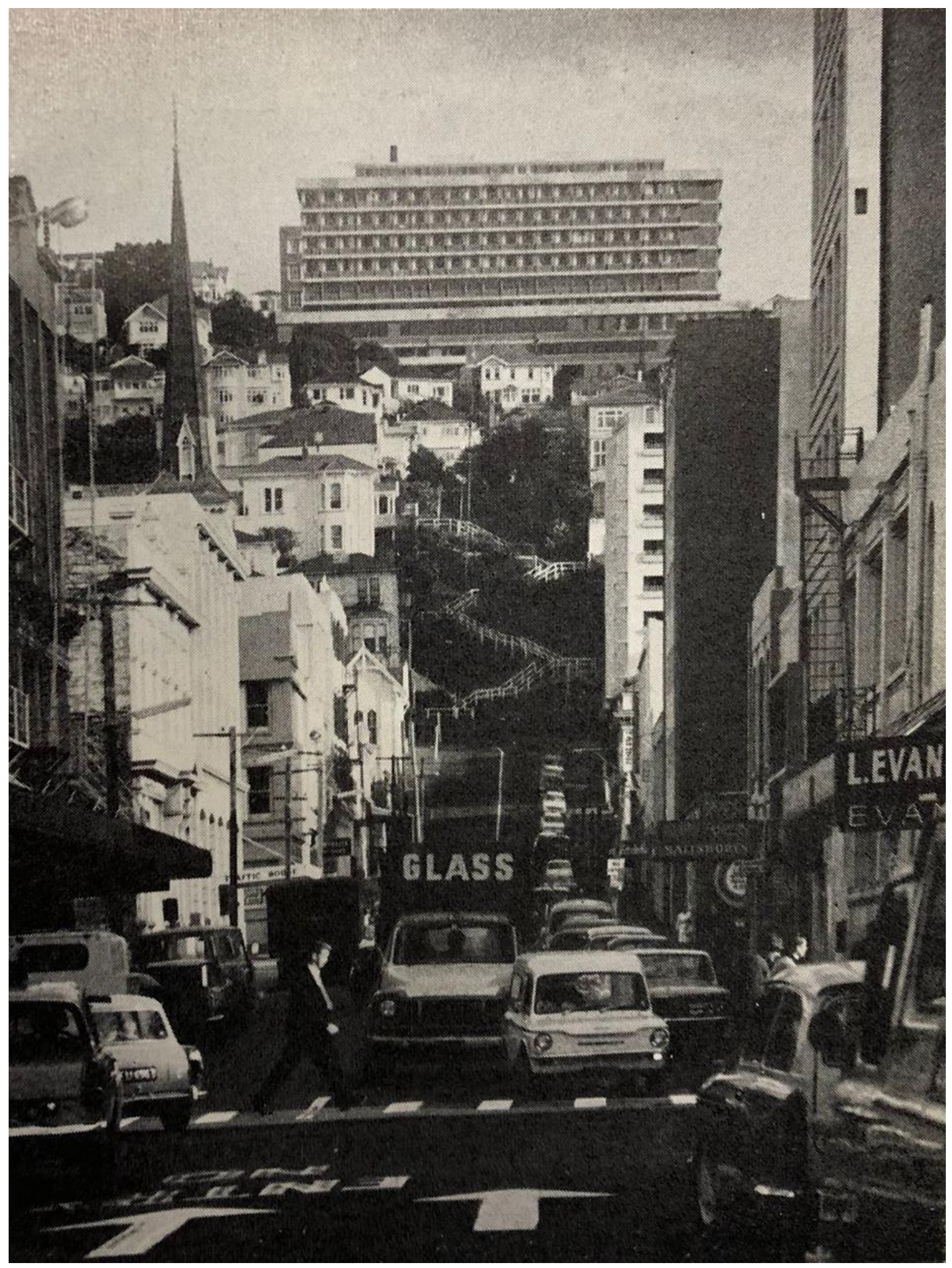

Figure 33: Duncan Winder. View up Dixon Street, NZIA journal, Volume 34, Number 8, August 1967. 


\section{Conclusion}

From this visual survey, multiple conclusions can be drawn about the development of architectural photography within New Zealand from the 1930s to the 1960s. First, it is evident that many of the international decade by decade trends in architectural photography (discussed earlier in this literature review) were also experienced in New Zealand. Second, the survey period saw the occurrence of important developments for the local architectural photography in New Zealand. This included an increase in the number of photographers practicing, as well as the quality of images produced. The discipline could be considered regional, with a number of key photographers and photography studios based across the country helping to solidify memorable styles and approaches to their work. In terms of the international influences that were seen locally, it is clear that New Zealand benefitted from the arrival of a number of émigré photographers who understood the New Photography approach to documenting architecture. In addition, photographs taken in New Zealand during the 1950s and 1960s demonstrate the strong influence of $A R$ and the imagery which it featured during this period. Over this period, New Zealand's architectural media showed a greater recognition of photography's value. Not only was this seen in the increasing number of articles and commentary by photographers within publications, it was also seen in the way in which photography was used as an educational tool to 'train the eye'. 


\section{CHAPTER THREE: IMAGE ANALYSIS}

\section{Introduction}

Analysing Winder's architectural photography provides insight into how the photographer chose to record twentieth century New Zealand built environments. This chapter examines Winder's work within the context of post-war architectural photography, both at international and domestic scales. Drawing on the findings of the previous chapter, it is appropriate that the present imagebased analysis is informed by specific post-war British architectural theories that would have been prominent during Winder's career as an architect practicing in mid-century Britain. The specific architectural theories selected to inform analysis are New Brutalism and Townscape. Analysis also considers the related concept of the Functional Tradition. Information on these theories was disseminated through British architectural journals available in New Zealand during the post-war period, which strengthens their applicability for the current image analysis.

In order to accurately contextualise Winder's work, a set of criteria for analysis has been prepared. This allows analysis to identify key compositional characteristics within Winder's photography. To represent the full extent of Winder's practice as an architectural photographer, this chapter looks at a range of architectural photographs within Winder's archive, including photographs of individual residential and commercial buildings, and their interiors, as well as streetscapes and other urban scenes. This chapter is structured with an overview of the method, criteria and framework used to analyse Winder's photographs. This is followed by the case study images used for the analysis, which are presented in categories. A summarised version of the framework-informed analysis is presented under the relevant category heading.

\section{Method}

The first essential process required for image analysis is an initial categorisation of Winder's photographs. It is advantageous that Winder's archive has been digitised, and is accessible on DigitalNZ, an aggregate and publicly available database of New Zealand digital content that allows users to organise images under specific headings. This platform was used to organise 4,674 of Winder's images into categories, based on subject matter. An iterative process was undertaken, initially sorting images under the headings of 'interior', 'exterior', 'streetscape', and 'other'. As distinct series of images emerged within these primary headings, new, more specific headings were also created. For example, it became apparent that Winder took a significant number of photographs of architectural models. Accordingly, the heading 'Photographs of architectural models' was created. On completion of this categorisation exercise, thirteen 
different headings had been created. It was necessary to categorise some images under multiple headings, for example a photograph of a residential interior that included people would be categorised under both 'Photographs of residential interiors' and 'Photographs of people'.

\section{Criteria}

The next process required for image analysis was the development of a framework in which to consider Winder's images. Initial criteria were developed based on key principles of New Brutalism and Townscape imagery, discussed in the literature review. These initial criteria included:

Does the perspective of the photograph seek to represent an 'unmediated experience' of its architectural subject? Or is there an evident attempt to depict the architecture in a particular way? How is this achieved?

This was included to differentiate between brutalist imagery (that strives to be direct and have architecture appear legible and comprehensible in two dimensions) and Townscape imagery (that seeks to represent the built environment with a specific accentuated drama and contrast). A framework based on the initial criteria was tested on a representative (in terms of subject matter) sample of Winder's photographs. Through this testing, several iterations of the framework evolved, which saw revision and merging of pre-existing criteria, as well as the addition of new criteria. The final version of the framework is included as Appendix One.

\section{Case studies}

The final version of the framework was then used to analyse the case study images presented in this chapter. These are presented in categories of related images. Some categories are based on architectural typology, while others are based on location.

\section{Limitations}

It is important to note some of the limitations of analysing images from the negatives contained in Winder's archives. It is likely that many of the images would have appeared differently to their appearance as negatives, given the processes involved in developing and publishing photographs. In some cases, the published version of the Winder's photographs has been sourced, and commented on, however, this has not been possible for all images. In addition, it has not been possible to confirm the exact dates of all of Winder's photographs meaning only a limited assessment of Winder's development over time has been possible. 


\section{Case studies}

\section{McKay House, Silverstream}

Winder's images of Bill Toomath's McKay House (1961) are memorable architectural photographs. Toomath designed the Silverstream residence for the McKays, a childless couple that saw New Zealand's timber building stock as 'flimsy', preferring the solidness of stone. ${ }^{102}$ Not being able to afford a masonry home, however, Toomath produced an elegant timber structure for the McKays that memorably included an internal living space defined by two brick half-walls that fulfilled the couple's wish for domestic robustness. ${ }^{103}$ Winder photographed the house for NZIA Journal and took at least ten images, which record both its environmental context and interior.

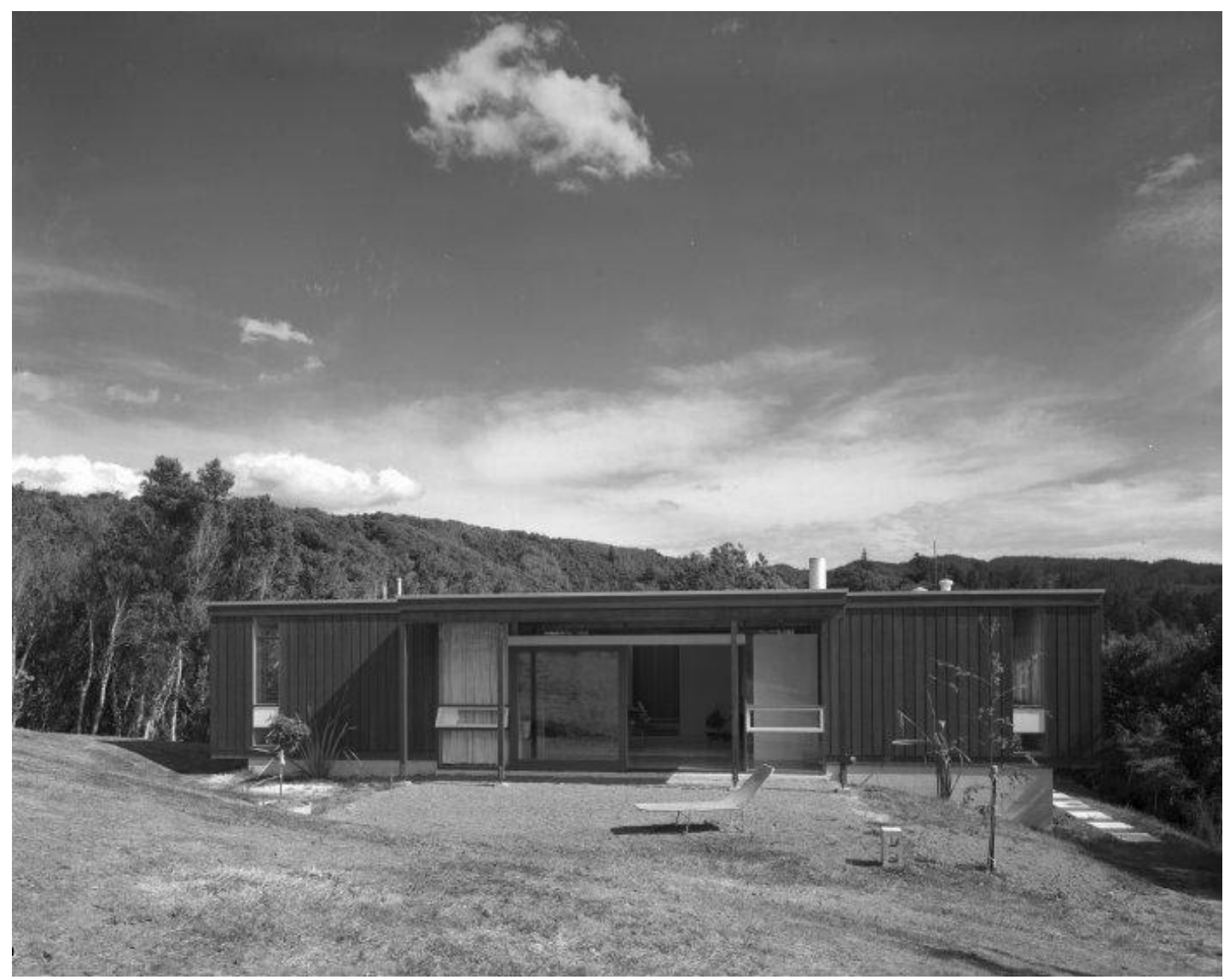

Figure 34: Duncan Winder, McKay house in Silverstream, Upper Hutt. Ref: DW-0271-F. Alexander Turnbull Library, Wellington, New Zealand. /records/23234614

102 Hiles, Antonello \& the Architect.

103 Ibid. 


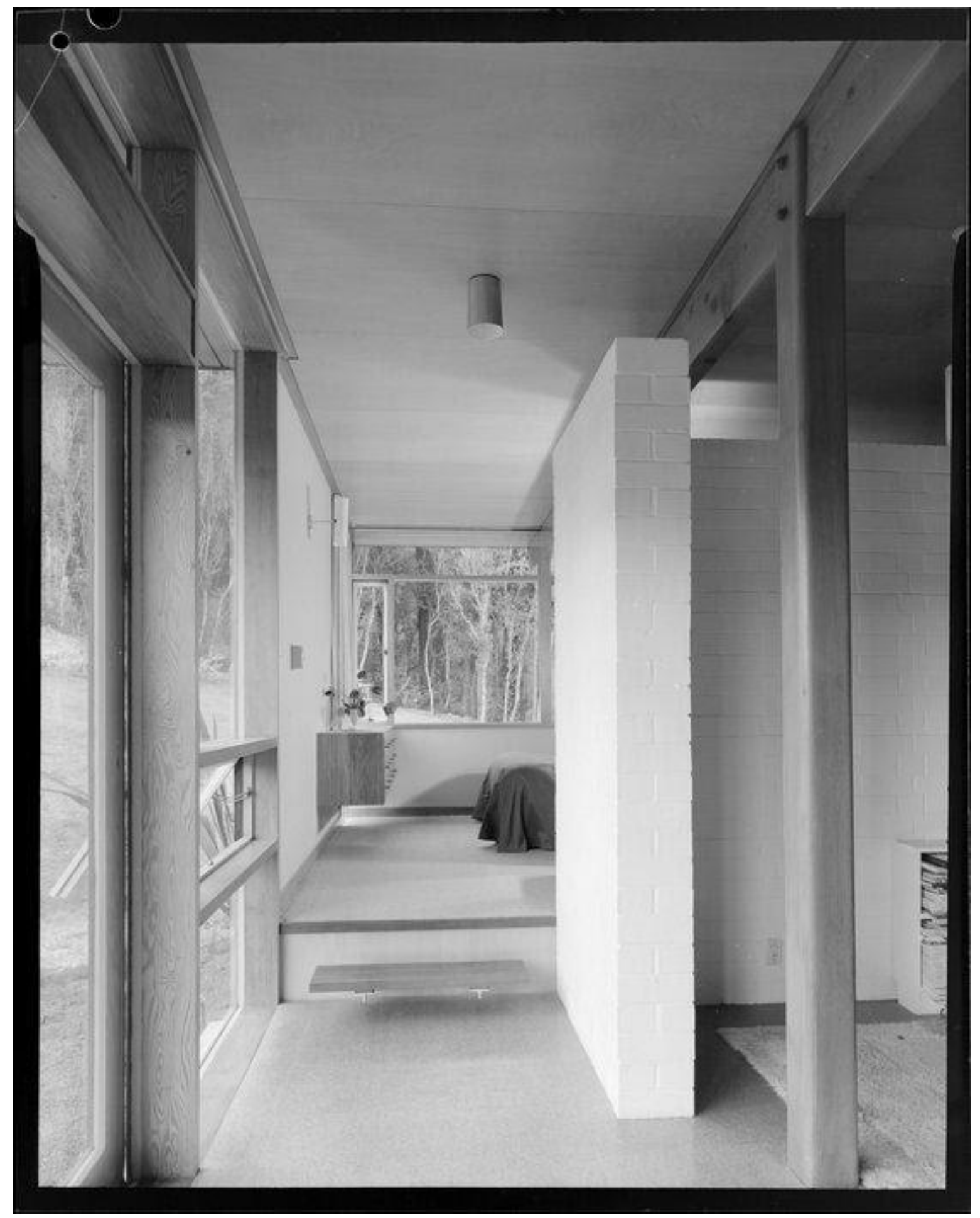

Figure 35: Duncan Winder, Hall interior, McKay house, Silverstream, Upper Hutt, Wellington. Ref: DW-0272-F. Alexander Turnbull Library, Wellington, New Zealand. /records/23122199 


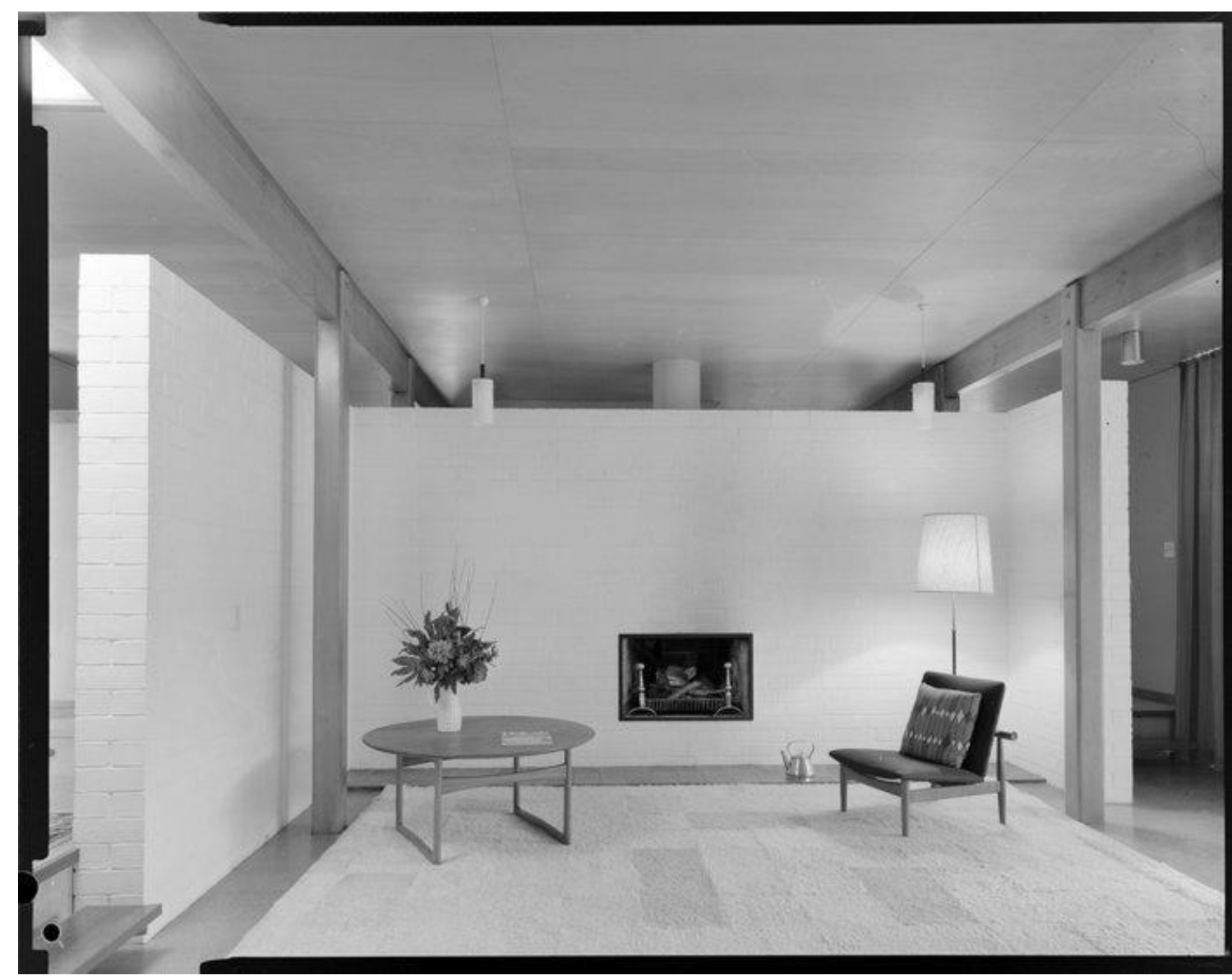

Figure 36: Duncan Winder, Lounge interior, McKay house, Silverstream, Upper Hutt, Wellington. Ref: DW-0276-F. Alexander Turnbull Library, Wellington, New Zealand. /records/22836858

The image of the house's exterior (Figure 34) illustrates its bucolic position amongst trees, set against a backdrop of Hutt Valley mountain ranges. In the McKay House images, the house's location in its landscape is plainly shown, with no attempt to accentuate the building or make it appear to dominant its landscape or the photograph. Despite this, the modern structure appears distinctive in its setting. In one image, the length of the house is presented in front of a distant mountain range and wide sky. A sliding door into the house is open, and the timber from the building's exterior can be seen repeated inside. In this image, the house is seen through a firmly objective lens that transparently emphasises its structure and materials. The image has a quality of an architectural elevation due to the factual information it conveys about the house.

There are two types of interior images of the McKay House, some that focus on recording the central living area and others that document the internal spaces surrounding the living area. Importantly, all of these images show the house with only sparse furnishing. When being photographed, many modern buildings would have been intentionally left bare in order to 
highlight the architectural qualities of the house, however, interesting in the case of the McKay House, the owners were recorded as noting that they felt restricted in the objects they could bring into their home due to its distinctive architectural nature. ${ }^{104}$

In a particularly accomplished interior image (Figure 35), Winder highlighted the symmetry inherent in the McKay House's design. The image is neatly composed in thirds, with architectural elements, and their varying materiality, used to structure and define the image. This approach highlights the textures within the house. The mid-angle photograph draws attention directly to the centre of the image where a window looks out into nearby bush. Rather than the more objective, exterior images of the McKay House, here, Winder has taken a more experiential image which illustrates the feeling of moving through the house.

In a second image of the interior (Figure 36), Winder has positioned himself in the centre of the house to photograph its core living space. Unlike other images of the McKay House where the relationship between interior and exterior is visible, this image concentrates on one aspect of the interior only. Due to its obviously styled furnishings and stark white brick walls, it has a real estate image quality. Winder's image the living space appears substantial and based off the image alone, it is difficult to understand exactly how large the space is in reality.

In Winder's images of the McKay House, his architect's eye is evident due to the attention that is paid to honouring the structure and its materials. While the house is overwhelmingly photogenic, in part because of its innate design, Winder's photographs highlight its sophistication and by making particular compositional decisions in his images, the integrity of Toomath's architecture is effectively conveyed.

It is interesting to observe the way in which Winder deals with symmetry in the interior images of the McKay House. While there is a clear symmetry in both interior images, neither is perfect. It could be possible that Winder chose not to achieve a 'perfect' symmetry, in favour of remaining more faithful to the full context of the interior. Alternatively, he may have intentionally aimed to achieve a sense of symmetry that was slightly irregular in order to position his photography as more modern, moving away from traditional or expected compositional approaches.

104 Hiles. 


\section{Wellington urban motorway}

Winder lived in Wellington during the development of the urban motorway. This was a largescale Ministry of Works infrastructure project that had significant impact on the nature of Wellington City. Responsible for the overall design of the project, Helmut Einhorn employed concrete surfaces both to humanise the immense scale of the project and to introduce visual interest that could be assessed at speed. ${ }^{105}$ Winder took multiple images of the motorway in development which illustrate how Einhorn's intended use of concrete surfaces was realised.

While Winder took many professional photographs for architects working in the public service, it is unclear whether these images of the Wellington Urban Motorway were part of commissioned work or if Winder took the images on his own volition. Regardless, these images are striking and highlight Winder's style of architectural photography.

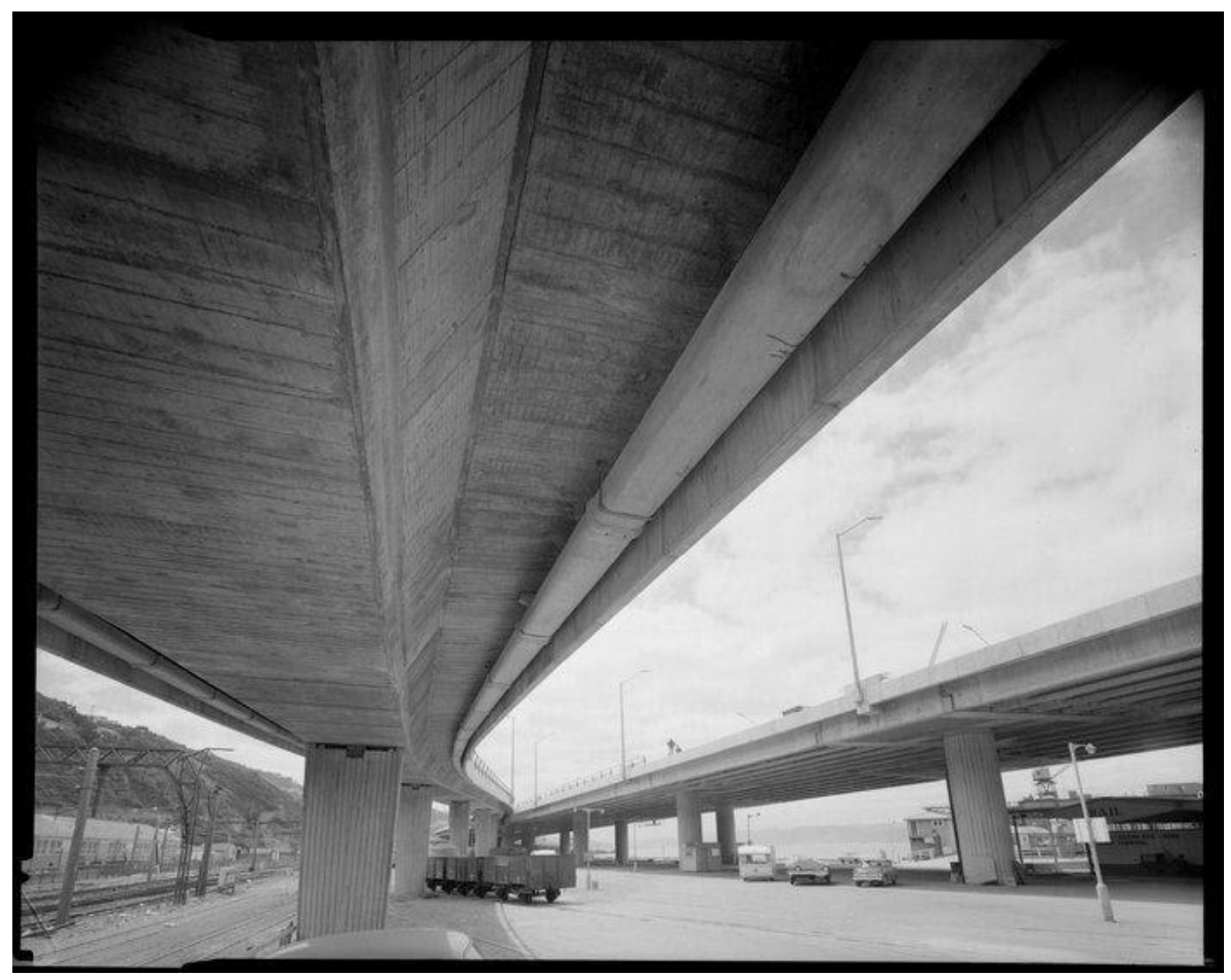

Figure 37: Duncan Winder, Underside of Wellington motorway.. Ref: DW-3729-F. Alexander Turnbull Library, Wellington, New Zealand. /records/22665195

105 Gatley, Long Live the Modern, 193. 


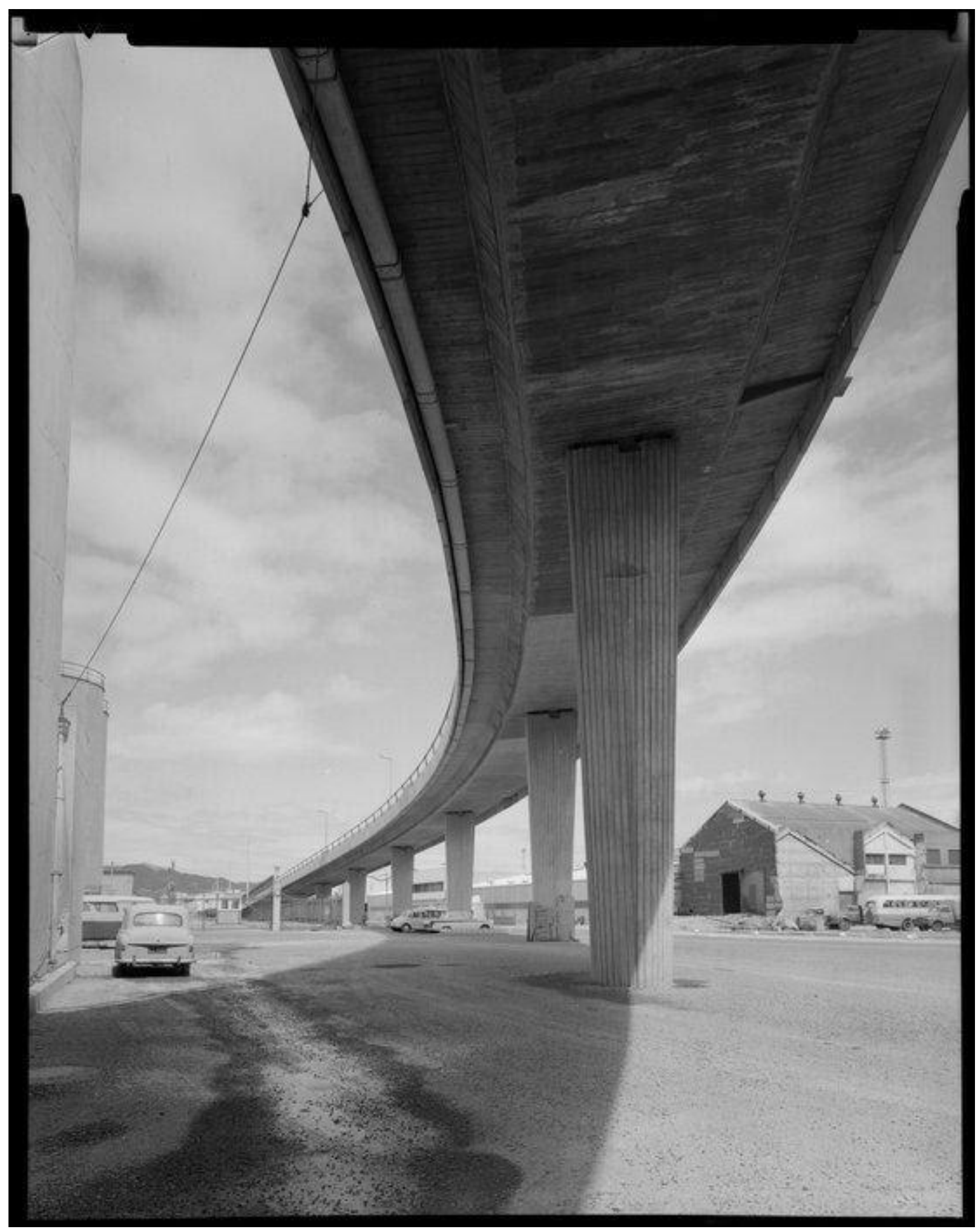

Figure 38: Duncan Winder, Underside of Wellington motorway. Ref: DW-3734-F. Alexander Turnbull Library, Wellington, New Zealand. /records/22310484 
Winder's images of the Wellington urban motorway include low-angle photographs taken from underneath the motorway. In these images, the texture and articulation of the pre-cast concrete panels is visible, and produces a satisfying rhythm due to the faceted nature of the motorway underside.

It is fair to say that Winder's images are one-dimensional in their compositional focus on the motorway structures themselves, rather than their broader environmental context. In Figure 37, the solidness and regularity of the motorway structure is enhanced against the opacity and lighter tone of the clouded sky backdrop. Despite the modern nature of the motorway structures, Winder has photographed them in a way which allows appreciation of their gentle curves that guide the viewer across the image, and the rhythm of the ribbed concrete piles. In Figure 38, the vacant surroundings devoid of people further convey a view that the aesthetics of these structures are overlooked, and that these photographs act as agents to invigorate public interest in the visual appeal of the motorway. The priority of these photographs thereby is to promote the attractiveness of the architecture. 


\section{Construction sites}

A note-worthy segment of Winder's archive relates to construction projects, and photographs of buildings mid-development. As a trained architect, it is unsurprising that Winder would have an interest in recording these stages of a building's fabrication. These photographs are definitively architectural in nature, yet retain much anonymity about their specific subject matter. In this way, they explore a keenly brutalist interest in viewing architecture as pure tectonics made of materials with intrinsic visual values.

Images of building projects were uncommon for publication in architectural journals; therefore, these images of Winder's were likely taken for his own purposes, or on the request of the relevant architecture or construction firm.

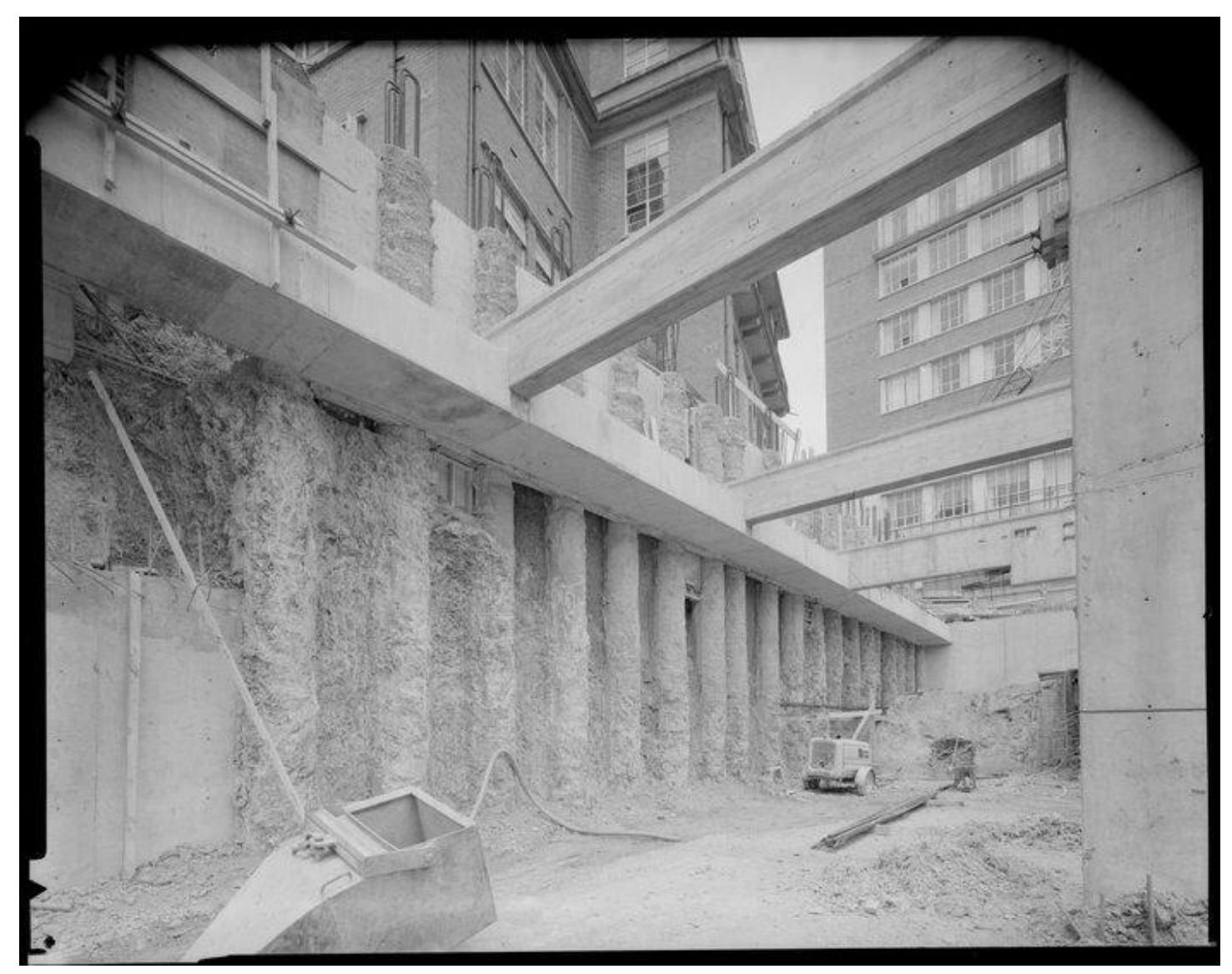

Figure 39: Duncan Winder, Victoria University of Wellington, site works. Ref: DW-4044-F. Alexander Turnbull Library, Wellington, New Zealand. /records/22460110 

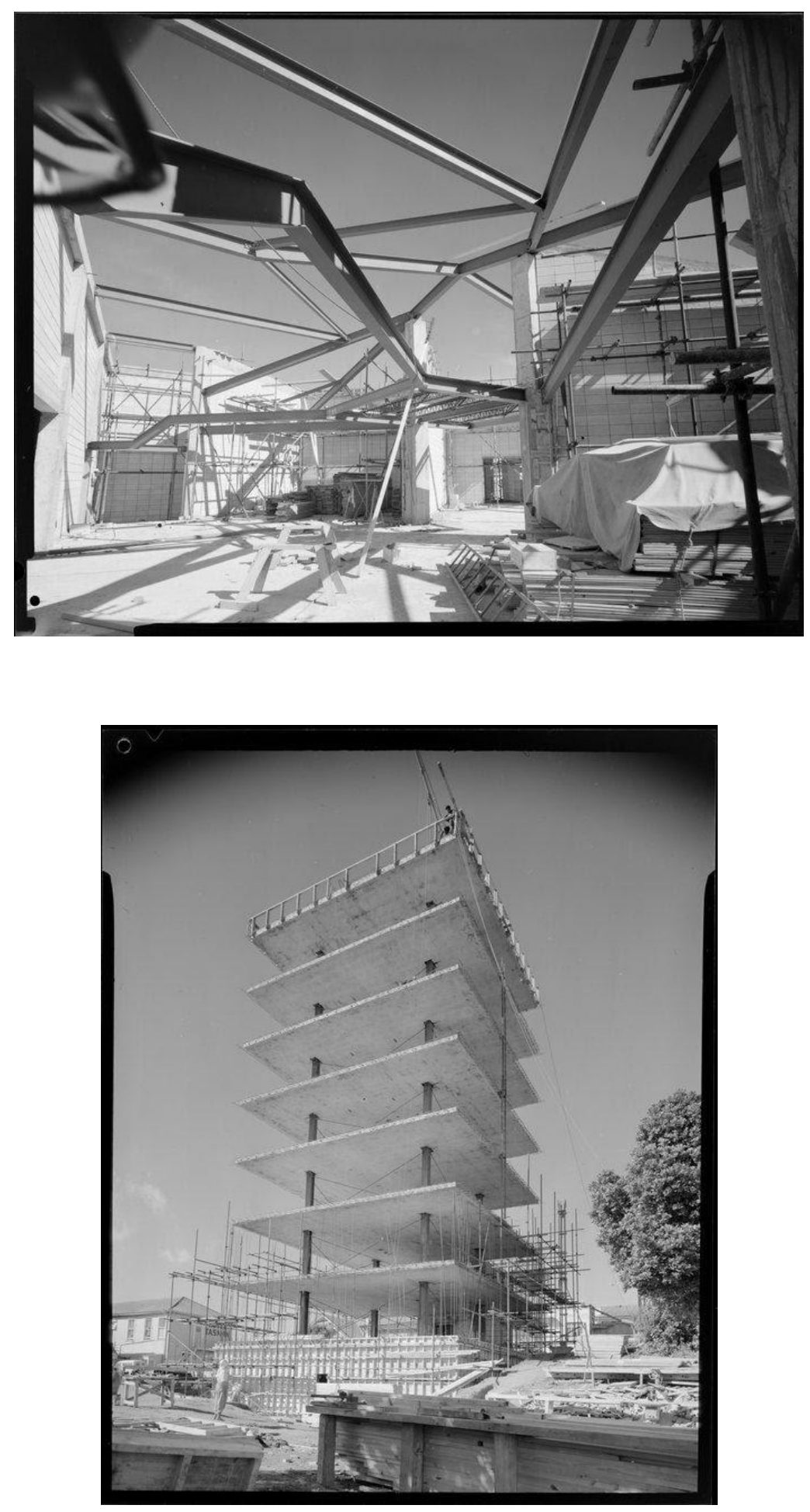

Figure 40 (top) and Figure 41: Duncan Winder, Art gallery [Dowse Art Museum] under construction, Lower Hutt. Ref: DW-4228-F. Alexander Turnbull Library, Wellington, New Zealand. /records/22303660, and Duncan Winder, Tasman Hotel under construction, New Plymouth, 1964. Ref: DW-0617-F. Alexander Turnbull Library, Wellington, New Zealand. http://natlib.govt.nz/records/23099984. 
The image of site works at Victoria University (Figure 39) has Winder positioned right within the construction site, with his camera directed upwards. This is an image ripe with juxtaposition. The textural contrast between the rigid, flat steel framing of the construction against the rough, earth wall becomes a focal point within the photograph. The steel frames the image, and helps to emphasise contrasts of horizontal and vertical lines found within the site. A secondary, and important, contrast in the photograph is that between the site works and the surrounding buildings. As Winder has taken his image from the site, it enables the viewer to access a different perspective for viewing the site and its context. By framing functional architectural spaces around an active construction site, we are reminded to consider the labour and processes involved in the building industry, instead of only seeing an isolated, finished product.

Unlike the image of the site works at Victoria University, where the form of the building in development is not yet discernible, Winder's image of the construction of the Dowse Art Museum, Lower Hutt (Figure 40) provides an example of a construction imagery where the building in development is more legible. Winder has captured a network of steel beams that make a compelling focus of the photograph. Against the clear sky, the beams appear as an abstract series of connected lines. Their many directions add a strong sense of dynamic movement to the image. Despite the open, sculptural quality of the construction materials in the photograph, this image also conveys a sense of interiority and enclosure thanks to the low angle used to capture the site. This sense of interiority is especially evident in the right side of the frame due to the presence of a wall in mid-distance. The approach to photographing the gallery mid-construction prioritises the legibility of the structure. A final construction image within the analysis is that of the Hotel Tasman, New Plymouth (1964) (Figure 41). Like in the image of the Dowse Art Museum, Winder has photographed a pivotal, if not crude, moment of hotel's construction when its form first becomes legible. Despite its obvious incompletion, the visible stratification of the hotel's floors provides necessary articulation of the building's structure. It appears monumental, and owing to the low angle that Winder has used to photograph the building, its impressive height easily dwarves its surroundings, including the tree and building to either side of the hotel. The low angle of the image enables the three-dimensionality of the structure to be emphasised. Instead of seeing the building straight on, where it would appear simply as linear, we are able to appreciate its spatial qualities and the depth of each layer of concrete. While a straight-on image may have made for a more compelling photograph, the approach taken by Winder accords to the brutalist commitment to anti-aesthetic architectural veracity and an attention to materiality. 


\section{Architectural models}

Analysing Winder's archive reveals an impressive and somewhat surprising number of photographs that he took of architectural models. There are over 200 images of architectural models in Winder's archive. During his period of practice, physical models were an essential agent of architectural information, and while they remain a niche part of his practice, they are worthy of discussion because of the way in which their representative role has changed over time, and as examples of architectural photographs taken at a different scale.

Before computer technology enabled three-dimensional modelling, physical architectural models were unrivalled for their ability to communicate architectural possibilities to public audiences. ${ }^{106}$ As architectural sites in their own right, physical models provided photographers with subject matter of a more intimate scale than they usually engaged with. The smaller scale enabled photographers' greater control and vantage over their subjects, however, many of the same conventions for photographing buildings were still applied when photographing models.

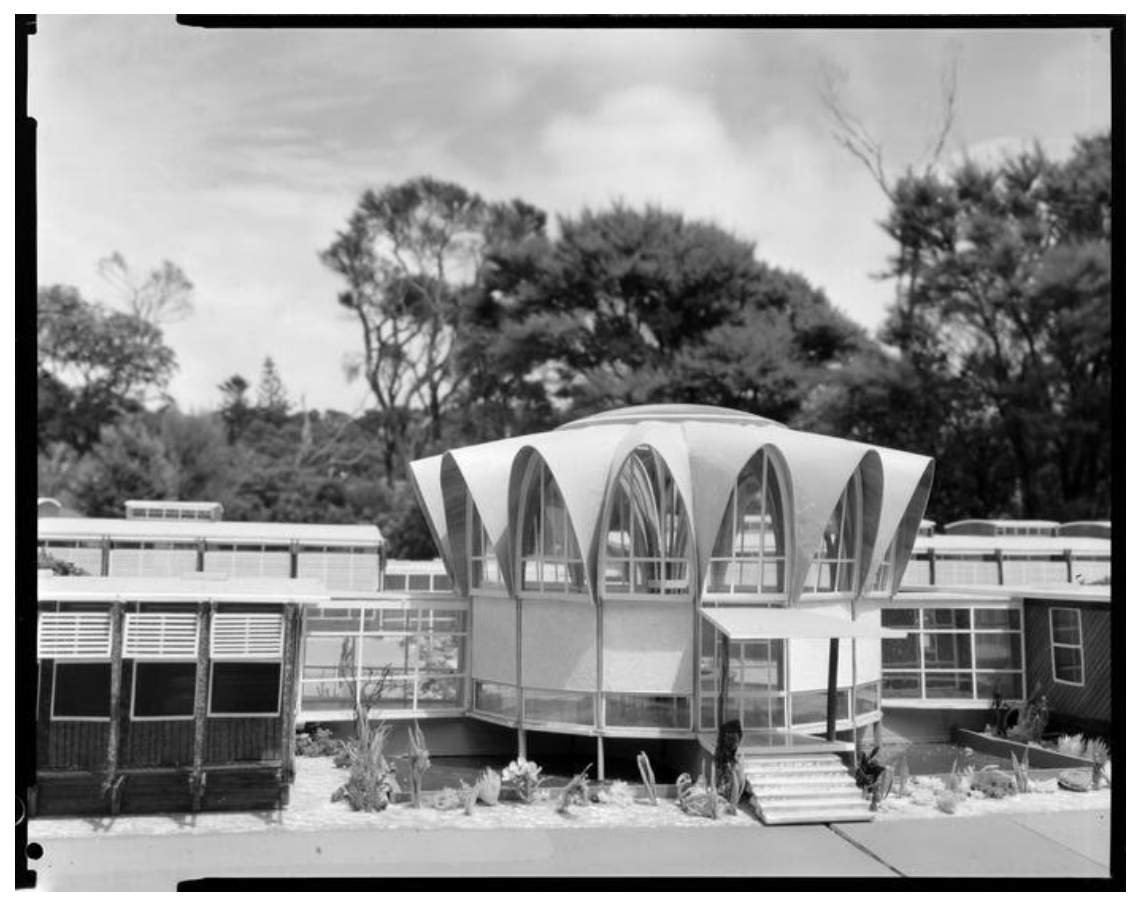

Figure 42: Duncan Winder, Architectural concept model of the proposed stage two build of the Forest Research Institute, Rotorua. Ref: DW-1739-F. Alexander Turnbull Library, Wellington, New Zealand. /records/22874646.

\footnotetext{
106 Kristianova, Joklova, and Meciar, "Physical models in architectural education and the use of new
} technologies", 2177. 

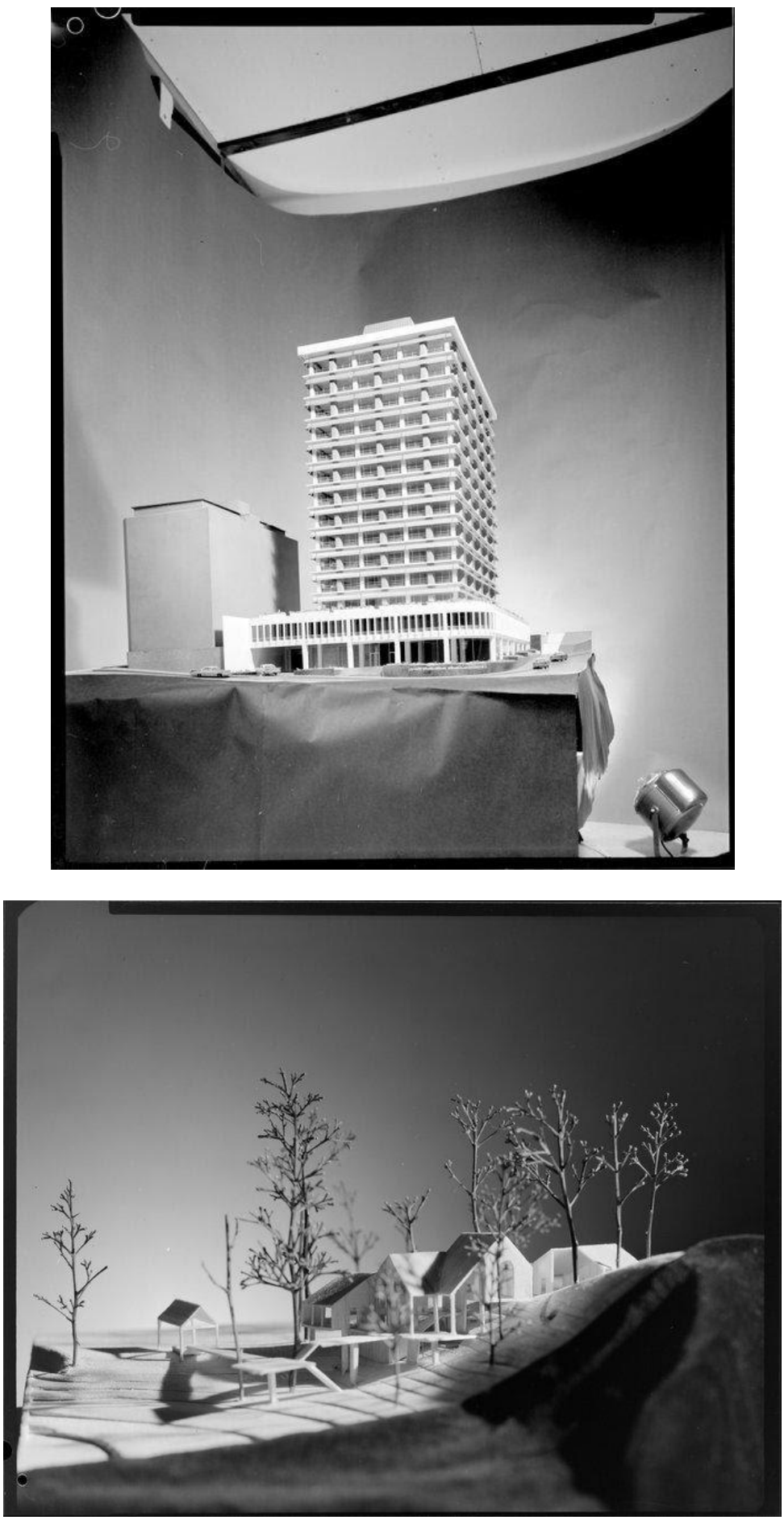

Figure 43 (top) and Figure 44: Duncan Winder, Architect's concept model, Reserve Bank Building, The Terrace, Wellington. Ref: DW-2103-F. Alexander Turnbull Library, Wellington, New Zealand. /records/22845932, and Duncan Winder, Balsa model of Aniwaniwa Visitor Centre, designed by John Scott. Ref: DW-4289-F. Alexander Turnbull Library, Wellington, New Zealand. /records/22890803. 
In the image of the concept model of the proposed stage two build of the Forest Research Institute, Rotorua, (Figure 42) Winder has positioned the model outside against a backdrop of distant trees and a clouded sky. The authenticity of the background helps to deceive the viewer that they are in fact looking at a model, rather than an actual building. Unlike the more objective photographs of models set against a plain background where the base of the model is visible, this image constructs a specific context for the model in order to make it appear more convincing as a genuine building. Contrasting architecture is visible in Winder's image, where the undulating roof of the central structure is contrasted against its low-rise, flat roofed surroundings. While the building represented in this model appears to have a level of symmetry, Winder has not emphasised this in his photograph. Instead, the angle used for the image is slightly off-centre, drawing attention to the central section of the model.

In Winder's image of the model of the Reserve Bank building for The Terrace (Figure 43), a different approach to photography is demonstrated. What the viewer first notices in Winder's image is not the architectural model, but its context. We gain a behind-the-scenes perspective on Winder's studio set-up, with the wrap around backdrop and floor light visible. Of course, much of this context would have cropped for publication, however in this unedited image there is no disguising the real scale and nature of the architectural subject, as opposed to the image of the Forest Research Institute model where there is a clear attempt to depict the model as an actual building. Positioned in the centre of the image atop a flat surface, the Reserve Bank building model is seen as the sculptural object that it is. The commercial realism of the image, where the subject is depicted like a product (with bright light directed clearly at the model), using straight-forward, truthful imagery is representative of many of the images of models that Winder produced.

Winder's image of the model of Aniwaniwa Visitor Centre, 1970 (Figure 44) illustrates a different approach again to his photography of architectural models. This model is cast against a plain background with the camera positioned in a way which highlights the topography of the terrain. It is an intimate image, and the small twigs which represent trees around the model add an other-worldly feeling to the image. Tonal contrasts further dramatise the composition. Winder's photograph does not seek to fully document the reality of the model, instead it demonstrates how the proposed built form will sit within its landscape. This is picturesque imagery that evokes emotion for the environment depicted. 


\section{Christchurch images}

Based on Winder's archive, he visited Christchurch in November 1965, and this may have been his only visit to the South Island city. As discussed in the visual survey of New Zealand architectural photography (in Chapter Two), the healthy regionalism of post-war architectural photography in New Zealand meant that the larger urban centres all had their own local photographers and the need to commission photographers from other parts of the country was uncommon. Winder's time in Christchurch enabled him to photograph new buildings by Warren and Mahoney, proponents of a distinct 'Christchurch style'. ${ }^{107}$ While the term 'Christchurch style' is applied to the city's local architecture, arguably, it can also be applied to the style of architectural photography used in its documentation. The strong geometry of the Warren and Mahoney's buildings, and their use of white and black gave way to a memorable style of architectural photography made most popular by Martin Barriball and the studio of Mannering and Donaldson. Winder took a diverse range of architectural photographs in Christchurch, which demonstrate how the same photographer could, and in some cases must, adapt their approach to photography based on their architectural subjects

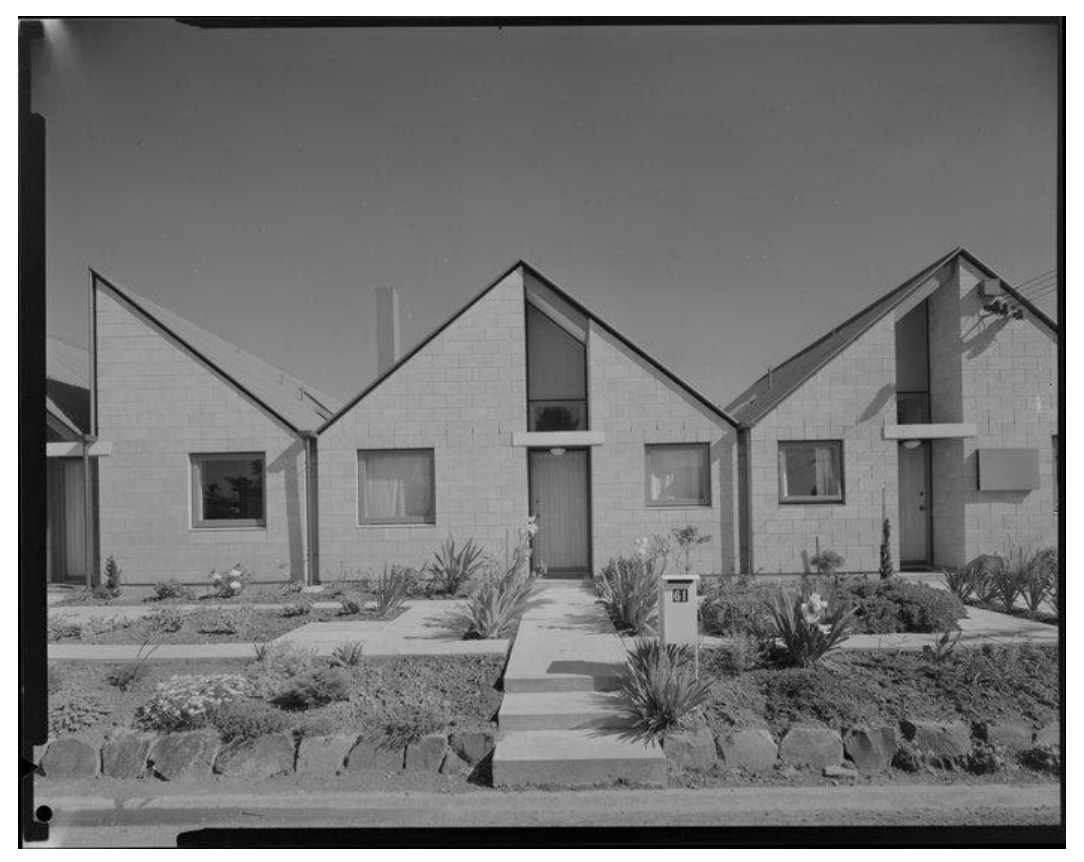

Figure 45: Duncan Winder, Houses designed by architect Miles Warren. Ref: DW-1813-F. Alexander Turnbull Library, Wellington, New Zealand. /records/22799629.

107 Christchurch Modern, "The Christchurch Style". 

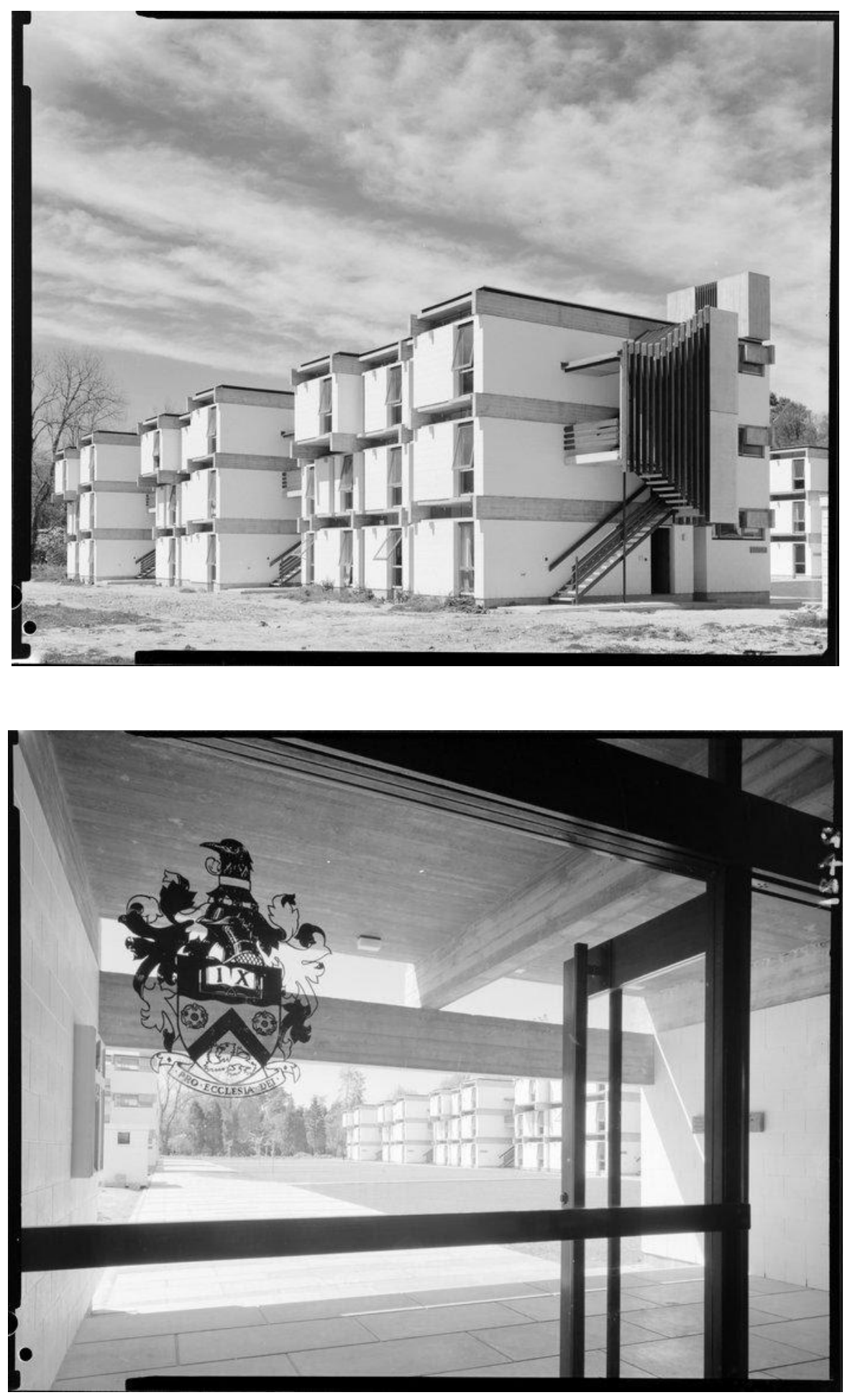

Figure 46 (top) and Figure 47: Duncan Winder, University of Canterbury student accommodation exterior, Christchurch. Ref: DW-2427-F. Alexander Turnbull Library, Wellington, New Zealand. /records/22717167, and Duncan Winder, University of Canterbury entrance, Christchurch. Ref: DW-2421-F. Alexander Turnbull Library, Wellington, New Zealand. /records/22541196. 

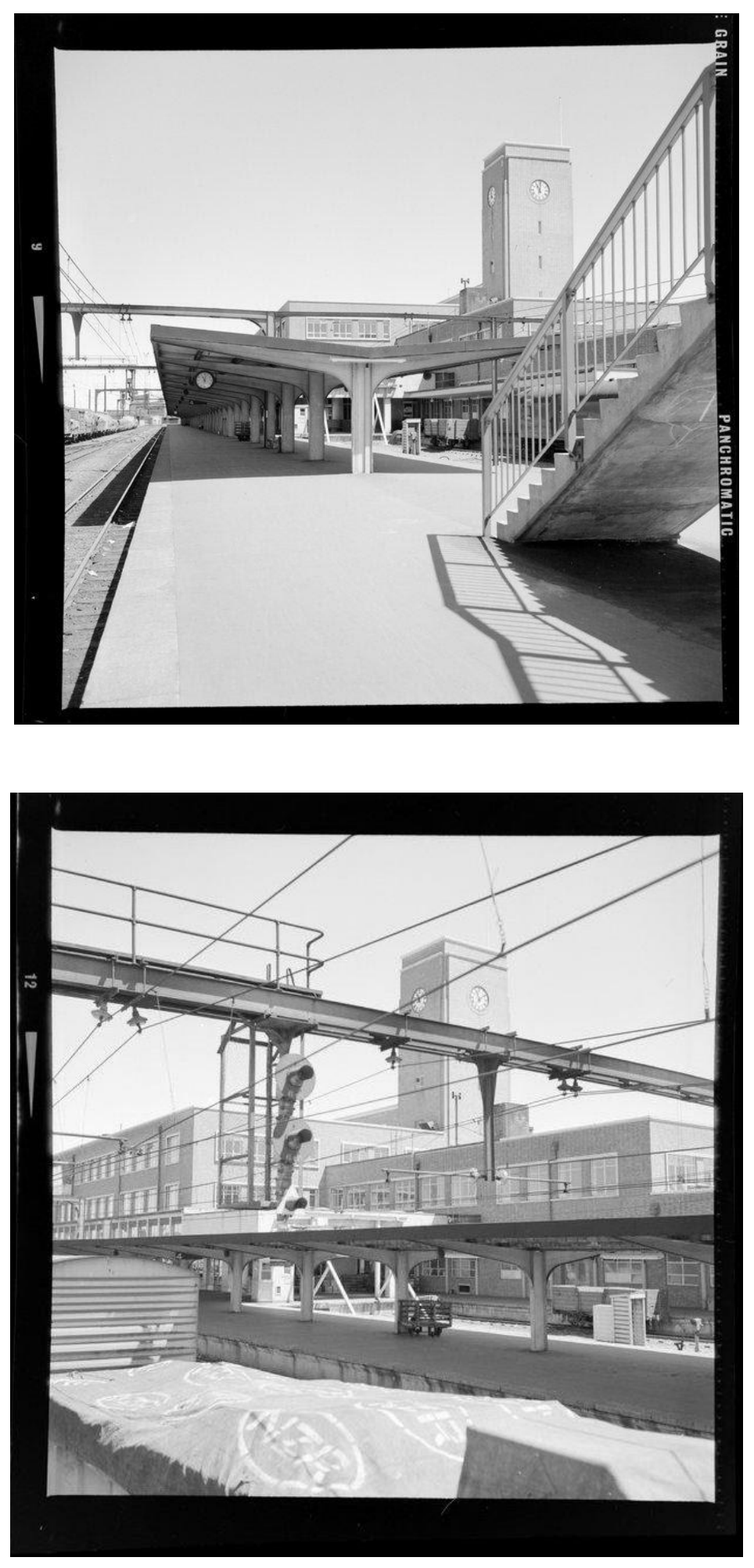

Figure 48 (top) and Figure 49: Duncan Winder, Platform, railway station, Christchurch. Ref: DW-5347-F. Alexander Turnbull Library, Wellington, New Zealand. /records/22564396, and Duncan Winder, View of railway station from the tracks, Christchurch. Ref: DW-5349-F. Alexander Turnbull Library, Wellington, New Zealand. /records/22827936. 


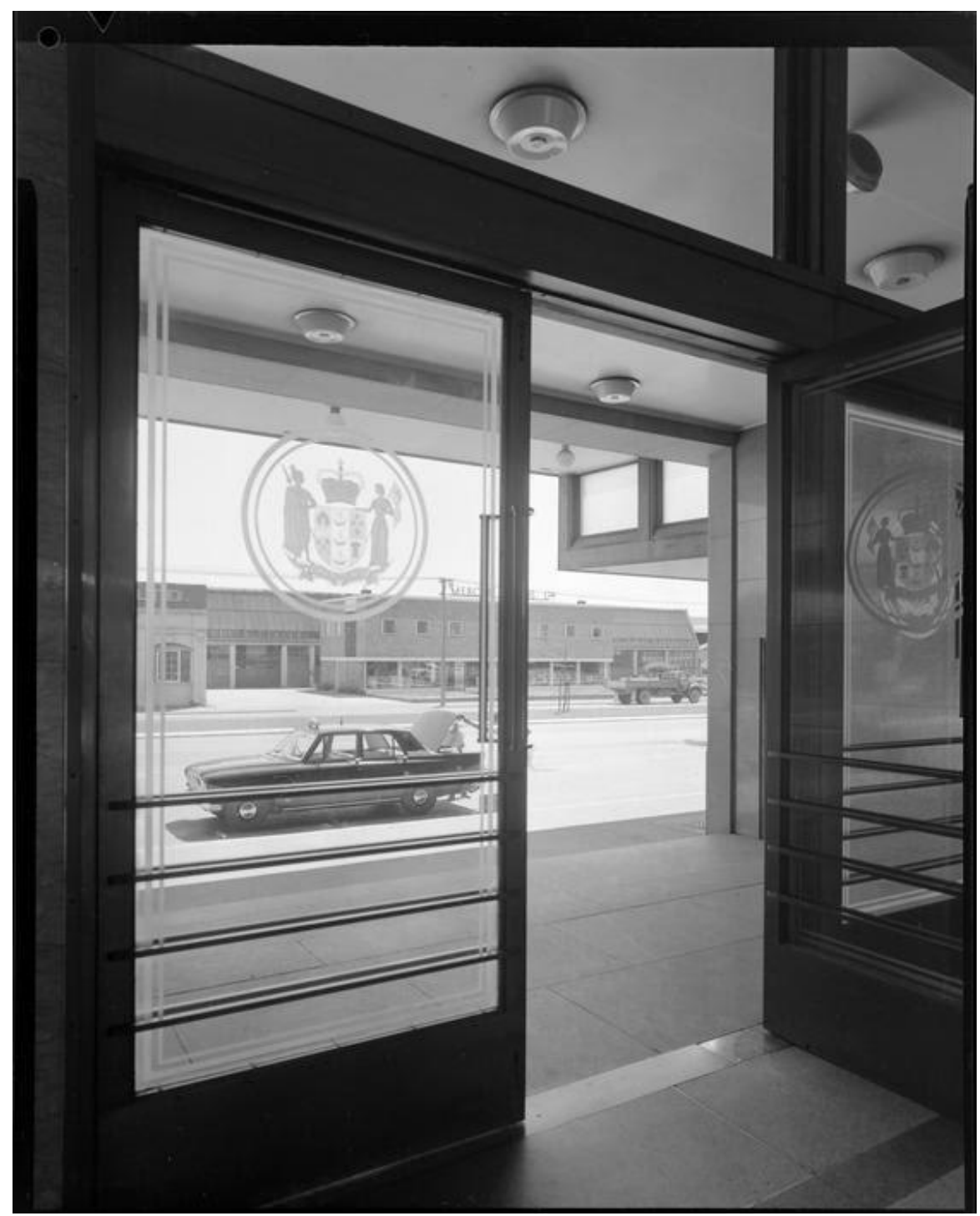

Figure 50: Duncan Winder, Christchurch Railway Station. Ref: DW-5118-F. Alexander Turnbull Library, Wellington, New Zealand. /records/23529973.

In the image of the Webb flats in Cox Street, Merivale (Figure 45), Winder has used a front-on angle which helps to achieve a flatness in the image (similar to the Mannering and Donaldson image of the Harewood Memorial Gardens Crematorium, Figure 32, included in the visual survey as part of Chapter Two). The flatness brings focus to the tone and texture of the built form and helps to emphasise contrasting elements in the image, such as the fine, organic texture of the plants against the solid, whiteness of the flat's façade. Photographs of Warren and Mahoney's post-war buildings help to illustrate the inseparable relationship between architecture and photography in shaping public understanding of and 'ways of seeing' modern architecture. 
Winder did not, however, always apply the same approach to photographing Warren and Mahoney buildings in Christchurch. In the image of College House (Figure 46), University of Canterbury (1964), Winder produced a more dramatic photograph. Instead of a front-on angle, Winder opted for an angle which makes visible the full extent of the building, profiling the rhythm and repetition in its architecture. While there are obvious differences in this image and that of the Webb flats, both images capture their subjects in isolation - with no people or environmental context discernible.

Interestingly, Winder took other images of College House which reveal the photographer's ability to document the same building in different ways. In a second image (Figure 47), Winder positioned himself at the entrance of a neighbouring building looking back towards College House. The same angle of the building has been used in both images, however, in the second image, Winder has revealed more context of the university grounds. The image also allows the viewer to gain a closer view of the textures of the materials used in the building's construction. Perhaps the most intriguing element of Winder's contextualised image of College House is the crest printed on the glass window, in immediate view of the camera. The crest appears as if a watermark over the image, introducing a new layer of non-architectural visual interest. This image could be compared to those taken by Nigel Henderson of the Hunstanton school during its construction (see Figure 11), where the photographer took images through windows displaying abstract smudges and finger drawings. ${ }^{108}$ The presence of these window features in architectural photographs attests to the mission of the exhibition that Henderson organised with the Smithsons', Parallel of Life and Art, which aimed to foster inclusive visual perception that was not concerned with privileging one category of aesthetic over another. In this way, it can be argued that Winder's image demonstrates a brutalist approach to presenting architecture, one conscious and accepting of all types of form, material and texture - and photographing them together 'as found'.

While in Christchurch, Winder also photographed the Christchurch Railway Station. Winder's photographs of the station prove an insightful addition to the present analysis, as they challenge a narrative that he operated in only one style during his time in Christchurch. Winder's images, taken on the station's platforms are composed in a way that emphasises its visual richness. Unlike the images of stand-alone buildings that can often appear lifelessly still, here Winder has captured the station as a functional environment, even without including people to humanise

108 Zimmerman, 206. 
and contextualise the space. In the first image, there are points of interests at different levels of the photograph and sightlines that guide the viewer.

Winder took multiple photographs of the platform (Figures 48 and 49), and collectively they offer viewers a means of moving through the space, which other visual elements such as tram lines dominating the sky (Figure 49) contributing further dynamism.

Winder's image of the Christchurch Railway Station entrance (Figure 50) is striking for its similarity to that of College House, as seen through a neighbouring building. Again, Winder has captured an open entranceway on which a crest is visible. Unlike the image of the College House, where Winder is looking towards the building from another, here, Winder is positioned inside his subject, the train station, looking out to the street. From this perspective, the circular crest prompts the viewer to look closely at the linear entranceway, with its many right-angles. It is useful to observe the types of images that Winder produced at different architectural sites, revealing how his approach to photography could be influenced in different stylistic directions, and additionally, where he was still able to maintain consistent perspectives and composition styles from site to site. 


\section{University architecture}

A feature of Winder's archive that becomes apparent through analysis is a consistent approach to the photography of university and educational spaces. The number of architectural photographs that Winder took of educational spaces is substantial. Campuses regularly make for compelling architectural subjects, as environments with multiple buildings in close proximity to one another - in arrangements and typologies that are distinct from urban and residential architecture. Winder's images capture the striking architectural and visual contrasts that can be found on campuses. When architectural imagery seeks to accentuate contrasts, complexity and drama in the built environment, it can be classified as exemplifying Townscape qualities. In fact, many of the first photographs used to illustrate Townscape principles were from educational built environments, in Oxford and Cambridge.

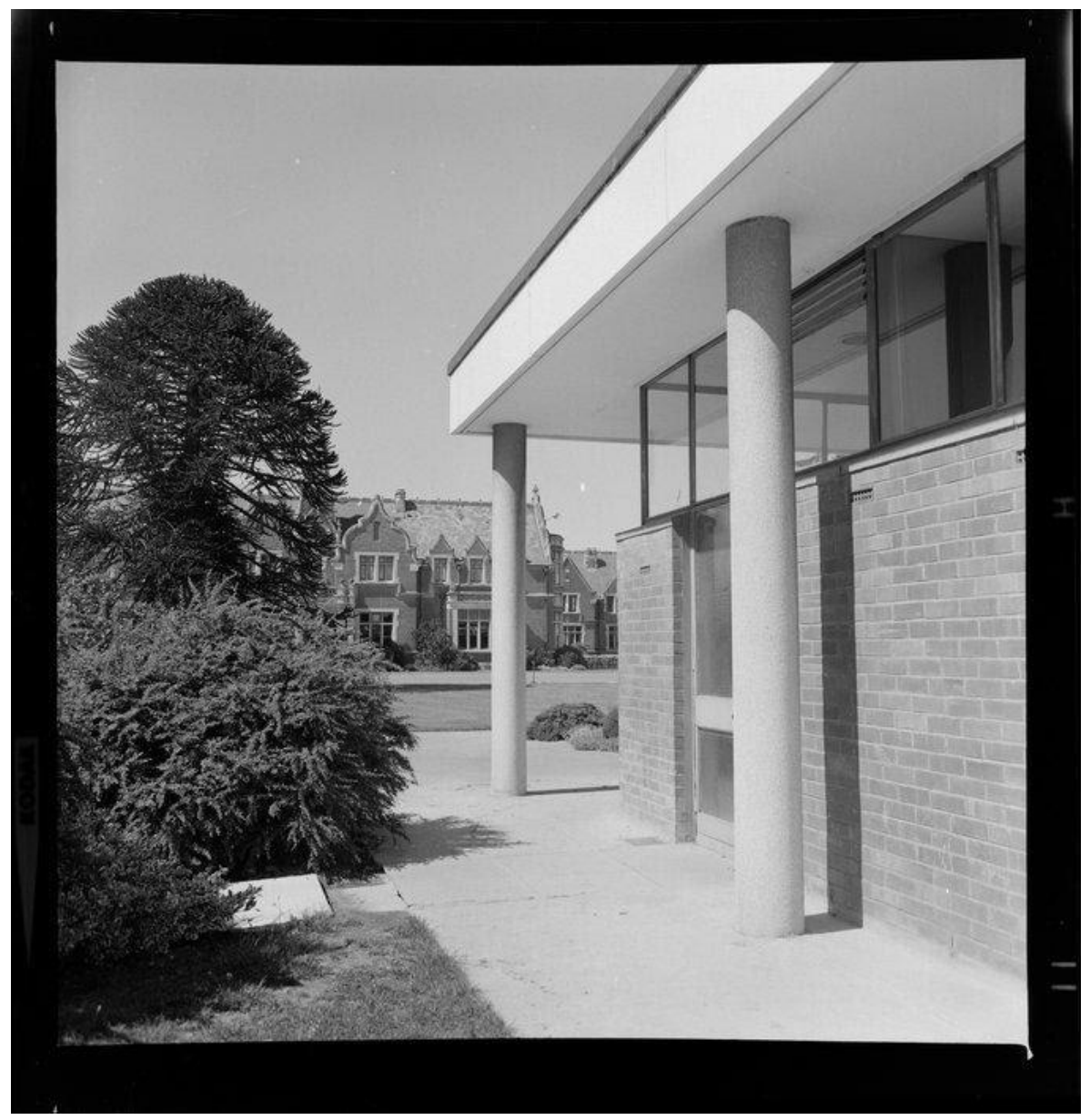

Figure 51: Duncan Winder, Exterior of Lincoln College, Canterbury. Ref: DW-4860-F. Alexander Turnbull Library, Wellington, New Zealand. /records/23063059. 

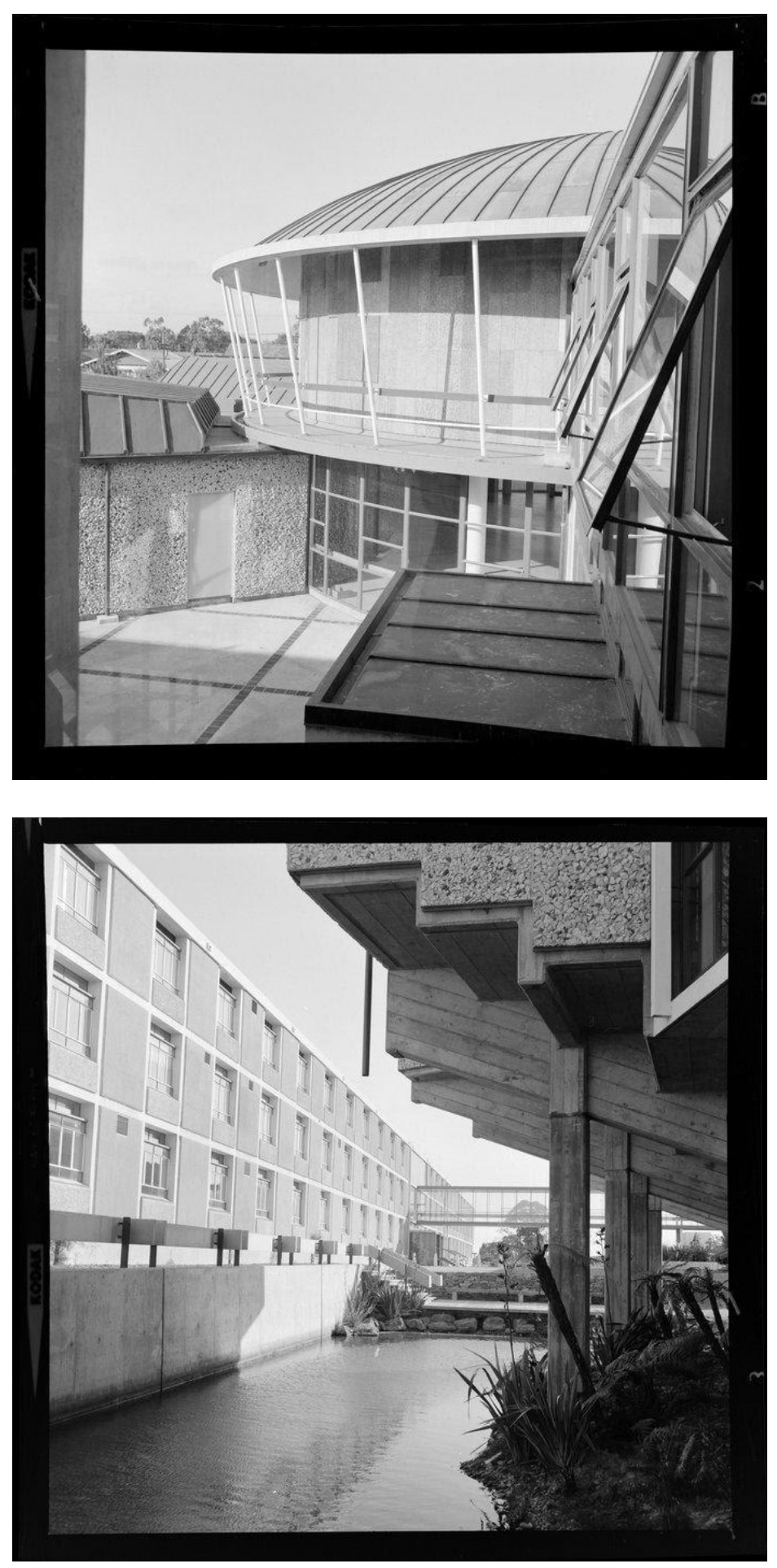

Figure 52 (top) and Figure 53: Duncan Winder, Exterior of School of Engineering at the University of Canterbury. Ref: DW-4873-F. Alexander Turnbull Library, Wellington, New Zealand. /records/22333042, and Duncan Winder, Exterior of School of Engineering at the University of Canterbury. Ref: DW-4871-F. Alexander Turnbull Library, Wellington, New Zealand. /records/23032874. 

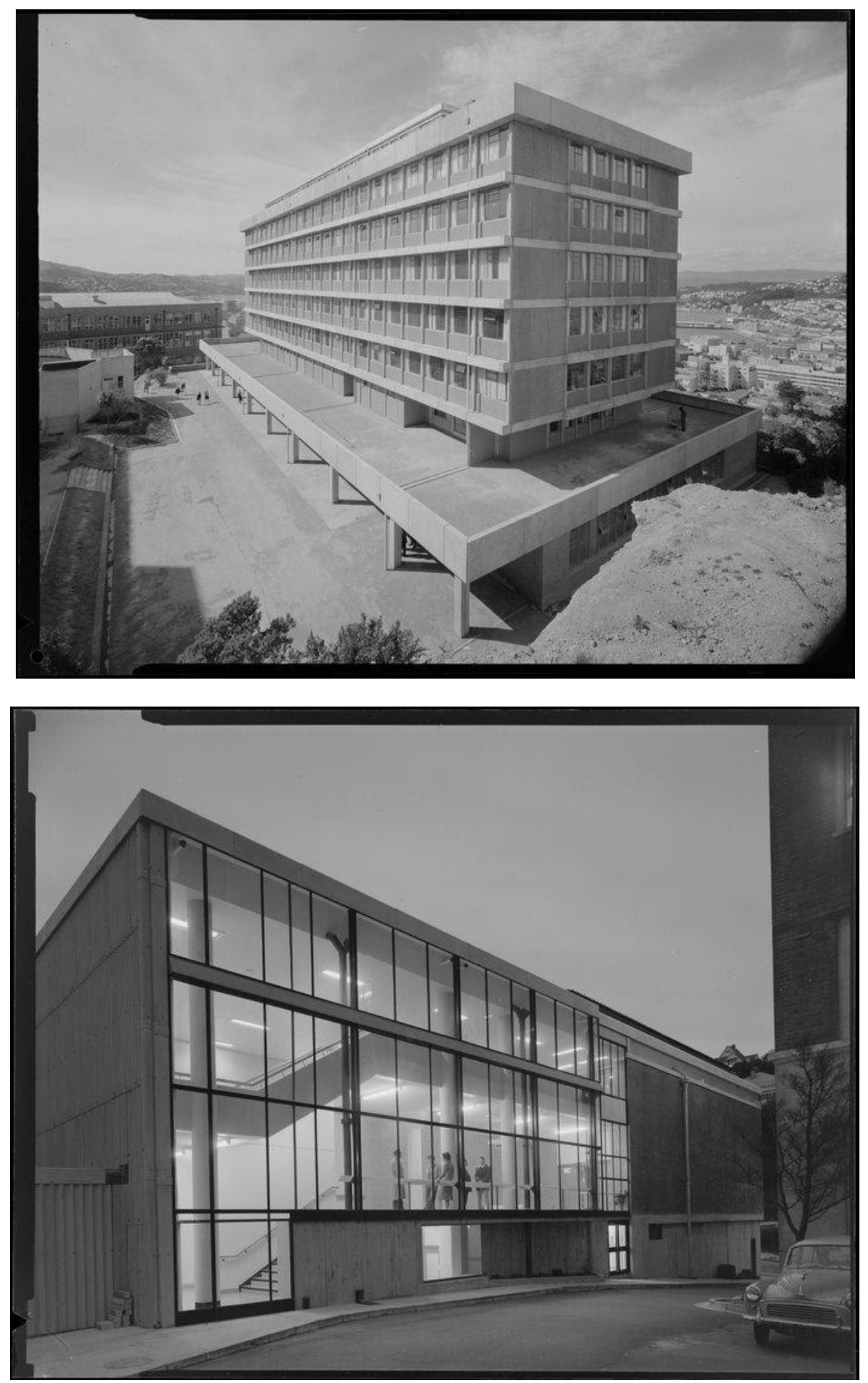

Figure 54 (top) and Figure 55: Duncan Winder, Victoria University library building, Wellington. Ref: DW-1638-F. Alexander Turnbull Library, Wellington, New Zealand. /records/22696208, and Duncan Winder, Lecture theatre, Victoria University of Wellington, Kelburn, Wellington. Ref: DW-3598-F. Alexander Turnbull Library, Wellington, New Zealand. /records/23222472. 
In Winder's image of Lincoln University (Figure 51), the Jacobean Ivey Hall (1878-80), designed by Frederick Strouts, can be seen in the distance. Its form is partly obstructed by foliage and a column around the George Forbes Library building (1960), designed by Jones, Adams, Kingston and Reynolds. While neither building is fully visible, Winder's image enables an effective contrast between their different architectures to be appreciated. The photograph is well composed with these architectural interests balanced in the foreground and background, and with textured vegetation in mid-distance. The angle at which Winder has composed the photograph creates a sense of movement along the edge of the library building, offering viewers the ability to 'feel their way through' the image.

In the images that Winder took of the School of Engineering at the University of Canterbury (Figures 52 and 53), we can observe his photographic ability to celebrate specific architectural qualities of buildings through choice perspective. In Figure 52, the mushroom-shaped lecture theatre, constructed as part of the Ministry of Works 1961 campus development, is profiled. This image is as much a study of lines and grids as it is of building being photographed. Almost every surface in the frame contributes to this study - the gridded arrangement of the courtyard, the slant of the open windows, and the elegant curved lines of the roof surface. As is common in the composition of Winder's photographs of building exteriors, one side of the image shows the angled length of a building, thereby drawing attention to the centre of the image where another building is emphasised. It could be considered that this in an extension of Winder's off-centre style of composition, which he used for photographing both interiors and exteriors.

In Figure 53, Winder is positioned between two buildings - which enables different qualities of each to be showcased. On the left of the frame, the solidness, mass and repetition of the building is presented. While on the right, the concrete underside of another building is shown, focusing on its stepped design and exposed aggregate façade. The image is cleverly balanced, with the left-hand side appearing much lighter in tone than the right, adding to the contrast in their architectural styles.

Winder's image of the Victoria University Library building, (Figure 54) designed by Kingston Reynolds Thom \& Allardice, 1965 is more conventional approach to architectural photography. Here, Winder has captured as much of the building as possible from an angle that overlooks the Wellington cityscape. From this view, the size of the library building appears accentuated, and its monumentality dwarfs the other buildings on campus. 
In another image of the Victoria University campus (Figure 55), Winder has documented a lecture theatre building. It is an elegant photograph that showcases the large glassed façade. The image appears to be taken in the evening which means the well-lit building interior becomes a striking focal point of the photograph. Winder has included people in the photograph, gathered inside the building near to the glass as to be highly visible. This was a popular way to photograph buildings with floor to ceiling windows. Winder's sophisticated and still evening image depicts it as a relatively empty space, rather than its much more actively used daytime function, when it would likely be filled with students. 


\section{Apartment buildings}

Winder's practice as an architectural photographer in Wellington coincided with a period of highdensity residential building in the city, which provided for compelling photographic subject matter. Many of the high-density residential buildings that were constructed in 1960s Wellington were located within inner-city suburbs that had well-established architectural styles. The construction of modern apartment buildings often made a dramatic impact on the suburban landscape. Winder regularly documented the juxtaposition between modern buildings and the pre-existing built environments in which they were located. The larger scale of the apartment typology both enabled and required photographers to apply different approaches in their photography. Winder's images of apartment buildings include some of his most dynamic photographs, and they also evidence the versatility of his photography.

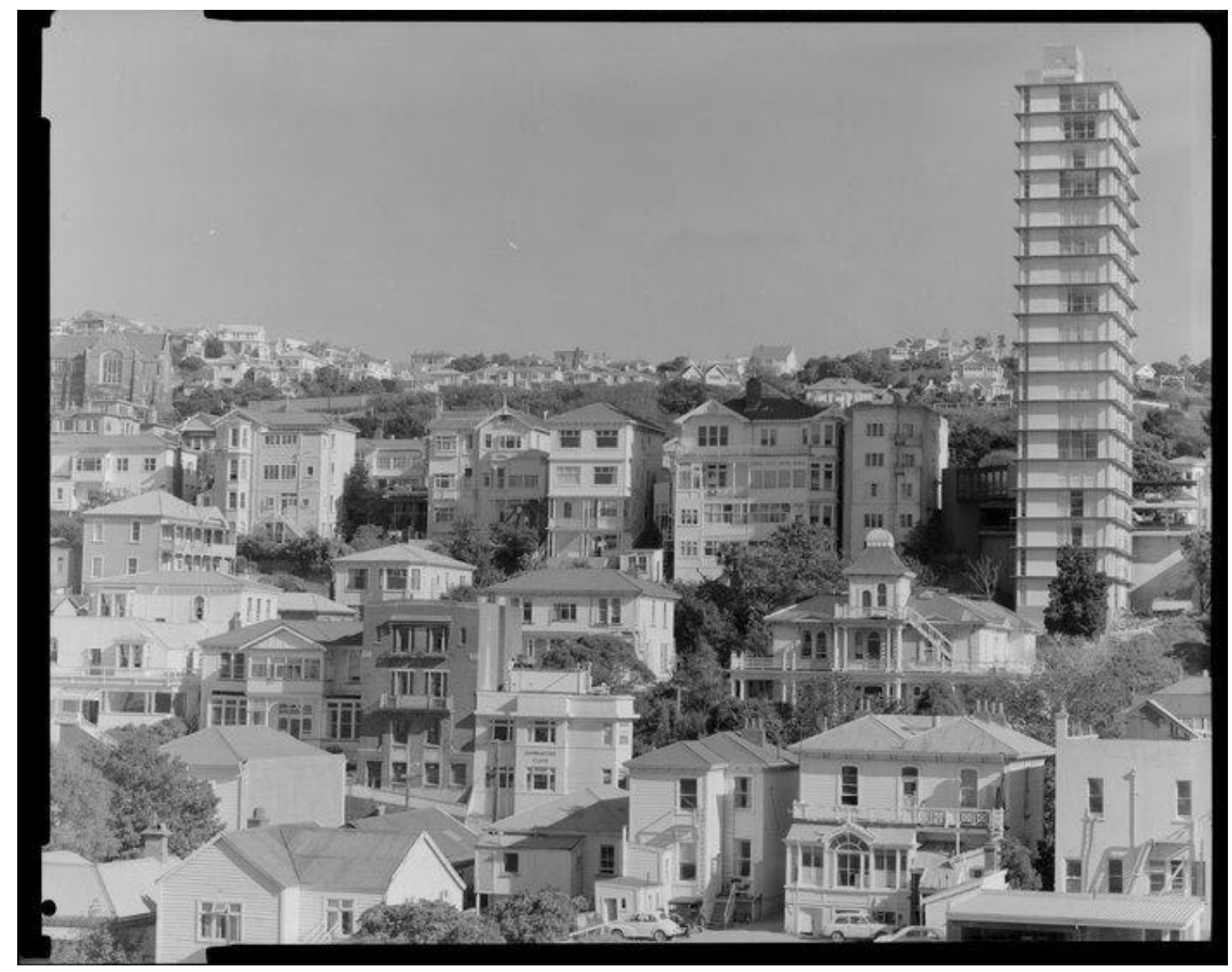

Figure 56: Duncan Winder, Houses, Te Aro, Wellington. Ref: DW-4219-F. Alexander Turnbull Library, Wellington, New Zealand. /records/22677108. 

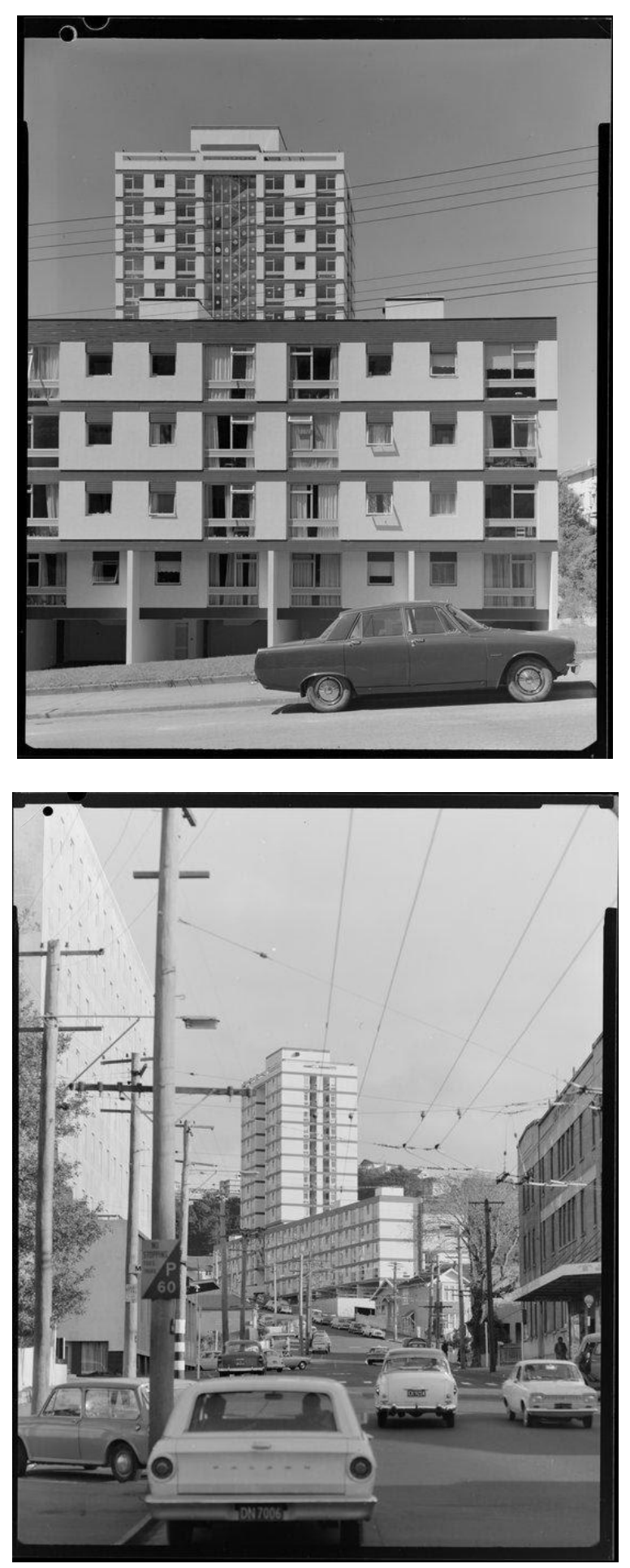

Figure 57 (top) and Figure 58: Duncan Winder, Flats, Nairn Street, Wellington. Ref: DW-3989-F. Alexander Turnbull Library, Wellington, New Zealand. /records/23065875, and Duncan Winder, Nairn Street flats, Brooklyn, Wellington. Ref: DW-4283-F. Alexander Turnbull Library, Wellington, New Zealand. /records/23175479. 


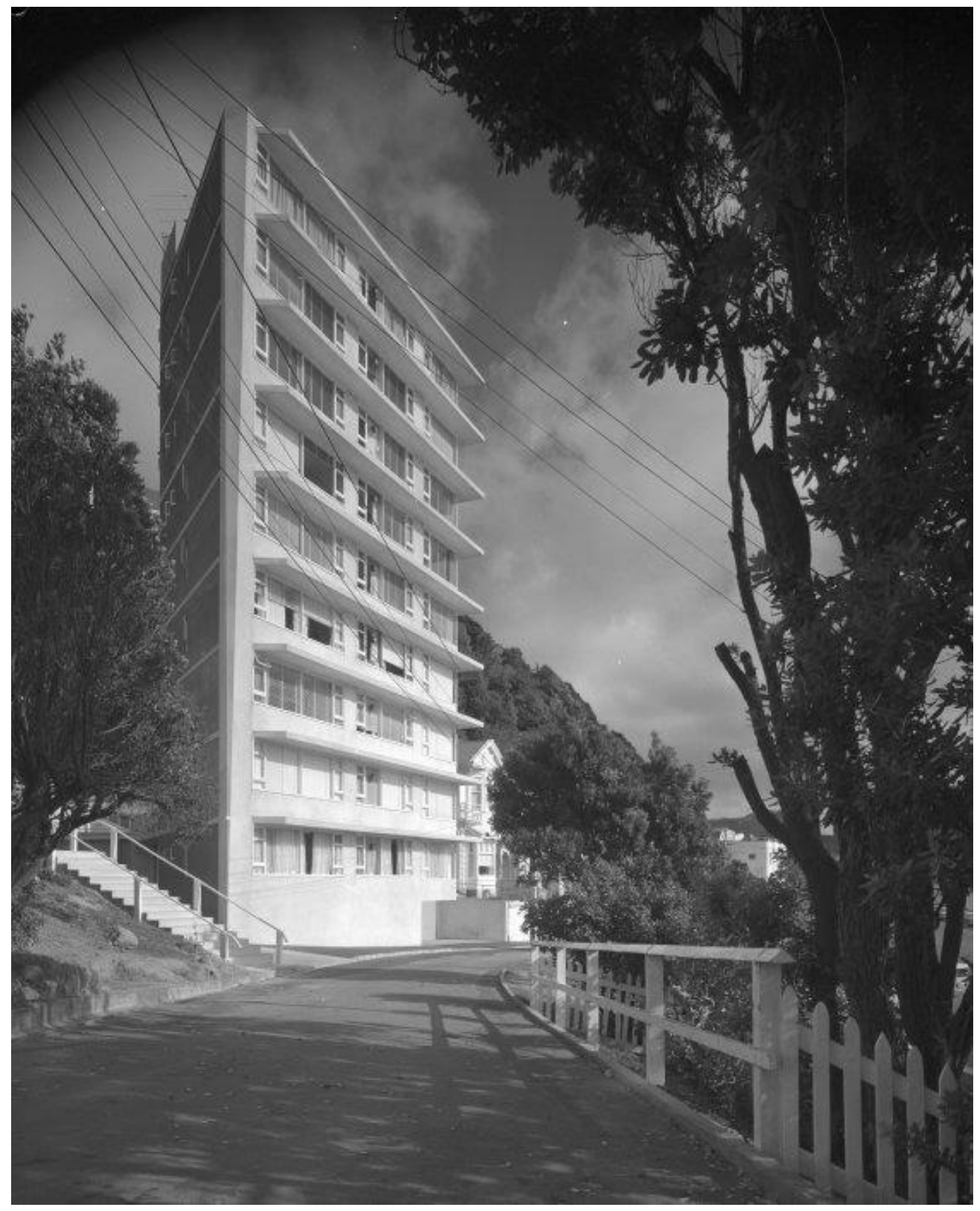

Figure 59: Duncan Winder, Clifton Towers, a block of flats in Wellington. Ref: DW-1071-F. Alexander Turnbull Library, Wellington, New Zealand. /records/23151904. 
Winder's use of juxtaposition is perhaps best exemplified in an image of Jellicoe Towers, designed by Allan Wild in 1968 (Figure 56). The landscape format of the photograph contributes to the horizontal stratification of the environment depicted, however, Jellicoe Towers introduces a sharp verticality into the frame. Winder has composed the image so that Jellicoe Towers defines the right side of the photograph. The other buildings visible in the image all appear to be of a consistent scale, and despite the range of architectural styles, they appear as a cohesive Townscape. Winder's image of Jellicoe Towers from this perspective keenly highlights the boldness of the building's design and how it drastically changed the Wellington cityscape. Due to the neighbourhood scale of the subject matter shown in this image, it could all too easily be categorised as a Townscape image, however, it remains an objective, 'matter of fact' documentation of Jellicoe Towers and its surrounds on The Terrace.

Winder's photographs of the Nairn Street flats (Figures 57 and 58) illustrate his ability to portray the same building in different ways. In Figure 57, Winder has used a front-on angle which emphasises the repeated graphic forms of the flats' façade, visible both in the foreground and background. The inclusion of the power lines introduces another layer of repeated pattern into the photograph. The inclusion of the car is worth noting, it provides another element of visual interest in the image, and reinforces the overall flatness, and front-on composition of the photograph.

While this image has strong sense of objectivity and clarity, Winder also took another, very different image of the building. In his other image (Figure 58), the flats are seen from a greater distance that allows the flats' pedestal and tower form to be understood. In this image, Winder's camera is positioned along a busy urban street which makes the context of the flats appear much livelier than in the first image, where only one parked car is visible.

While Winder's two images of the Nairn Street flats illustrate diverse qualities, his photograph of Clifton Towers, Wellington (Figure 59) displays yet another style of architectural photography. In this striking photograph, Winder has captured the apartment building at a low angle which reveals both its imposing height and distinctive wedge corner. Winder has balanced the tonality of the photograph in a way which focuses attention on the bright building, framed by shadowy trees on either side. Tonal contrasts appear to be more marked in this image than most of Winder's other photographs. The pictorialist quality of this image appears distinct from other images in this section. The low-angle perspective suggests that the focus here is on emphasising the sculptural qualities of the apartment building. 


\section{Urban streetscapes}

Looking at Winder's urban streetscapes provides a useful means to consider the ways in which he applied the visual language of Townscape in his photography. Urban photography, as opposed to the photography of single architectural sites, has an increased number of variables to consider, including the more pedestrians, road traffic, and buildings of different architectural styles all in close proximity. These variables can work together to produce striking and dynamic images, which celebrate the functional and people-focused lives of built environments.

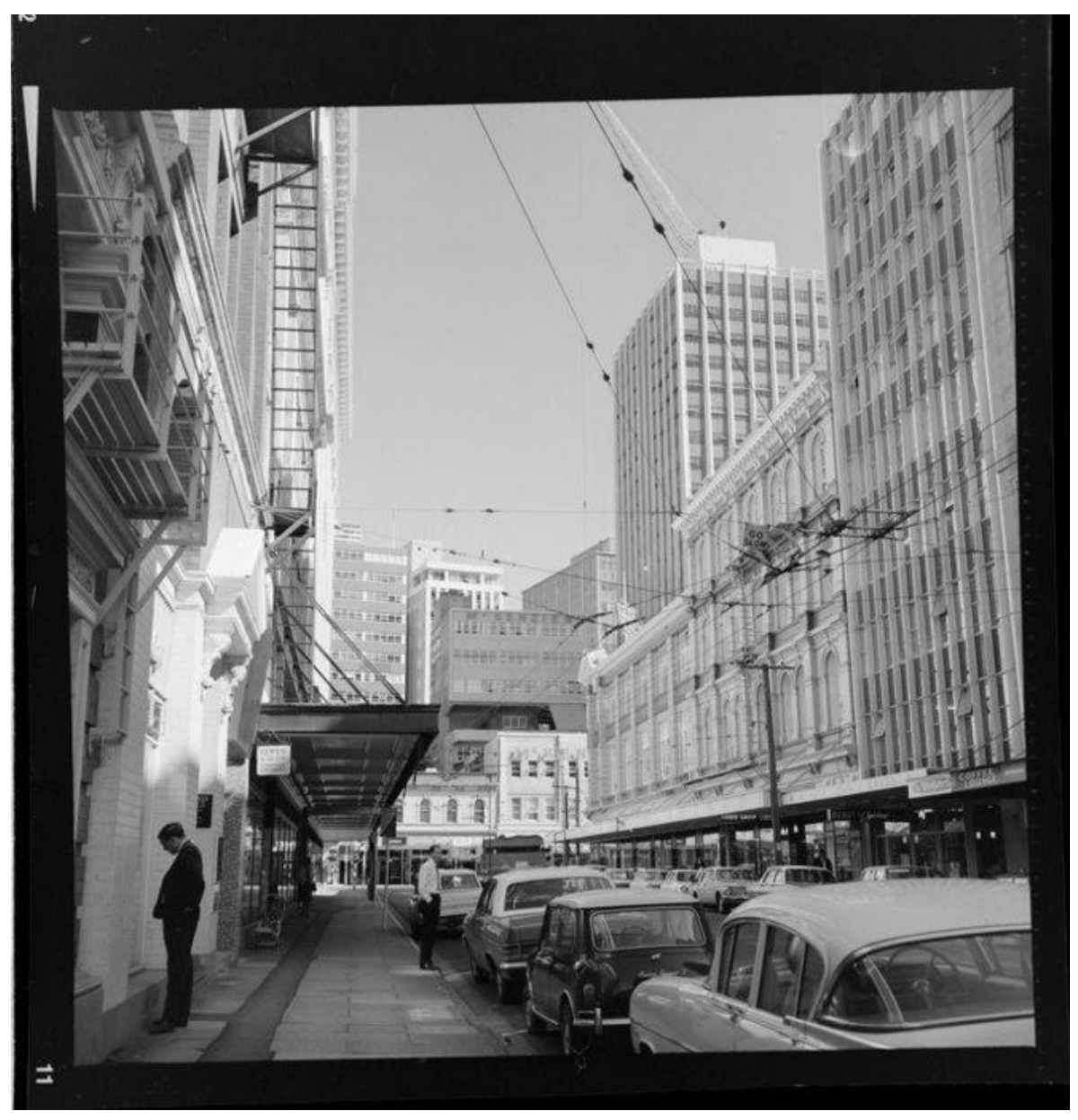

Figure 60: Duncan Winder, Brandon Street, Wellington. Ref: DW-4838-F. Alexander Turnbull Library, Wellington, New Zealand. /records/22916074. 


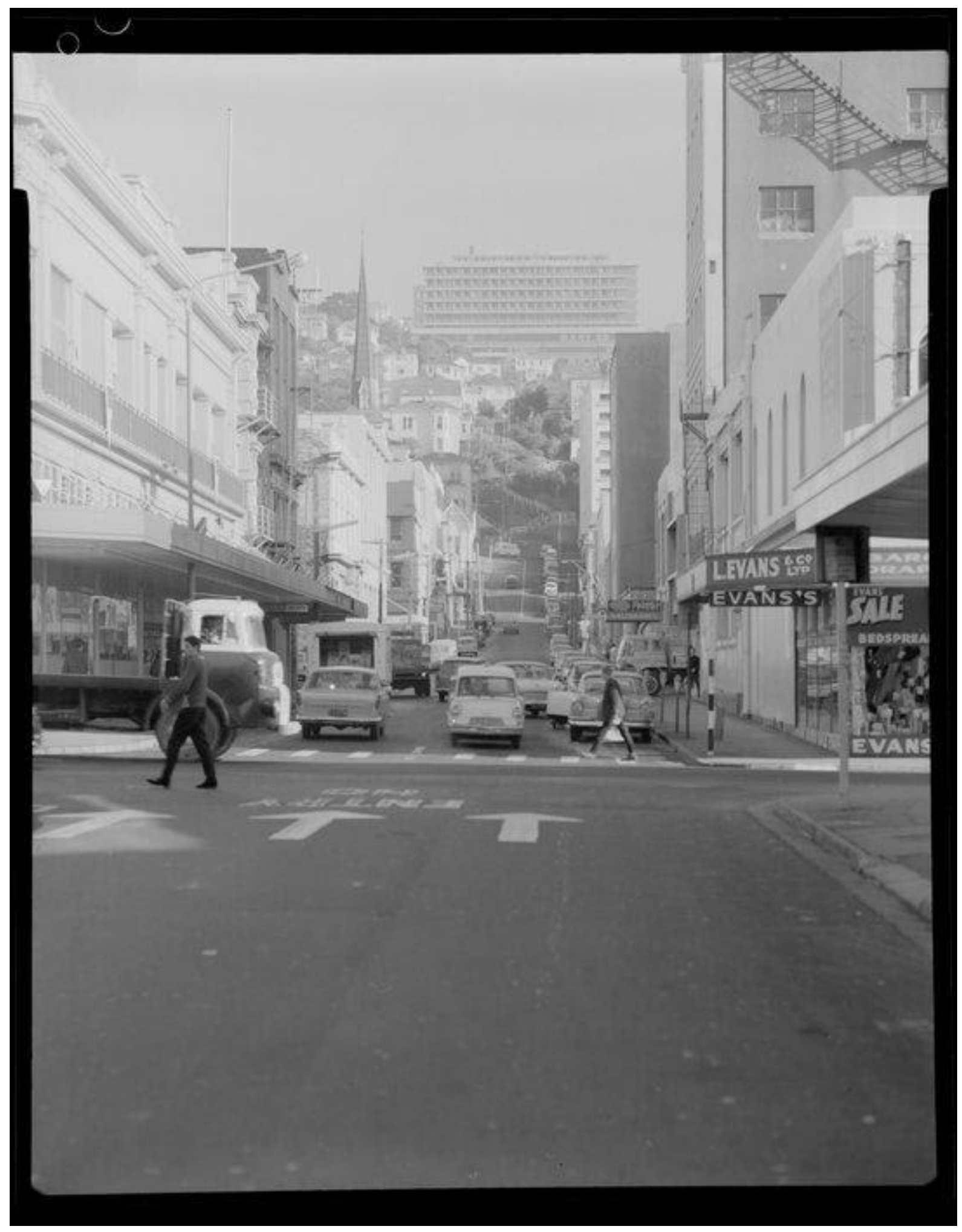

Figure 61: Duncan Winder, Dixon Street, with Victoria University of Wellington in the distance, Wellington. Ref: DW2760-F. Alexander Turnbull Library, Wellington, New Zealand. /records/22717504. 


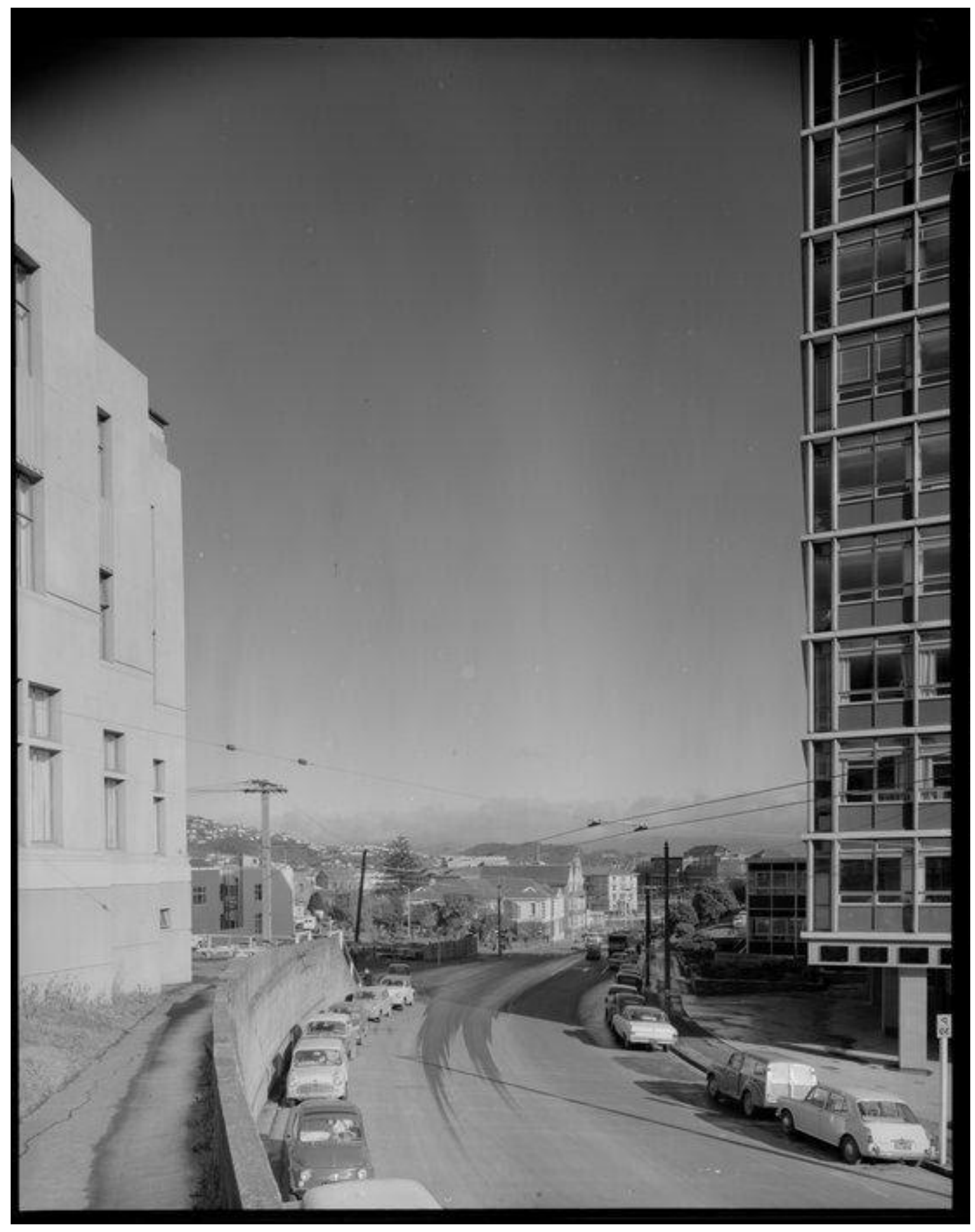

Figure 62: Duncan Winder, Bowen Street, Wellington. Ref: DW-1521-F. Alexander Turnbull Library, Wellington, New Zealand. /records/22639490. 

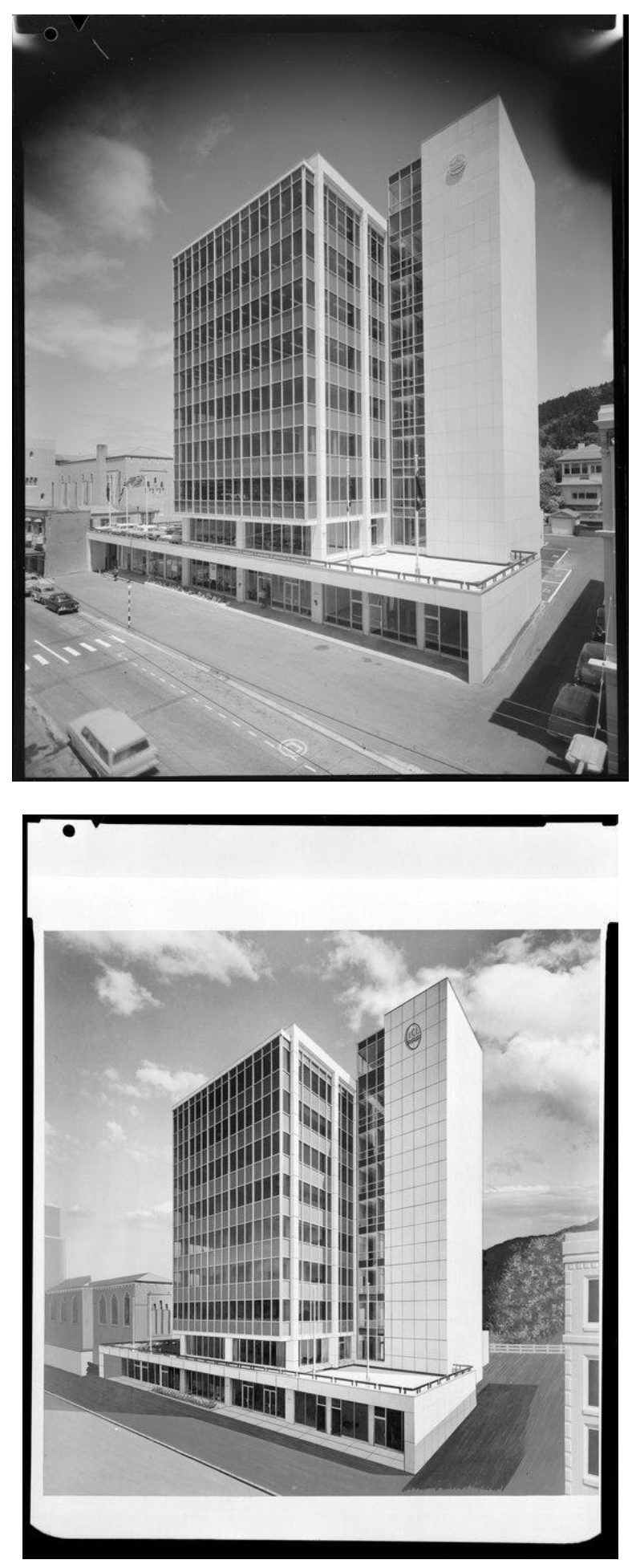

Figure 63 (top) and Figure 64: Duncan Winder, Imperial Chemical Industries Ltd, ICI House, Wellington. Ref: DW1319-F. Alexander Turnbull Library, Wellington, New Zealand. /records/23059027, and Duncan Winder, Imperial Chemical Industries (ICI), ICI House, Wellington, artists design. Ref: DW-1287-F. Alexander Turnbull Library, Wellington, New Zealand. /records/22815390. 
Winder's image of Brandon Street, Wellington (Figure 60), despite being firmly an urban scene, has a sense of interiority to it. It depicts the richly interesting and diversity of Wellington's central area, as observed from Brandon Street. Here, Winder has used a similar composition to capture the space, as he does for domestic interiors. Positioned on the footpath, near to the built form of left side of the street, the photograph provides a clear, broad view of the street. This image does not privilege any one built form over another and instead provides a vantage to look at the built environment as a whole, celebrating the varying textures, tones, and forms of urban architecture.

Similar to the image of Brandon Street, Winder's photograph of Wellington's Dixon Street (Figure 61), conveys many of the same principles. Here, Winder has taken the photograph from the middle of the road, a common vantage point for the photographer, which enables a broad view of the street and its features. There is much to see throughout this image. Moving cars, pedestrians and shop signs activate the street level, while a diverse range of built forms are visible in the middle section of the image. The upper section of the image features the Victoria University Library Building proudly overlooking the city, with a flagpole and church spire visible to its left, and the shadow of a staircase reflected on a building exterior to the right. There is a satisfying balance to the image, with almost equal interest in the left, right and centre of the image.

In his image of Bowen Street (Figure 62), Winder has used architectural elements of buildings as the frame for his photograph (NB: this photograph has been reversed). Instead of profiling the buildings more fully, the photograph includes only slender segments of the buildings. With the roadway at the centre of image, the image shows the stepped set-back of the building to the left, from an angle which emphasises its pleasing geometry. This building's light tone is effectively contrasted against the building on the right side of the image. Its modern design with finely articulated façade appears stark and out of scale with the rest of the urban environment seen in the distance of the image. While Winder did not include people in all of his urban photography, their absence in this photograph affords it an eerie quality. The image appears compositionally different from other urban images taken by Winder, however, it can still be understood within the canon of images designed to promote a 'visual re-education' around the built environment. This is a more abstracted image.

Winder took multiple images of the ICI Tower, Molesworth Street. Figure 63 is a typical modern architectural photograph which captures the building on a corner angle to showcase its depth 
and three-dimensionality. Despite its urban setting, the framing and composition of the image focuses primarily on the $\mathrm{ICI}$ Tower, with very little of its surroundings visible.

It is also typical for the fact that the photograph records the first period of the building's life, when it looks spotless and yet to be populated with people. It is a straight forward type of architectural image, showing a realistic and focused perspective of the building. However, what is most interesting about this image is revealed when comparing it to an artist drawing of $\mathrm{ICI}$ House (Figure 64). The artist drawing (which, given its near identicality to the photograph, is likely to have been traced from it) demonstrates how closely aligned the media of photography and drawing were - using similar artistic conventions to convey the same architectural information. This similarity could reveal how Winder approached his photography, initially looking at how buildings have been represented in drawing and seeking to replicate this photography. 


\section{Interiors}

The photography of interior spaces is a significant component of Winder's archive of architectural images. As opposed to streetscapes and other images of building exteriors, the photography of interiors enables more experiential, subjective documentation of architecture. It also allows for creative, often unexpected, views of internal space. In the early to mid-twentieth century, as architectural photography became more established as a commercial industry, photographers increasingly captured interiors with a deceptive spatial generosity, often positioning the camera at a room's extremities in order to make its space appear as large as possible.

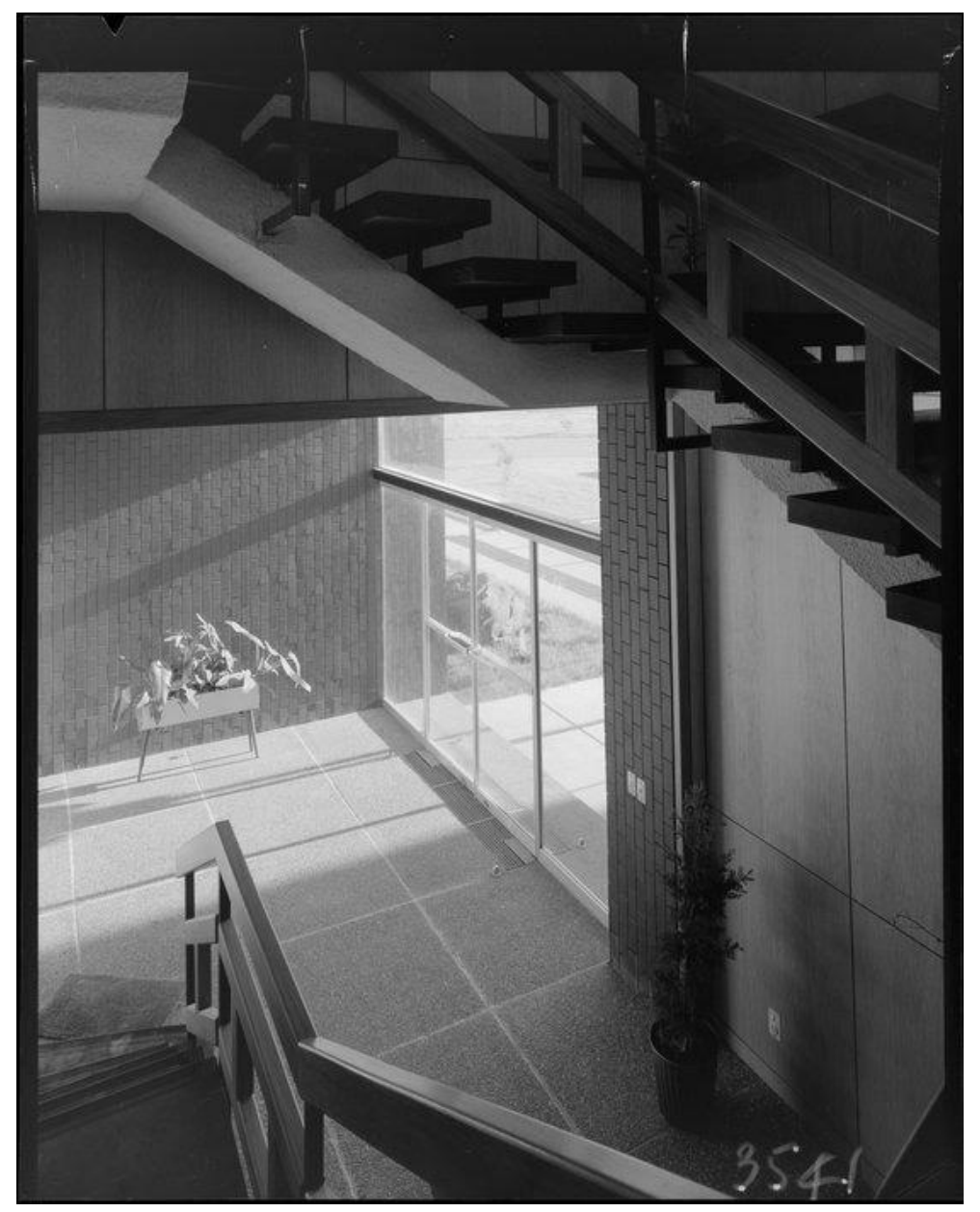

Figure 65: Duncan Winder, Looking down stairs to entrance of H H York Ltd, Petone, Lower Hutt. Ref: DW-3541-F. Alexander Turnbull Library, Wellington, New Zealand. /records/22517416. 

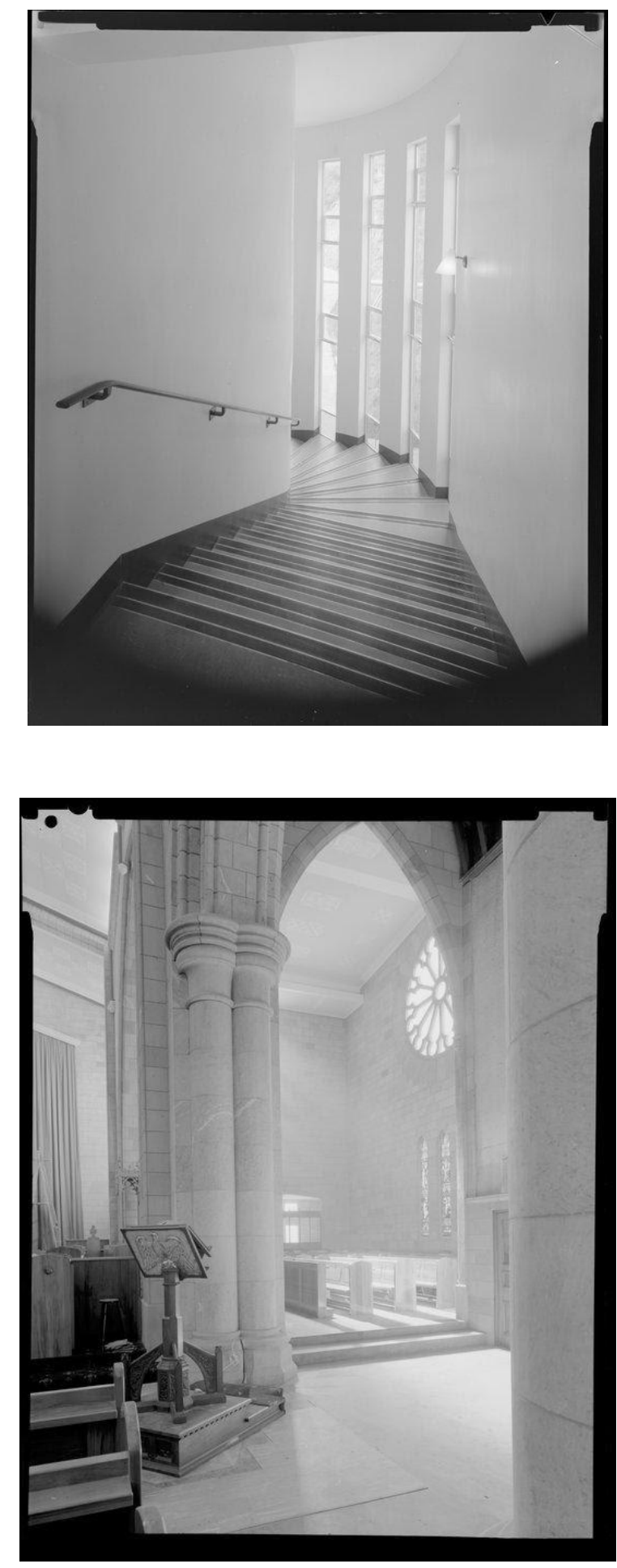

Figure 66 (top) and Figure 67: Duncan Winder, Staircase, Roman Catholic mission house, Napier. Ref: DW-3262-F. Alexander Turnbull Library, Wellington, New Zealand. /records/23031217, and Duncan Winder, Anglican cathedral, interior, with lectern, Nelson. Ref: DW-2774-F. Alexander Turnbull Library, Wellington, New Zealand. /records/22651959. 

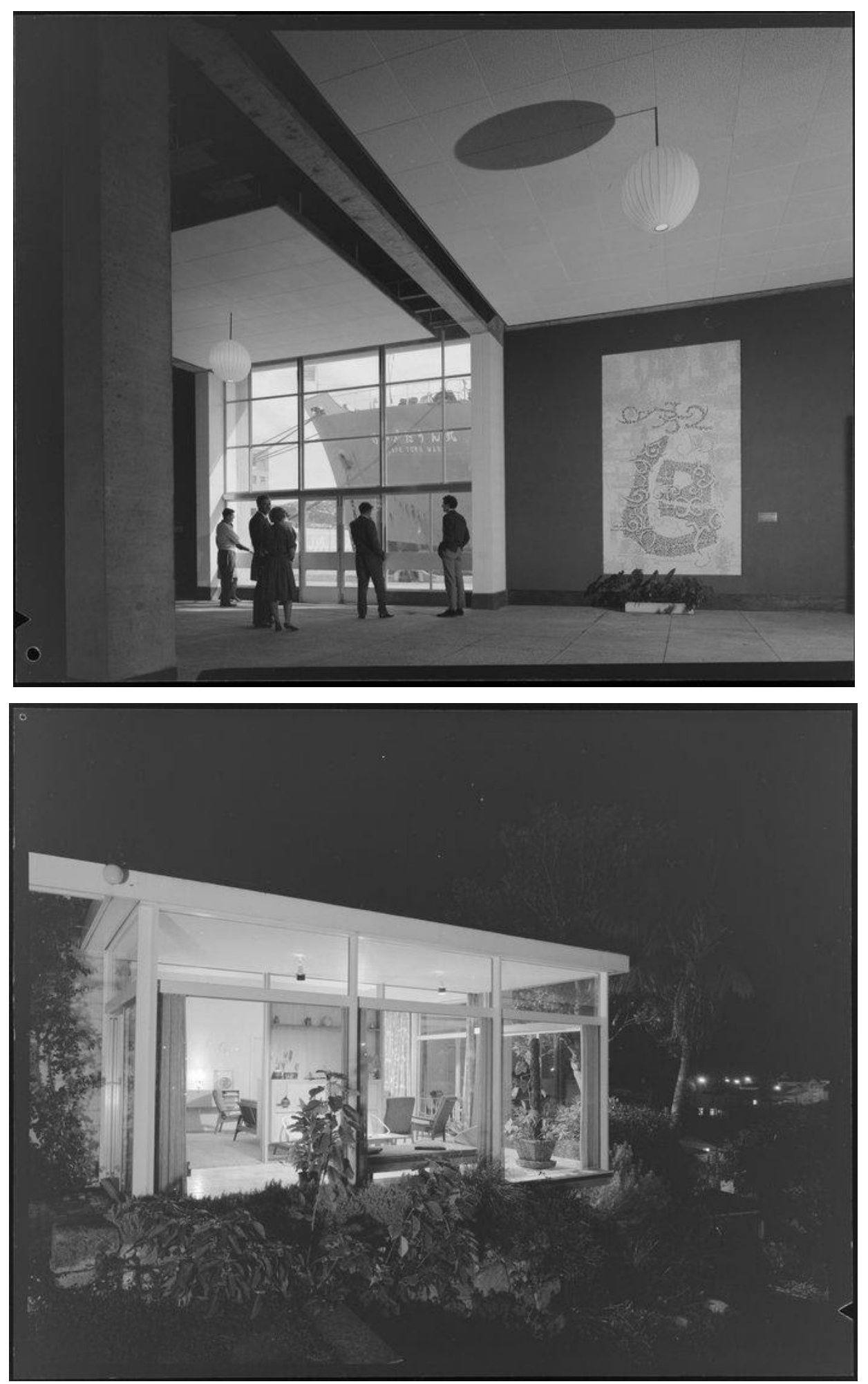

Figure 68 (top) and Figure 69: Duncan Winder, Mural inside overseas terminal, Clyde Quay, Wellington harbour. Ref: DW-1418-F. Alexander Turnbull Library, Wellington, New Zealand. /records/22822309, and Duncan Winder, Natusch house, by night. Ref: DW-3303-F. Alexander Turnbull Library, Wellington, New Zealand. /records/23156491. 


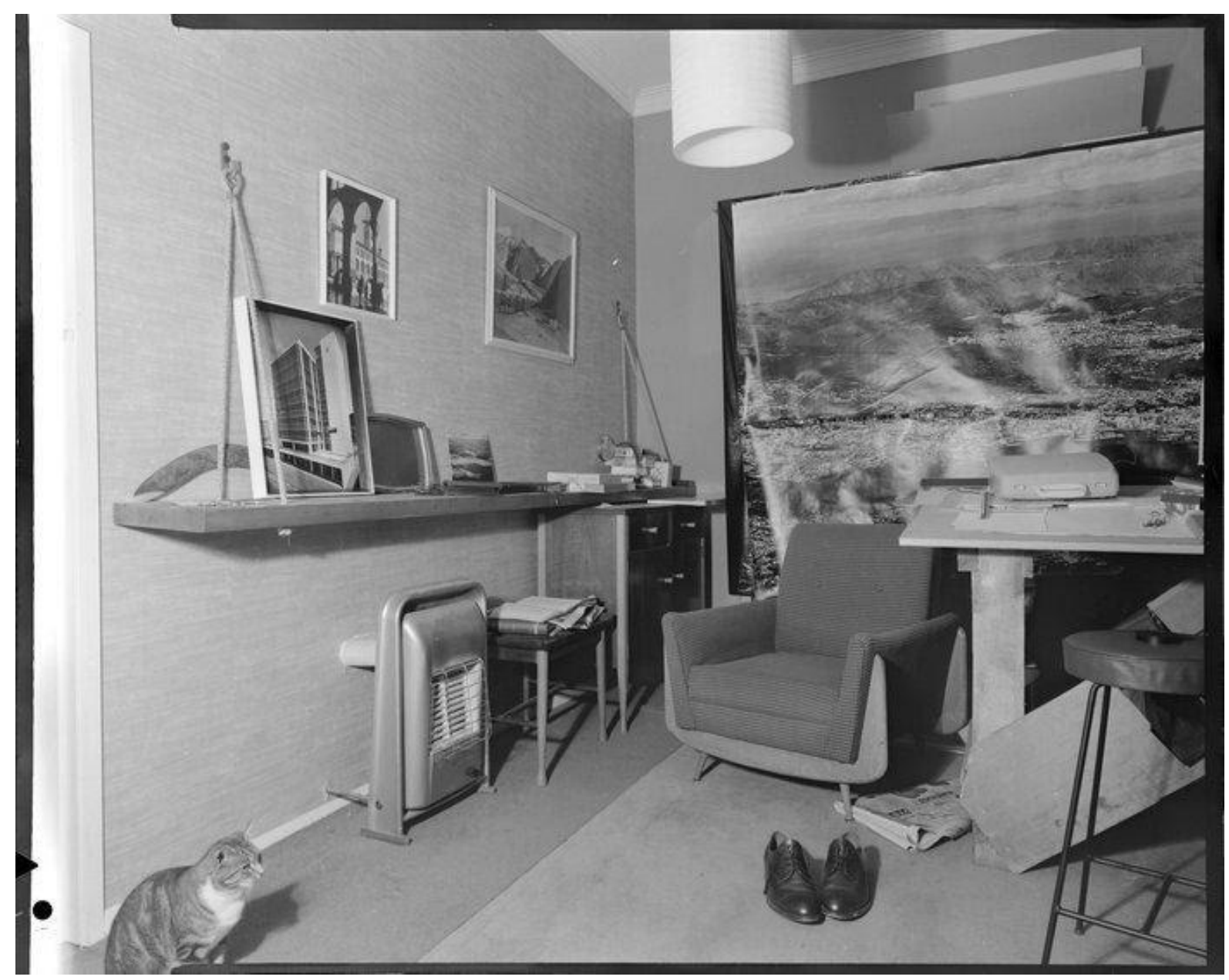

Figure 70: Duncan Winder, House interior, study.. Ref: DW-5162-F. Alexander Turnbull Library, Wellington, New Zealand. /records/22306720

Winder's interior images are typified by a cool objectivity, perhaps more than other commercial photographers of the day, and through their balanced perspectives, they reveal Winder's trained architectural eye.

The photograph showing the foyer of $\mathrm{H} \mathrm{H}$ York Ltd, Petone, Lower Hutt (Figure 65), as seen from the halfway landing of its internal staircase is representative of the many office interior images that Winder produced, including many in Lower Hutt. The position of the camera allows for a dynamic view of the staircase, as seen both from above and below. While the composition of the image is not divided into definitive thirds, the light in the image is focused sharply in the centre of the image which contributes to a strong tonal variance within the image. Winder has not made any element of the interior a clear focus of the image, yet there is plenty of visual and 
textural interest within the photograph. For example, the light streaming into the foyer puts a spotlight on the planter box and does draw the viewer's eye towards the centre of the image.

The image of the foyer is reminiscent of the 'Worth Looking At' images published in Design Review, 1950 (Figure 21). The images in Design Review indicate how the 'visual re-education' editorial imperative that drove post-war $A R$ influenced architectural culture in New Zealand. This image, while documenting a functional and modestly scaled interior space, succeeds in encouraging viewers to see patterns (such as repeated grid forms of the floor tiles and door edges) within everyday built environments.

In Winder's 1968 image of the Roman Catholic mission house, Napier (Figure 66), we see a dramatic view of the aesthetics of a staircase - revealing the architectonics of the mission house. The positioning of the camera at the top of the stairs is carefully angled to feature the full extent of the windows along the staircase, and to reveal some of the staircase's curve. It could be said that the photograph is a study of light and curvature, more than of the mission house staircase, as the composition is tightly focused with only one area of interest. This further allows for a memorable tonal quality in the photograph, which is overwhelming light and bright. There are almost no textures or objects present in the image, which adds a smoothness and enables the priority focal point in the image to remain on the curvature of the staircase.

Winder photographed many churches during his career, most of them modern, however, his photography of the Nelson Cathedral (Figure 67) illustrates how his standard interior photography translated for different kinds of architectural spaces. In Winder's image of the cathedral, soft light affords the photograph a serenity that is reminiscent of the ecclesiastical photography of Frederick Evans, discussed earlier in the literature review (see Figure 4). Here, Winder has chosen to showcase only one view, taken between two columns. Winder has used the columns as a way to frame the image, highlighting their smooth stone material. The image evidences how Winder was able to shift away from the brutalist aesthetics he often used for documenting modern architecture, and was able to apply more of a pictorialist approach when he was photographing more historic architectural sites. While Winder's composition does not result in any symmetry in the image, it retains a balance between the space visible in the foreground and the space seen in the background. The way in which Winder chose to only partial show the rose window in the upper righthand quadrant of the image contributes to an evocative quality to the image, piquing the interest of the viewer in seeing more of the interior. In this way, this photograph does not prioritise providing a faithful representation of the interior, but instead it asserts a feeling of the space. 
In Winder's artful image of the Overseas Terminal Building (Figure 68), we see a clear compositional balance that has been achieved between the two spaces visible within the frame. On the left, the visual interest is on either side of the windowed wall, with observers inside and the front of a ship visible in the harbour. While on the right side of the image, the visual interest is on the wall itself, in the form of a large mosaic. The lanterns on either side of the space help to divide the image into two distinct spaces. In addition, the lanterns add an interesting stillness to the image, especially the closer lantern on the right with its looming shadow.

Here, Winder has used a low, and wide angle to capture much of this internal space. Consistent with his other photographs of interiors, he has utilised a column to partially frame the image. In this case, the texture of the column, on the left-hand side of the frame, is visible and adds another visual element to the image. The image contains a noteworthy variety of different categories of imagery, including abstract visual art, silhouettes of people, the view of the ship, graphic shadows, and the interior architectural space itself. Having all of these aspects visible together in one photograph evokes the intention of the brutalist exhibition Parallel of Life and Art where different visual 'sources' were presented in close proximity to one another in order to promote a non-hierarchical approach to thinking about visual references and imageries.

A different approach in Winder's photographing of interiors can be seen in his image of a Natusch house (Figure 69). Night-time photography of domestic interiors grew in popularity during the post-war period. By virtue of their design, modern houses which were often built around courtyards and with floor to ceiling windows, were well-suited to being photographed at night time and from a mid-distance. The popularity of this style of photography was evident both at international and local scales, with Julius Shulman's seminal image of Pierre Koenig's Case Study House No.22 (1960) and in the work of Auckland photographers Bill Sparrow and Barry McKay (as discussed in Chapter Two's visual survey). ${ }^{109}$

Winder did not produce many night-time images, however, the images that he did take include some with a distinct modern perspective. This includes Winder's photograph, Natusch house, by night which is a well-orchestrated image showing a well-lit living room as seen from a garden area, with lights from the city visible in the distance. The contrast in tone of the dark surrounds, and well-lit building draws the attention directly to the interior spaces, which are highly visible due to the mid-angle composition of the photograph. While no people can be seen in the image,

109 Melton, "A Shot In The Dark: The Unknown Story Behind L.A.'s Most Celebrated Photograph". 
the furnished living room enables the building to be understood as someone's home, rather than simply as an empty architectural space.

The final interior image (Figure 70) has been included in the analysis not because it is an exceptional architectural photograph but rather for the intriguing visual information it contains. While the photograph has only a generic title, and it cannot be confirmed whether it shows the domestic work space belonging to Winder, another photographer, or architect - there are elements within the image which would suggest it is Winder's own studio and this makes it valid for consideration.

The image shows an office space with draughting table and several architectural photographs. It appears to be in a residential context, due to the domestic furniture, shoes on the floor, domestic heater, and pet cat. Atop the shelf on the left side of the photograph, a framed image of Winder's photograph of ICI House (featured earlier in this chapter, see Figure 63) is visible. It sits below another frame photograph, of what immediately appears as a Townscape image. The view of a building as seen through shadowed arches - it evokes the approach to looking at the built environment that Pevsner advocated. The closeness of these two images is interesting for it reveals how photographers could be influenced and drawn to different approaches to documenting built environments. The large-scale aerial photograph in the study is evidence of yet another approach to using photography to document urban environments, indicating the multitude of perspectives that photographers used for documenting their architectural subjects. 


\section{Other images}

Winder's archive of publicly viewable negatives (now held in the Alexander Turnbull Library) includes a wide range of photographs, and not all would be considered architectural photographs. However, many of these 'other' images taken by Winder display sympathy with the Functional Tradition movement seen in the pages of $A R$ (discussed on earlier in Chapter Two, from page 39). While in some images the sympathies are only subtle, other images appear to be directly influenced by the Functional Tradition principles, and the photography of Eric de Maré.

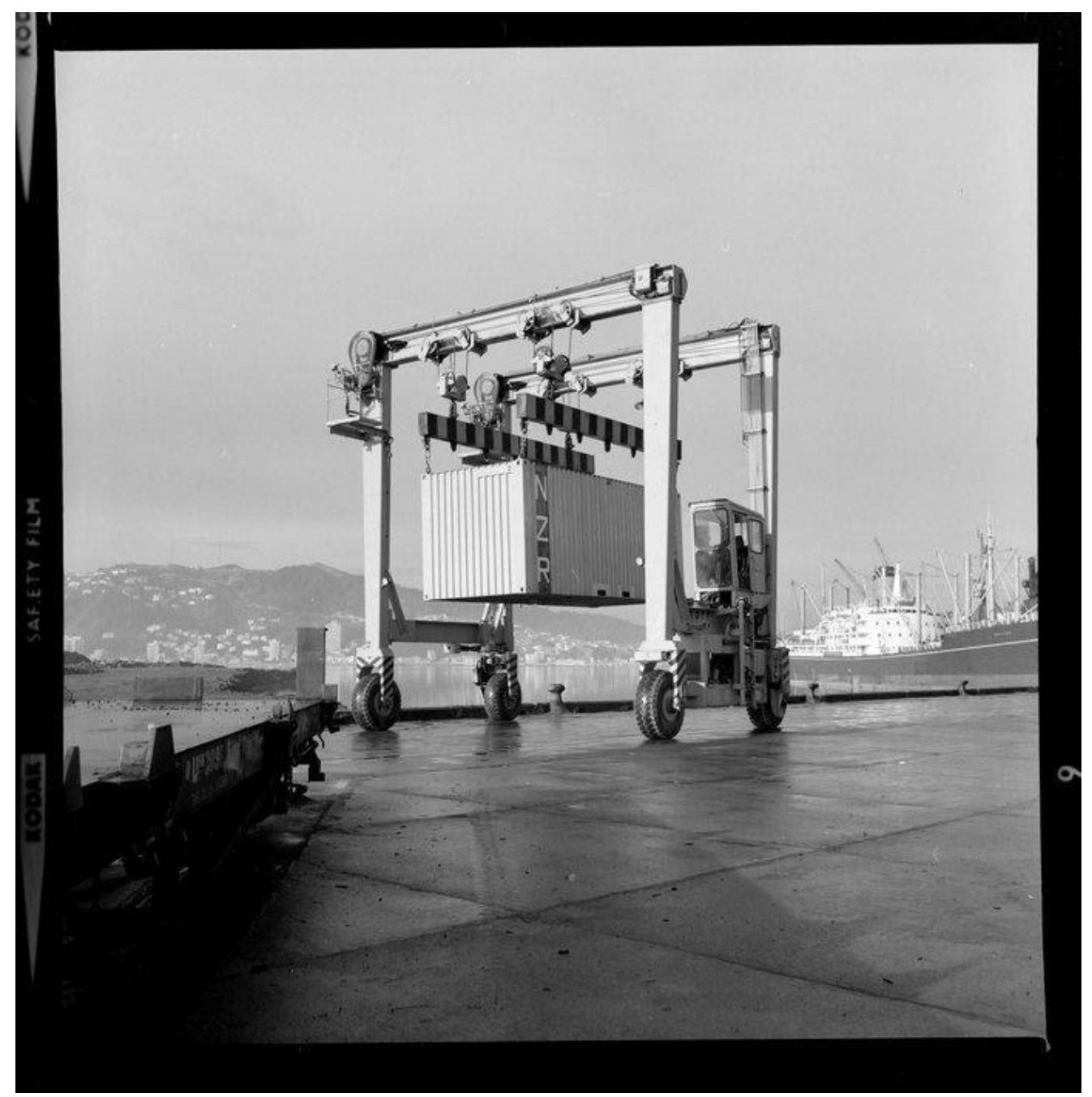

Figure 71: Duncan Winder, Drott travelift loader demonstration with container, Wellington Harbour Board. Ref: DW4694-F. Alexander Turnbull Library, Wellington, New Zealand. /records/23250765. 


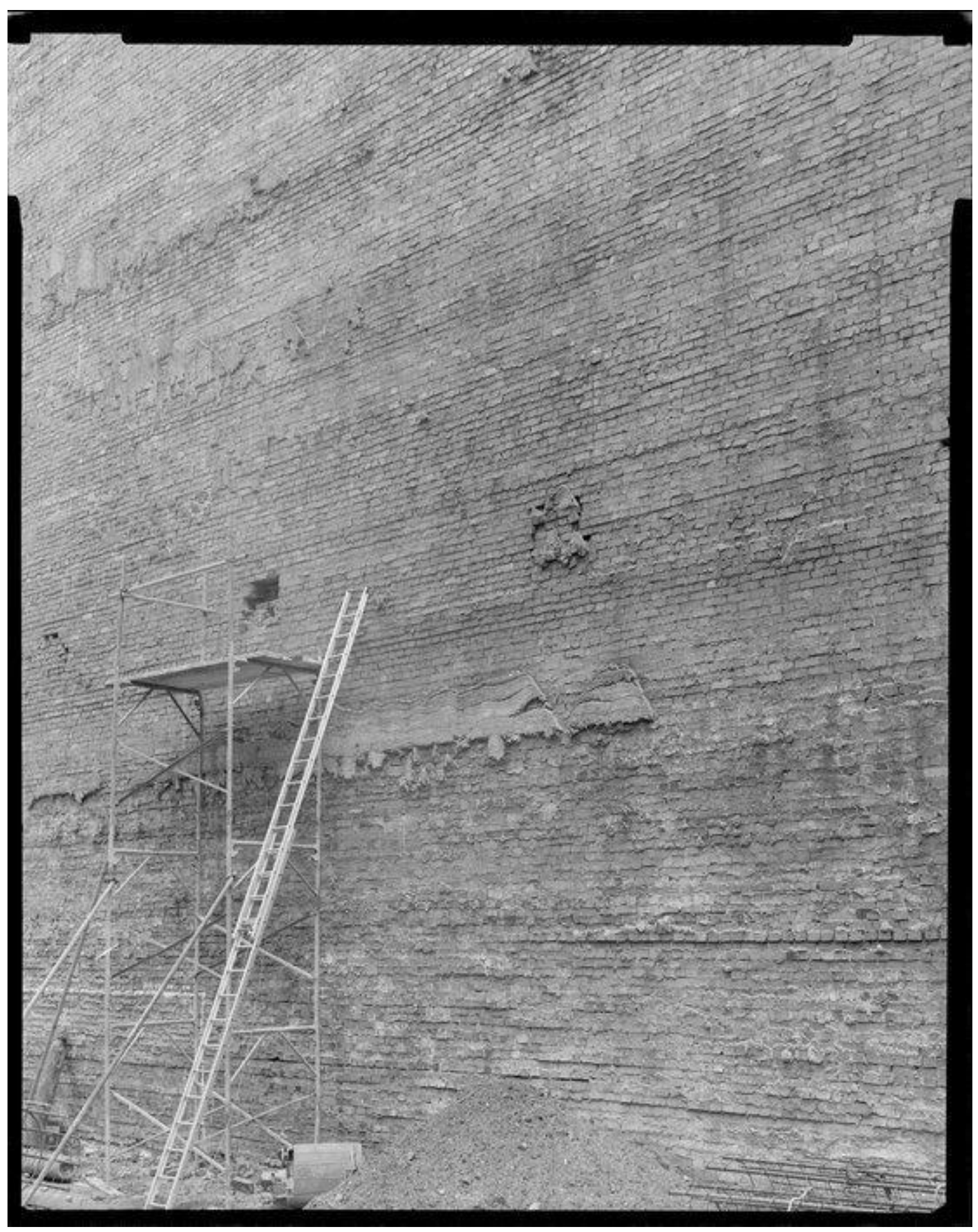

Figure 72: Duncan Winder, Very large brick wall, unidentified location. Ref: DW-4338-F. Alexander Turnbull Library, Wellington, New Zealand. /records/22716017. 


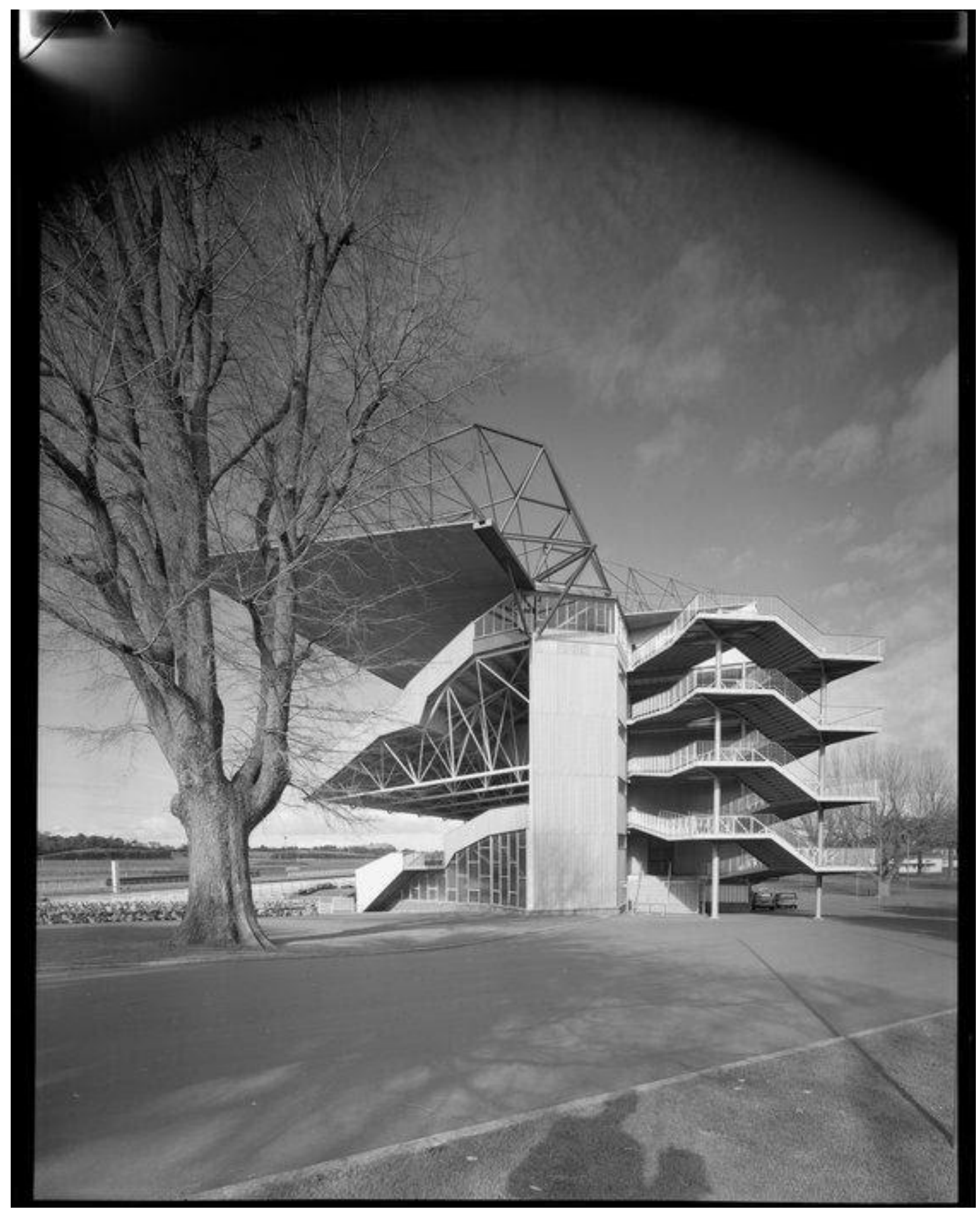

Figure 73: Duncan Winder, Ellerslie Racecourse, Auckland. Ref: DW-3919-F. Alexander Turnbull Library, Wellington, New Zealand. /records/22369235 
Functional Tradition imagery was often associated with maritime industries and structures, with photographs of historic lighthouses as a definitive example. In Winder's image of the Wellington wharves, a low-angle composition has been employed to privilege the view of a crate-moving vehicle. While no building is in the frame, Winder's image emphasises the solid, almost sculptural form of the vehicle- the inherent architecture of its design. Bringing attention to the man-made aesthetics of the working parts of the built environment was a central driver for proponents of the Functional Tradition, who considered that brutalist architecture lacked a humanising empathy. ${ }^{110}$

Winder's image of the crate-moving vehicle (Figure 71) not only allows the viewer to take note of its boxy-form, but we also appreciate it within its natural context, lifting a crate against a backdrop of the Wellington harbour and skyline. While this visible context could be used to claim the photograph has a Townscape quality, the obvious centring on the vehicle as the focus of the photograph confirms its more apt alignment with the Functional Tradition.

It could be argued that Winder's attention to documenting construction sites evidences an interest in Functional Tradition imagery. While there are commonalities between his images of construction sites (which focus on recording the structural elements and processes that contribute to a building's fabrication, discussed earlier in this chapter) and other more abstracted images like that of the large, unidentified brick wall, these more abstract images deserve particular consideration on their own terms. Winder's image of what appears to be repair works on a large brick wall (Figure 72) reveals an affinity with the photography of de Maré. Winder's study in anonymous architectural texture enables an appreciation of the patina of the wall, attentive to both the regularity of the bricks and also the moments of irregularity where bricks have fallen out, and elsewhere have been layered with smooth concrete. Winder's composition of the image is such that the edges of the wall cannot be seen, which gives the impression that it is much larger than the extent depicted. The monolithic scale of the wall is further emphasised by the inclusion of the ladder and scaffolding, which appear delicate in contrast to the solid wall upon which it leans.

Winder's image of the Ellerslie Racecourse (Figure 73) is one of very few images that Winder took in Auckland. Likely because of the number of Auckland-based architectural photographers, Winder would not have been commissioned to take photographs there. His image of the Ellerslie Racecourse, however, is a striking photograph that showcases the architecture of the

110 Higgott, "Eric de Maré: between the functional and the beautiful", 887. 
modern grandstand. The composition captures the grandstand from its most dramatic angle and creates an effective juxtaposition between the structure's form and that of the tree in the foreground.

The side-on perspective of the grandstand allows its layers and materials to be legible, enabling viewers to understand its structural make-up. This could be used to argue it has a brutalist quality. In the context of Winder's Functional Tradition images, however, it is apparent that New Brutalism and Functional Tradition imageries had similarities. The angle used to capture the grandstand is reminiscent of Functional Traditional images where a structure is presented centrally in a photograph for maximum attention and visibility - highlighting its overall aesthetic qualities. This image is also of interest for the shadow in the foreground, showing the outline of Winder and his camera. It is rare to see the photographer in his own image, and Winder's archives does not include any self-portraits. 


\section{CHAPTER FOUR: DISCUSSION}

\section{Introduction}

This chapter draws on the image analysis of Chapter Three, and presents a discussion about Duncan Winder's overall approach to architectural photography. There are two key components to the discussion. The first component provides a general assessment of Winder's architectural photography, overserving both the commonalities and variations that exist in his oeuvre, as well commentary on other noteworthy aspects of his practice. To contextualise Winder's style of photography, the discussion includes comparisons with some of his local architectural photography contemporaries, in order to better appreciate the distinctiveness of his approach. Consideration is also given to the international influences that Winder drew upon, and how they were applied and are visible in his photographs.

Overview of Winder's approach

Duncan Winder had a very good eye. The only problem was that it saw things quietly. Winder might best be described in a wider context as a reliable photographer. His images show technical competency, but they generally lack the sophistication and dramatic appeal found in international architectural photography of the same period. ${ }^{111}$

Few historians have written about Winder's approach to photography, therefore, it is worth including the above passage from Peter Wood's commentary on Winder for Architecture New Zealand to begin this assessment of Winder's architectural photography. As the quote above attests, Wood's 2005 essay, The quiet hunter, offers both praise and criticism of Winder's output. Interestingly, Wood argues that it is some of Winder's shortcomings that contribute to the appeal of his work. Specifically, he notes that many of Winder's photographs "display compositional arrangements that are made striking by ... their ordinariness".

'Ordinariness' as a descriptor may not fully enable recognition of the particular perspective that Winder captured in his photography. It is a fair assessment that in general Winder's images can be considered understated. As the image analysis demonstrated, Winder did not often exploit tonal or textural contrast in his photography, instead his images provide more honest and faithful representations of their subjects. Wood's claim that Winder's photographs lack the drama of international architectural photography of the time can also easily be accepted.

111 Wood, "The quiet hunter", 104. 
However, comparisons with 'international photographers' (a term that brings to mind professionals clearly in another league to Winder, such as Shulman and Stoller) are perhaps unfair given the more established architectural cultures within which these photographers operated. In this way, these international comparisons do not reveal a great deal about Winder's style. When considering the lack of drama in Winder's images, it is much more useful to reflect on how Winder's images differed from those of other local photographers, whose work was printed in the same publications, and therefore might have been expected to conform to the same broad set of photographic conventions as Winder's. Unlike New Zealand peers examined in the visual survey of Chapter Two, such as Bill Sparrow and Mannering and Donaldson, Winder's images have a calmness to them and mostly evade any display of obvious drama through such techniques as contrasts in tone. It is important to note that a lack of drama in Winder's images should not be read as failure to achieve such visual effect, but instead as a deliberate choice, which demonstrates an interest on Winder's part in translating, with integrity, the reality of an architectural site into the photographic medium.

Based on the image analysis in Chapter Three, it is evident that Winder did apply a number of consistent conventions in his photography. These include the use of thirds in his composition (seen in interior images of the McKay House at Figure 35, the exterior of the Webb Street Flats at Figure 45, and the streetscape of Bowen Street at Figure 62). It is evident that Winder also utilised off-centre perspectives, which allowed for memorable architectural contrasts to be seen in his photography (seen in images of university campus exteriors at Figures 51 and 52 as well as in his interior photography of Nelson Cathedral at Figure 67, and in images of construction sites at Figure 39). A third consistent stylistic trait in Winder's photography is his attentiveness to tone, which is never overly amplified but used in a way which gently enables focus on key architectural details and materials (seen in images of Wellington urban motorway at Figure 37, and images of Victoria University campus at Figure 55, and even in Winder's photography of architectural models at Figure 44).

Winder's architectural training and practical experience was an obvious strength that he brought to his photo-making. Perry Martin Hill described the 'outstanding quality' of Winder's photography. ${ }^{112}$ This praise from a member of the professional architectural community indicates that Winder's photography resonated with architects, who would have appreciated the architectural perspective that he brought to his practice. Winder's ability to satisfy architectural clients is consistent with Wood's assessment of him as a 'reliable photographer', and implicit in

112 Hill, 324. 
Winder's reliability was a comfort with photographing different styles of architecture. ${ }^{113}$ The relationship of Winder to the local architectural community is worth considering. Given his connections to practicing architects, Winder undertook a significant amount of photography work for the Government Architect's Office. In this way, Winder's photography can be viewed as serving a public interest. This may have informed the way in which he photographed public buildings, favouring matter of fact and faithful documentation over any stylised or distorted depictions.

When characterising the published component of Winder's archive, it can be argued that it possesses a brutalist quality. Here brutalist is meant in the tradition of the Smithson's 'as found' aesthetic concept, which as discussed in Chapter Two, was a term that was established after the couple observed in an architectural photograph a 'perceptive actuality' around its architectural subject. ${ }^{114}$ 'As found' promoted honest representations of architecture, which embraced context - both spatial and temporal. Winder's images are matter of fact in their presentation of buildings and their materials and form, and he regularly included within the frame a level of spatial context for the primary subject that other photographers may have omitted. Winder's inclusion of context in his images may also have contributed to the assessment of his images as conventional, or having an 'ordinariness'. When Wood declared Winder's work striking for its ordinariness, he may not have related the term to the Smithsons, however, it keenly aligns with their understanding of as found, which they considered to be a "new way of seeing the ordinary". ${ }^{115}$ An apt statement to position Winder's published work within a framework of New Brutalism.

A complexity that comes with assessing Winder's complete digitised archive of images is that invariably some of images would not be of publication standard, and other images may have been edited before being published (through cropping, flattening, or enhancing their contrast). Despite these limitations, it is apparent from the image analysis that Winder did often position himself off-centre from his architectural subjects. As a result, diagonal lines did not always connect elegantly to the corners of frames, and the balance of a composition may have appeared slightly off equilibrium. This allowed for photographs which could be read, by Wood for example, as lacking in sophistication, or perhaps this was again an intentional, modernist decision, to photograph a space in a way which was subtly unexpected, making the viewer

\footnotetext{
113 Wood, 105.

114 van den Heuvel, 60.

115 Ibid., 60.
} 
notice symmetries, or almost-symmetries, within the composition depicted. Viewing these compositional imperfections with intentionality enables them to also be seen to possess an educative quality, and recognise how Winder's photography could have been influenced by, and contributed to, visual re-education objectives.

Winder's consistent style for the photographs that he produced for architectural publications has been discussed, however, many of the architectural photographs that he produced which were not published also have their own distinct qualities that are worth discussing. Winder's photographs which were unlikely to have been taken for publications or other clients can be considered to have a more artistic, evocative quality. This dual type of practice was not uncommon for post-war architectural photographers, and Eric de Maré is perhaps the best international example of such a practitioner. ${ }^{116}$ Like de Maré, Winder often photographed more abstract features of the built environment. Unlike more conventional architectural photographs, these photographs do not have a strong brutalist quality. Instead, their perspective is more picturesque, evocative of both Townscape and the Functional Tradition movement which de Maré espoused in $A R$, and later found popularity in New Zealand. Captured within these picturesque images is the sense of Winder as an urban wanderer, looking carefully at architecture and urban spaces, and with his camera, patiently recording anonymous and special features of his localities. One example is Winder's photography of the Wellington urban motorway (Figures 37 and 38). Despite the visible roughness of the concrete's texture, and the association that New Brutalism maintains with this modern material, Winder's images of the motorway are arguably not strongly brutalist in style. There are obvious compositional choices that Winder has taken which are aligned more closely with the Townscape movement. One way to consider this component of Winder's archive is as experimentation. It may not fit into the visual re-education category of his archive, but instead, it was part of his own ongoing education and development.

While recognising both the technical consistency across Winder's images, as well the distinct qualities of his works, it is apparent that by looking across all of his images Winder's approach was able to be responsive and malleable to the specific architectural subject of each image. This indicates the undeniable relationship between architectural subject and resultant photographic product and Winder's ability to perceive both media in order to create memorable architectural photography. Demonstrative of Winder's ability, the contrast between the two images of the Nairn Street flats (Figures 57 and 58) indicates that while proponents of

\footnotetext{
116 Higgott, 873.
} 
Townscape and New Brutalism claimed that their movements were oppositional, Winder could comfortably navigate between their imageries, to suit his own photographic purposes.

Interestingly, Winder's photography also shows how these supposedly different approaches to photography can be seen in a single image. Both of Winder's photographs of the Canterbury campus (Figures 52 and 53) demonstrate qualities of New Brutalism and Townscape imageries - highlighting some of the ways in which the two movements were allied. Their attention to building elements and abstracted architectonics enables the images to be seen as brutalist, however, the contrasting textures and off-centre perspectives demonstrate an allegiance to Townscape principles.

\section{Comparison to other New Zealand architectural photographers}

Another means of understanding Winder's approach can be achieved through comparative analysis with his local contemporaries. As has been previously mentioned, Winder's approach to architectural photography was distinct from others that worked in the New Zealand field. In part, his training in architecture and preference for working alone provides an explanation for the differences in his photography from the Bill Sparrow studio photographers (including Sparrow, Rod Harvey and Barry McKay) who worked consciously to develop a consistent, recognisable style of architectural photography that was informed from Sparrow's own background in advertising. ${ }^{117}$

Locally, Winder's approach to photography was arguably most consistent with that of other photographers who had migrated to New Zealand from continental Europe. The photography of Frank Hoffman and Irene Koppel, for example, displayed a similar impartiality as seen in Winder's work. The cool, documentary style of their photography, which showcased conventions of New Photography, has visible commonalties with Winder's, especially in images of residential interiors, where any staging to accentuate or portray space in a particularly commercial way appears low-key and muted. ${ }^{118}$

It is interesting to reflect on the diversity of architectural photography approaches of the 1960s, which Winder contributed to, in light of the assessment of New Zealand architectural photography of the 1940s and 1950s as discussed in Looking for the Local. Clark and Walker note commentary from Design Review which stated, 'architectural photography in New Zealand

117 Lloyd Jenkins, 95.

118 Bell, 57. 
was poor and that photographers did not use their equipment fully'. ${ }^{119}$ It is evident that the architectural photography profession as a whole matured positively from the 1950s into the 1960s, when the profession can be described as productive, relatively diverse, and owing to many of its contributors, was also making images of high quality. Winder, despite having only a brief period of practice, did undoubtedly have a part in the elevation and advancement of the local profession during the post-war period.

${ }^{119}$ Clark and Walker, 21. 


\section{CHAPTER FIVE: CONCLUSION}

This thesis sought to advance understanding and awareness of Duncan Winder's contribution to post-war New Zealand architectural culture. In addition to providing a biographical narrative of Winder, the thesis aimed to position Winder within the broader context of modern architectural photographers (both in New Zealand and internationally), and explore how his approach to architectural photography reflected influences of the post-war British architectural movements of New Brutalism and Townscape.

In terms of Winder's biography, the thesis provided an overview of key information about his early life and training. This includes his identity as an Englishman, WWII veteran, and post-war migrant to New Zealand. Winder's transition from trained architect to architectural photographer is also noteworthy, and is consistent with historic trends in the international developments of architectural photography, discussed in Chapter Two, of architects (such as Ezra Stoller) becoming successful photographers.

The post-war period was an important peak for architectural photography when it was used 'to put on' the idea of modern architecture to mainstream audiences. ${ }^{120}$ In the content of New Zealand, Winder was part of a new generation of architectural photographers that brought increased professionalism and quality to local publications. The generation included several European émigrés who shared their knowledge of the New Photography approach to the medium. New Zealand's network of post-war architectural photographers had healthy representation across all of the country's regional centres, meaning that Winder's photography was largely based in Wellington and surrounding central North Island regions, with a notable visit to Christchurch in the early 1960s. Importantly, within the context of his local architectural photography contemporaries, Winder is the only photographer whose archive has been digitised and made publicly accessible.

Analysis of Winder's photographic output against his peers, undertaken through the visual survey of New Zealand architectural photography in Chapter Two and the image analysis of Chapter Three, demonstrates the definite way in which Winder's style was informed through his architectural background. This is seen in his carefully calculated compositions and attention to structure, rather than favouring overt or dramatic styling and contrast techniques. At the time that Winder was producing photographs, some other photographers were championing more staged approaches to photography, however, Winder's style was more closely connected with

120 Robinson, 118. 
that of other émigré photographers. These photographers arrived from continental Europe and employed a more objective, refined approach to photography that was aligned with the New Photography movement which was gaining international popularity and application.

Not only was Winder informed by his architectural training, it was also evident that he and his contemporaries were influenced in their photography approaches by the images published in $A R$. $A R$ was a seminal forum for introducing ways of perceiving and representing architecture and was pivotal in the promotion of both New Brutalism and Townscape. As discussed in Chapter Four, it is evident that Winder's photography exhibited qualities of both New Brutalism and Townscape, as well as the Functional Tradition. The fact that his approach was not bound to only one style speaks to the level of versatility in his practice and the ways that specific architectural sites prompted photographers to use specific approaches when documenting them.

The exercise of assessing Winder's photography through a framework informed by the visual languages of New Brutalism and Townscape enabled further discussion about the two movements, and their relationship to one another. As previously noted, historians have used the medium of photography to draw attention to the connections between the movements, despite the ways in which their respective supporters saw them as oppositional. ${ }^{121}$ Looking at Winder's images to compare the movements demonstrates that while New Brutalism and Townscape had specific ways and reasons for their approaches to imagery and photography, analysis indicates some of the ways in which they were aligned. These include their shared concerns with realism and their interests in conveying picturesque qualities, even when these concerns and interests materialised differently. In New Brutalism, the picturesque was abstracted, while realism took a commercial, almost Pop-Art style. In Townscape, the built environment was portrayed with sentimental realism, and a keen attentiveness to directly materialising aspects of the picturesque in post-war urban environments. The ways in which New Brutalism and Townscape are related also expose some of the limitations of using the movements to inform analysis.

\section{Limitations and further research recommendations}

Reflecting on their ability and effectiveness to inform analysis, it is evident that in the absence of any direct commentary from Winder about his own approach to architectural photography, New Brutalism and Townscape have been able to facilitate appropriate, contextual assessment of his photographs. This approach is therefore valid for analysing post-war New Zealand architectural

${ }^{121}$ Calder, 200. 
photography, however, in future it could be strengthened by looking not only at images themselves, but also how they were written about at the time - and whether this reveals anything further about how ideas of New Brutalism and Townscape were communicated through New Zealand architectural media. Chapters Three and Four noted further limitations and the challenges associated with assessing an entire archive of images that includes many photographs which Winder himself would not have considered publication. In this way, assessments of his output are interpretative and subjective, rather than definitive. This is reinforced by some of the aspects of the discussion in Chapter Four which disagree with other commentary on Winder's photography made by Peter Wood.

A lack of biographical information about Winder was a significant limitation of the research. Oral history interviews were considered as a potential method to inform the historical narrative of Winder; however, it was determined that no individuals that knew Winder closely were available to be interviewed as part of the research. This highlights the immense value of recording oral history interviews with members of New Zealand's architectural community while such opportunities still exist, in order to deepen our understanding of local architectural histories.

The lack of close consideration of Winder's archive by other historians has meant there was little historiography to consider as part of this research, however, it also highlights a significant opportunity for further research. There are several archives of New Zealand post-war architectural photography of which there is limited access to and awareness of. These archives are valuable sources of information on New Zealand's architectural history, and warrant examination. In order for this examination to occur, these archives should be digitised and made publicly accessible. The fact that Winder's archive has been digitised has accorded it a greater sense of importance and access, relative to comparable archives. Other photographers, who had a much more substantial practice (and arguably more distinctive photography styles) have not had their archives digitised, and duly, are overdue historical consideration of their respective contributions to architectural cultures. For example, what effect did Christchurch-based photographers play in the promotion of a Canterbury-style of architecture? Winder's archive is modest in relation to his peers who operated larger and longer lasting practices. Specific analysis of the Mannering and Donaldson collection and Sparrow Industrial Pictures would be worthwhile.

Digitisation would support the ability of future researchers to present more general and comprehensive accounts of the history of architectural photography in New Zealand. Existing research in this area (from Clark and Walker on developments in the 1950s, and Bell on the 
contribution of émigrés in the post-war period) are incredible valuable, however, there remains rich territory to traverse. It would be valuable to extend research beyond the 1960s, to further highlight just how productive this period was, especially for the multitude of photographers operating at this time, and how this changed in successive decades.

Finally, the value of raising awareness of these photographic archives through future research is not only important for advancing understanding of our architectural cultures, it is also useful for promoting general appreciation of New Zealand's modernist architectural heritage, and the need to document and conserve its significance. 


\section{REFERENCE LIST}

Ackerman, James. "On the origins of architectural photography." In This Is Not Architecture. New York, N.Y: Routledge, 2002.

The Architectural Centre. Design Review. Volumes 1 - 6. Updated 2016. http://nzetc.victoria.ac.nz/tm/scholarly/tei-corpus-DesignReview.html

The Architectural Review. London : EMAP Publishing Limited

Archives New Zealand, "Passenger Lists, 1839-1973 database: Auckland (inwards), SS-1-230, Apr.-Jun. 1955". https://www.familysearch.org/ark:/61903/3:1:S3HY-XCT4-

$B K L ? \mathrm{i}=11 \& \mathrm{cC}=1609792$ \&personaUrl=\%2Fark\%3A\%2F61903\%2F1\%3A1\%3AQJDVLR2C.

Banham, Reyner. The New Brutalism: Ethic or Aesthetic?. London: Architectural Press. 1966.

Bell, Leonard. Strangers Arrive: Emigres and the Arts in New Zealand, 1930-1980. Auckland: Auckland University Press, 2017.

Boyer, M. Christine. Not Quite Architecture: Writing around Alison and Peter Smithson. Cambridge, Mass: MIT Press, 2017.

Brookes, Susan. Index to the Journal of the New Zealand Institute of Architects, 1912-1980. Working paper no., WP 82-13. Wellington: School of Architecture, Victoria University of Wellington, 1982.

Busch, Akiko. The photography of architecture: twelve views. New York : Van Nostrand Reinhold Co, 1987.

Calder, Barnabas. "Brutal enemies? Townscape and the 'Hard' Moderns". In Alternative Visions of Post-War Reconstruction: Creating the modern townscape. London, England: Routledge, 2014.

Carullo, Valeria. "The Robert Elwall Photographs Collection at the RIBA British Architectural Library." Royal Institute of British Architects. Updated 2015. http://www.historyphotography.org/doc/CARULLO_The_Robert_Elwall_Photographs_Co llection.pdf.

Christchurch Modern, "The Christchurch Style". n/d. http://www.christchurchmodern.co.nz/christchurch-architectural-style/. 
Clark, Justine and Walker, Paul. Looking for the Local: architecture and the New Zealand modern. Wellington: Victoria University Press, 2000.

Colomina, Beatriz. Privacy and publicity: modern architecture as mass media. Cambridge, Mass. : MIT Press, 1994.

Cox, A. D. M. "The Lebanon: Some Memories of Mountain Warfare Training during World War II". Alpine Journal, 1992/93, 191-198.

Crouch, Christopher. Design Culture in Liverpool, 1880-1914: The Origins of the Liverpool School of Architecture. Liverpool: University of Liverpool, 2001.

Cullen, Gordon. The Concise Townscape. London: Architectural Press, 1961.

de Maré, Eric. Photography and Architecture. England: Penguin Books, 1961.

Design Facts. "No. 66 - First printed halftone photo". Design Facts. Updated 2020. https://www.designfacts.org/designfacts/fact-66.

Elwall, Robert. Building with light: the international history of architectural photography. London, England: Merrell, 2004.

Gatley, Julia, ed. Long Live the Modern, New Zealand's New Architecture, 1904-84. Auckland: Auckland University Press, 2008.

Herschman, Joel. "Part 1: 1839 to 1880." In Architecture Transformed: A History of the Photography of Buildings from 1839 to the Present. New York, N.Y: Architectural League of New York, 1987.

Higgott, Andrew. "Eric de Maré: between the functional and the beautiful". Journal of Architecture, Volume 21, Number 6 (2016): 873-889.

Higgott, Andrew. Mediating modernism: architectural cultures in Britain. New York, N.Y. : Routledge, 2007.

Hiles, Tony, dir. Antonello \& the Architect. 2007; Wellington, City Associates Films, 2007. DVD.

Hill, Perry Martin. "Obituary”. NZIA Journal, Volume 37, Number 10, 1970, 324.

Initiatives of Change New Zealand, "History". n/d. https://nz.iofc.org/history.

Kristianova, Katarina, Joklova, Viera, and Meciar, Ivor. "Physical models in architectural education and the use of new technologies". Paper presented at 11th annual 
International Conference of Education, Research and Innovation.

https://www.researchgate.net/publication/329225754_PHYSICAL_MODELS_IN_ARCHI TECTURAL_EDUCATION_AND_THE_USE_OF_NEW_TECHNOLOGIES.

Lichtenstein, Claude. As Found: the discovery of the ordinary. Zurich: Lars Müller Publishers, 2001.

Lineham, Peter J. "Interdenominational Christianity". Te Ara - the Encyclopaedia of New Zealand. Updated 2018. https://teara.govt.nz/en/interdenominational-christianity/print

Lloyd Jenkins, Douglas. "Early bird". Architecture New Zealand, 2005, Issue 3.

Macarthur, John and Aitchison, Mathew. "Pevsner's Townscape." In Visual Planning and the picturesque. Los Angeles : Getty Research Institute, 2010.

Melton, "A Shot In The Dark: The Unknown Story Behind L.A.'s Most Celebrated Photograph". Los Angeles Magazine. Updated 2016. https://www.lamag.com/longform/a-shot-in-thedark/

Moholy-Nagy, László. "A New Instrument of Vision". Telehor 1, 1-2 (Brno, Feb. 28, 1936): 3436.

Mountain Warfare Training Centre, "Staff". Updated 2006. http://www.mrzsp.demon.co.uk/mwtc/staff.htm.

Mountain Warfare Training Centre, "The Training Centre". Updated 2006. http://www.mrzsp.demon.co.uk/mwtc/mwtc.htm.

National Archives United Kingdom, "Marriage licence for Leonard Norman Winder and Marion Rowed." Updated 2020. http://discovery.nationalarchives.gov.uk/details/r/bec5c9044ca5-464f-896f-0ffc6930bce7.

New Zealand History, “Assisted immigration to New Zealand 1947-1975". Updated 2014. https://nzhistory.govt.nz/culture/assisted-immigration-to-nz-from-the-uk.

New Zealand Institute of Architects. Home and Building. Volumes 1 - 33. 1937 - 1970.

New Zealand Institute of Architects. Journal of the NZIA. Volumes 1-29. $1930-1962$.

New Zealand Institute of Architects. NZIA Journal. Volumes 30 - 37. $1963-1970$. 
Nilsen, Micheline. Architecture in Nineteenth Century Photographs: Essays on Reading a Collection. England: Ashgate Publishing Limited, 2011.

Pare, Richard. Photography and architecture, 1839-1939. Montreal, Canada : Centre canadien d'architecture/Canadian Centre for Architecture, 1982.

Parnell, Steve. " $A R$ 's and $A D$ 's post-war editorial policies: the making of modern architecture in Britain." Journal of Architecture, Volume 17, Number 5 (2012): 763-775.

Potts, Alex. "New Brutalism and Pop". In Neo-avant-garde and Postmodern: Postwar Architecture in Britain and Beyond. London: YC British Art, 2010.

Pevsner, Nikolaus. "C20 Picturesque". In Visual Planning and the picturesque. Los Angeles : Getty Research Institute, 2010.

Richards, Pevsner, Lancaster and Hastings, "The second half century/the first half century." The Architectural Review, Volume 101, 21-36.

Richmond, Peter and Dunne, Jack. The World in One School: The History and Influence of the Liverpool School of Architecture 1894-2008. Liverpool: University of Liverpool, 2009.

Robinson, Cervin. "Part three: 1930 to 1970". In Architecture Transformed: A History of the Photography of Buildings from 1839 to the Present. New York, N.Y. : Architectural League of New York, 1987.

Smith, Joel. The life and death of building: on photography and time. Princeton, New Jersey: Princeton University Art Museum, 2011.

United Kingdom Parliament, "Conscription: the second World War." Updated 2020. https://www.parliament.uk/about/living-heritage/transformingsociety/privatelives/yourcountry/overview/conscriptionww2.

van den Heuvel, Dirk. "As Found: The Metamorphosis of the Work of Nigel Henderson, Eduardo Paolozzi, and Alison and Peter Smithson (1953-1956)." OASE, Volume 59, 52-67.

Winder, Norman Henry Duncan. Winder, Duncan, 1919-1970: Architectural photographs [19621970]. https://natlib.govt.nz/records/39537652?search\%5Bil\%5D\%5Bcreator\%5D=Winder\%2C +Norman+Henry+Duncan\%2C+19191970\&search\%5Bpath\%5D=items\&search\%5Btext\%5D=duncan+winder. 
Wood, Peter. "The quiet hunter". Architecture New Zealand, 2005, Issue 3, 104-106.

Woods, Mary, N. Beyond the architect's eye: photographs and the American built environment. Philadelphia, Pennsylvania: University of Pennsylvania Press, 2013.

Zimmerman, "Photographic Images from Chicago to Hunstanton." In Photographic Architecture in the Twentieth Century. Minnesota: University of Minnesota Press, 2014. 
APPENDIX ONE: FRAMEWORK FOR IMAGE ANALYSIS

\section{CRITERIA}

Composition

Description of what is seen

Does the perspective of the photograph seek to represent an 'unmediated experience' of its architectural subject? Or is there an evident attempt to depict the architecture in a particular way? How is this achieved?

Does the composition evoke a sense of movement through the represented space? Or is the image static?

Has the built form been documented straight-on or has a particular angle been chosen to profile specific aspects of the architecture? What aspects of the building are omitted?

What attempts (if any) are there to achieve symmetry in the image?

What angle has been used for the photograph? How close up is the photograph? What effect does this have on the architecture?

How many different levels of view are present in the photograph? What is the effect of this?

Are architectural elements used to frame the image in any way?

To what extent are compositional decisions used to manipulate how architecture is represented in the photograph?

1 (Not at all)

2(Somewhat)

3(Significantly) 
What is prioritised as a result of these compositional decisions (identify all that apply)?
a) the legibility of structure/ faithful representation of subject
b) the environmental context
c) the attractiveness of the architecture
d) the abstraction of architectural elements
e) the scale of the architecture

Tone

Have tonal qualities, light and shadow been used to emphasise/distinguish architectural elements within the image?

To what extent have tonal qualities been utilised to amplify visual drama in the image?

1 (Not at all)

2(Somewhat)

3(Significantly)

\section{Texture}

Have textures in the image been enhanced/emphasised? Has this been done to contrast different architectural elements? Or to focus attention on a particular architectural feature? Does the texture appear exaggerated?

To what extent have textural qualities been utilised to amplify visual drama in the image? 1 (Not at all)

2(Somewhat)

3(Significantly)

Non-architectural elements

Does it include people? Does the inclusion of people humanise the photograph, or are people included to illustrate the monumental scale of the architecture?

Does it include trees or plants? What is their relationship to the built forms in the image?

Are there objects present in the photograph? Furniture, cars, signage, power lines? Have these elements been emphasised in anyway? Or do they appear noticeably absent? 
To what extent have non-architectural elements been employed to contribute to the photograph?

1 (Not at all)

2(Somewhat)

3(Significantly) 